

\section{LIBRARY OF CONGRESS.}

ड़न 907

Chap. SA Copyright No

$\frac{\text { Shelf.A } 96}{\text { UNITED STATES OF AMERICA. }}$ 






\author{
THE
}

\title{
CLINICAL DIAGNOSIS
}

OF

\section{LAMENESS IN THE HORSE}

BY

W. E. A. WYMAN, V.S.,

Professor of Veterinary Science at Clemson A. ANd M.

College, and Veterinarian to South Carolina

Experiment Station.

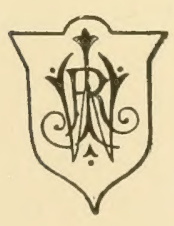

NEW YORK :

WILLIAM R. JENKINS,

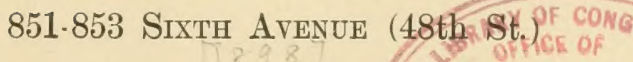




\section{3}

Copyright, 1898, by WiLliam R. Jenkins.

All Rights Reserved.

PRINIED BY THE

Press of William R. Jenkins,

NEW YoRK. 


\section{Dedicated}

TO MY

ALMA MATER,

THE NEW YORK COLLEGE OF VETERINARY SURGEONS AND SCHOOL OF COMPARATIVE MEDICINE,

BY

THE AUTHOR. 



\section{PREFACE.}

The total absence in the English language of a work on the Clinical Diagnosis of Lameness in the Horse, induced me to gather material from all obtainable works, American, English, and especially German, to supplement my lectures; this little work therefore is primarily a compilation. The treatment of this subject is so scattered and not fully discussed in auy particular work on Surgery, that an expensive and voluminous library at once becomes necessary to study this important branch of Surgery. The extreme courtesy of the eminent surgeon, Professor Doctor H. Möller, Berlin, Germany, has wade it possible for me to issue this contribution toward Veterinary Surgery, since he most kindly permitted me to use his various excellent works. This little effort is a resume, embodying mainly the teachings of Professor Doctor Müller, arranged, as I hope, in a practical manner.

To the different chapters, short anatomical sketches and drawings, as well as important anatomo-physiological laws, have been added. This compendium is chiefly intended for the student, to give him a concise treatise on the symptoms accompanying the various forms of lameness, the differential diagnosis wherever an error is liable to be made, and recognized practical methods of examination to aid him in the detertion of the seat of the lameness. The practitioner may possibly find some points of interest in this little work in his moments of leisure. 
I take this opportunity to thank Professor Doctor $\mathrm{H}$. Möller for his great kindness.

I am also under obligations to Messrs. Parey, Cox and Lupton, for granting me the use of various cuts, some of which have been remodeled to more clearly illustrate points of interest.

In conclusion, I wish to express thanks to my publisher, William R. Jenkins, for the liberal assistance rendered me in every respect.

W. E. A. WYMAN.

Clemson College, S. C, 


\section{TABLE OF CONTENTS.}

CHAPTER I.

Detection of the Lame Leg.......................

CHAPTER II.

Detection of the Seat of Lameness .................. 13

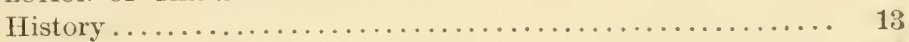

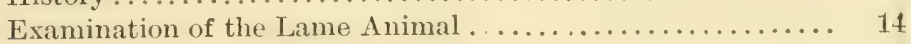

Examination of the Hoof....................... 14

CHAPTER III.

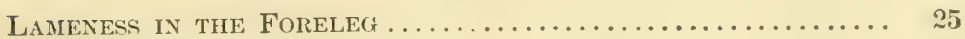

Anatomo-Physiological Review.................. 25

CHAPTER IV.

LAMENESS IN THE REgION OF THE SHOULdER.............. 35

1. Shoulder Lameness........................ 35

Diseased Conditions of the Shoulder-Joint and its Neigh-

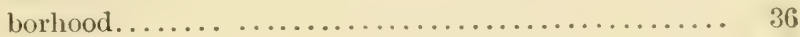

Inflammatory Swellings and New Growths........ 36

Thrombosis of the Brachial Artery.............. 36

Disease of the Muscles of the Shoulder........... 37

Contusions and Distortion of the Scapulo-humeral

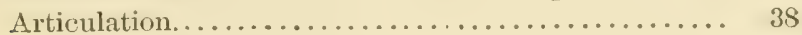

2. Luxation of the Scapulo-humeral Articulation......... 39

3. Inflammation of the Bursa and Tendon of the Posteaspinatus Muscle. ...................... 39

4. Paralysis of the Supra-scapular Nerve. ............ 40

5. Inflammation of the Bursa of the Flexor Brachii Muscle... 40

6. Paralysis of the Radial Nerve................. 42

7. Paralysis of the Brachial Nerve Plexus.............. 44

8. Fracture of the Scapula..................... 45

9. Fracture of the Fore-itrm . . . . . . . . . . . . . . 15

Fracture of the Diaphysis................. 45

Fracture of One of the Condyles............... 46 
CHAPTER V.

LAMIENESS IN THE REgION OF THE ELBOW AND FORE-ARM ...... 47

1. Inflammation of the Elbow-Joint................ 47

2. Fracture of the Ulna........................... 47

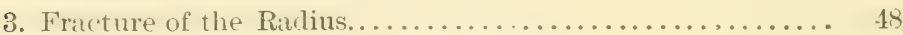

4. Wounds and Bruises of the Fore-arm............... 48

CHAPTER VI.

LAMENES IN THE REGION OF THE KNeE............... 49

1. Injuries to the Anterior Surface of the Knee........... 49

2. Fratcure of the Bones of the Knere............... 49

3. Chronic Inflammation of the Knee................ 50

4. Inflammation of the Carpal Bursa of the Flexor Pedis Tendons............................. $\quad 50$

5. Distension of Articular and Tendinous Synovial sacs...... 51

CIIAPTER VII.

Lameness in the Region of the Metacarpus............ 56

1. Rupture of the Flexor Tendons and Sesamoidal Ligaments. $\quad 56$

2. Inflammation of the Flexor Tendons............... 57

3. Fracture of the Metacarpal Bone.................. 58

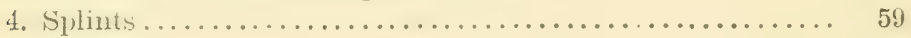

\section{CHAPTER VIII.}

Lameness in the Phalangeat Region................. 62

1. Luxation of the Phalanges.................... 64

2. Distortion of the Phalangeal Articulation............. 64

3. Inflammation of the Posterior Ligaments of the CoronetJoint ................................. 65

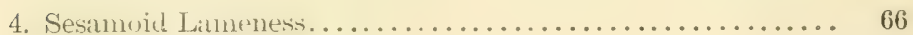

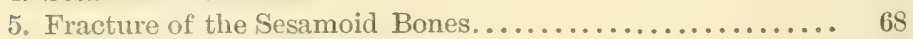

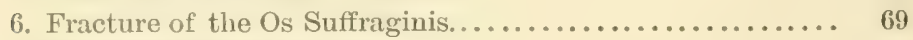

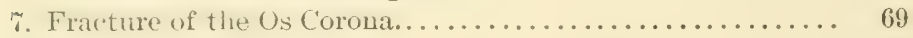

8. Fracture of the Os Pedis ....................... 70

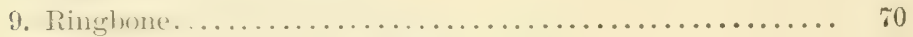

10. Fracture of the Navicular Bone ................. 73

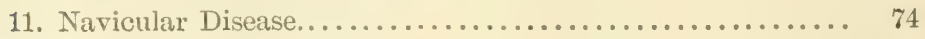

\section{CHAPTER IX.}

LAMENESS IN THE HiNd LEG.................... 78

Anatomo-Physiological Review................... 78 
CHAPTER X.

Lamieness in the Gluteal Region ................. 87

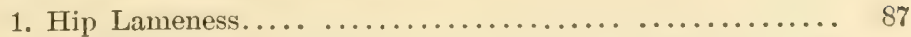

2. Inflammation of the Tendon and Tendon Sheath of the

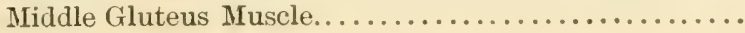

CHAPTER XI.

LAMENESS IN THE REgION OF THE HIP JOINT............ 91

1. Luxation of the Femur..................... 91

(a) Forward Luxation of the Femur.............. 91

(b) Backward Luxation of the Femur............. 92

(c) Inward Luxation of the Femur............... 92

(d) Outward Luxation of the Femur.............. 92

2. Inflammation of the Hip Joint................... 93

3. Fracture of the Femur....................... 93

CHAPTER XII.

Thrombosis of the Posterior Aorta and Its Branches...... 95

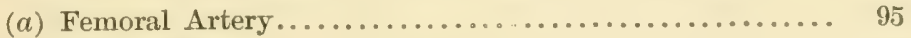

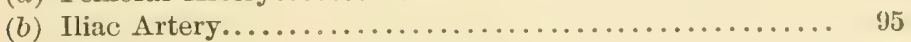

CHAPTER XIII.

Peripheral Nerve Paralysis...................... 96

1. Tibial Nerve............................. 96

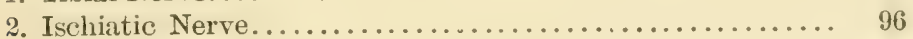

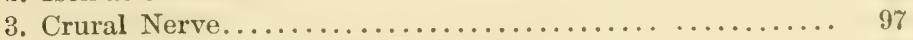

4. Incomplete Paralysis of the Hind Leg.............. 98

CHAPTER XIV.

Lameness in the Region of the Femoro-Tiblal Articulation • 100

1. Acute Inflammation of the Stifle Joint............. 101

2. Chronic Inflammation of the Stifle Joint.............. 101

3. Luxation of the Patella ....................... 103

Outward Luxation of the Patella.................... 104

4. Rupture of the Straight Ligaments of the Patella......... 105

5. Fracture of the Patella......................... 105

CHAPTER XV.

LaMeness in The Region of the TIBIA................. 106

1. Fracture and Fissure of the Tibia................ 106

2. Rupture of the Flexor Metatarsi Muscle............. 107

3. Rupture of the Tendo-Achilles .................. 108 
CHAPTER XVI.

Lameness in the Region of the Hock Joint ............ 109

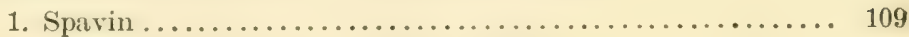

2. Acute Inflammation of the Hock Joint ............. 112

3. Fracture of the Bones of the Hock................ 113

Fracture of the Os Calcis...................... 113

Fracture of the Astragulus.................. 114

Subfacial Cellulitis....................... 114

Fracture of Other Bones of the Tarsus............. 114

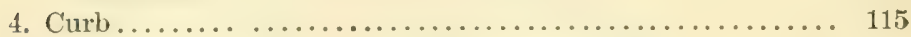

5. Luxation of the Flexor Pedis Perforatus Tendon......... 116

\section{CHAPTER XVII.}

Lameness in the Region of the Metatarsus.............. 117

1. Chronic Thickening of the Sesamoidal Sheath.......... 117

2. Acute Septic Inflammation of the Flexor Tendon Sheath... 117

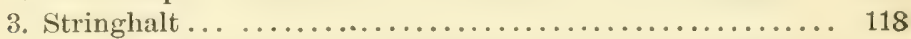

4. Lameness Resulting from Interfering and Its Complications 119 CHAPTER XVIII.

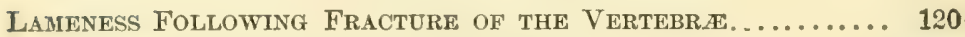

Fracture of the Body of the Vertebræ.............. 120

CHAPTER XIX.

Lameness Resulting from Fracture of the Peltis ......... 122

1. Fracture of the External Angle of the Ilium.......... 122

2. Fracture of the Shaft of the Ilium............... 122

3. Fracture Through the Obturator Foramen............. 123

4. Fracture of the Os Pubis...................... 124

5. Fracture in the Cotyloid Cavity. ............... 124

6. Fracture of the Tuberosity of the Ischium. . . . . . . . . 124

7. Fracture of the External Branch of the Ischium........ 125

CHAPTER XX.

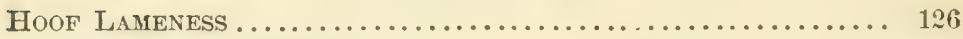

Anatomo-Physiological Review.................... 126

CHAPTER XXI.

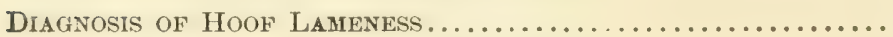

CHAPTER XXII.

Lameness Following Acute Superficial and Parenchymatous Inflammation of the Podophyllous Membrane........ 136 
CHAPTER XXIII.

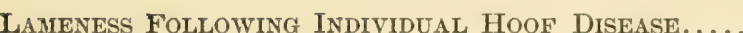

1. Laminitis.................................... 140

2. Wounds of the Coronet...................... 142

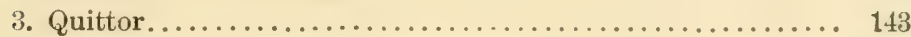

4. Punctured Wounds of Sole and Frog............... 144

5. Pricking in Shoeing .......................... 145

6. Corns ...................................... 145

7. Side-Bones............................... 146

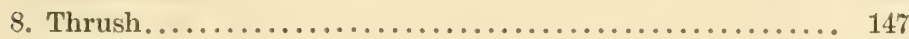

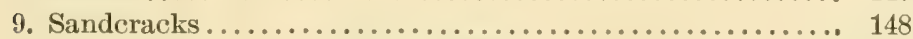

10. Loosening of the Sole from the Wall ............. 148

11. Seedy Toe.................................. 149

12. Contracted Hoof........................... 150

Contraction in the Region of the Quarters......... 151

Contraction of the Sole Only................ 152

Contraction in the Coronary Region............ 153

\section{CHAPTER XXIV.}

Lameness Resulting From Different Causes Not Described in THE Foregoing Paragraphs................. 154

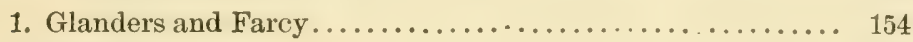

2. Influenza................................... 154

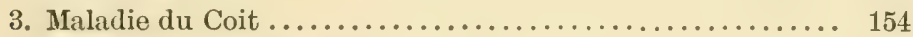

4. Purpura Hromorrhagica........................ 155

5. Inflammatory Conditions of the Skin.............. 155

6. Shoulder Abscess. .......................... 155

7. Inflammatory Changes in the Mammary Glands ......... 155

8. Inflammation of the Spermatic Cord and Testicles ........ 155

9. Enlarged Inguinal Glands..................... 156

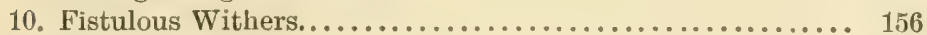

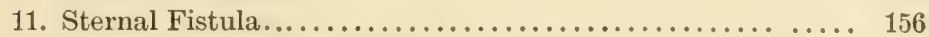

12. Wounds and Inflammatory Conditions of the Skin and Underlying Tissues of the Organs of Locomotion....... 156

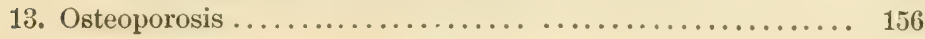

CHAPTER XXV.

Disease of the Head of Suspensory Liganient ............ 157

Paresis of the Flexor Pedis Perforans................. 158 



\section{TABLE OF ILLUSTRATIONS.}

FIG.

1. Muscles of the foreleg ............................ 28

2. Rupture of suspensory ligament, flexor perforatus, and flexor

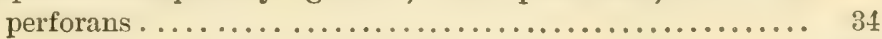

3. Lameness from bursitis inter-tubercularis............... 41

4. Complete paralysis of the radial nerve............... 43

5. Schema of the more important tendon sheaths and bursæ of the fore-limb seen from in front and without........... 52

6. The same, as seen from the front................... 52

7. Rupture of the superior sesamoidal or suspensory ligament... 56

8. Excessive dorsal flexion......................... 57

9. Location of splints............................. 60

10. Flexor pedis perforans and perforatus tendon in a case of sesamoidal lameness ........................... 67

11. Articular ringbone.............................. 71

12. Peri-articular ringbone $\ldots \ldots \ldots \ldots \ldots \ldots \ldots \ldots \ldots \ldots \ldots \ldots \ldots$

13. Muscles of the hindleg....................... $\quad 79$

14. Tendon sheaths and bursæ of the hind-limb of the horse, seen

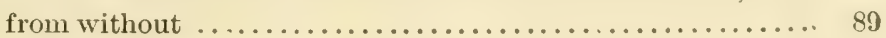

15. Incomplete crural paralysis ..................... 97

16. Left-sided chronic inflammation of the stifle joint......... 102

17. Bilateral chronic inflammation of the stifle joint.......... 103

18. Luxation of the patelia............................ 104

19. Rupture of flexor metatarsi muscle................. 107

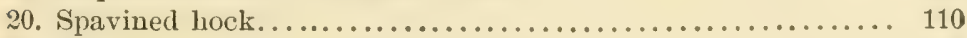

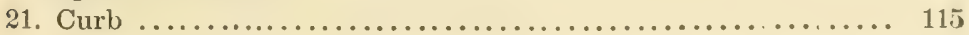

22. Position of the limb in infectious inflammation of the flexor pedis perforatus sheath in the fetlock region............ 118

23. Schema illustrating fractures of the pelvis in the horse...... 123

24. Position of the hoof in disease of the plantar cushion........ 137

25. Position of anterior limbs in laminitis................ 138

26. Hoof deformed by chronic laminitis................. 141

27. Ossification of the lateral cartilages ................. 147

28. 1, Loose wall ; 2 and 3 , hollow wall.................. 149

29. Complete bilateral contraction .................... 151

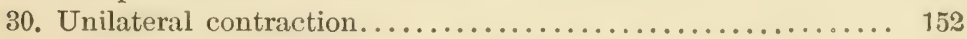

31. Contracted sole and dislocation of the wall at the toe ....... 153

32. Coronary contraction........................... 153 xiii 



\section{SYNOPSIS OF LAMENESS.}

The diagnosis of lameness involves three problems:

1. Detection of the Lame Leg.

2. Detection of the Seat of Lameness.

3. Detection of the Causes of Lameness.

Lameness depends on :

1. Painful Sensations in the Limb or adjoining parts.

2. Paralysis of Nerves or Museles.

3. Pathological conditions mechanically interfering with locomotion.

4. A combination of the above.

Lameness may be:

1. Severe, the lame leg not supporting any weight.

2. Moderate, the lame leg supports weight imperfectly.

3. Slight, the lame leg supports the full weight, but the period during which it supports weight is shortened. 



\section{CHAPTER I.}

\section{DETECTION OF THE LAIME LEG.}

In cases of slight lameness an educated eye and constant practice are imperative. Severe lameness is readily recognized, as even at rest distinct symptoms, such as pointing or frequent raising of the suffering limb, are noticeable. By pointing is understood the resting of the foot either in front, behind, to the outside or inside of an imaginary vertical line drawn from the point of the shoulder to the ground. The animal's instinct leads him to place his foot into a position which relieves pain. Unless lameness is severe the animal is either trotted, ridden or driven. If no conspicuous irregularity in the gait is present, the ear is of value, the louder hoof-beat coming from the sound leg, while the lame leg, being put to the ground more lightly, produces a weaker sound.

High-strung animals, when improperly led, as, for instance, with too short a halter rope or too slowly, often step shorter with one leg than with the other; such animals are best ridden or driven. Horses with wide chests and hips have normally a rolling, wabbling gait; horses which have done a good deal of hard work, or those which are old, lose elasticity of movement; horses with upright shoulders show a quick, short step; some horses, when going beyond a certain speed, hop behind, this hop disappearing when 
taken out of the harness and trotted with a loose rein. Colts occasionally go apparently lame, before they get used to the bit; this bridle lameness disappears when they are trotted with a halter and loose rein. If no halter is handy this feigned lameness can be easily recognized by watching the animal from both sides, as the nodding of the head corresponds with the right as well as with the left leg, thus excluding lameness. Unless discretion is used in such cases as just mentioned, the animal may be pronounced lame while in reality sound.

In locating the lame leg, trot the horse with a halter on, leaving a foot and one half of rope, thus allowing free play to all muscles concerned in locomotion, and have him trotted slowly toward the observer. If lame in one fore-leg, the right one, for instance, his head will nod more or less when he steps upon the left fore-leg, while the head jerks up at the moment the right leg (the lame one) is placed upon the ground. Hence the head of the lame animal always nods when the sound leg is planted.

Should there be lameness in both fore-legs, the action is stilty, the naturally elastic stride is wanting, the steps are shortened and the feet are kept close to the ground. Almost invariably the hind-legs are picked up higher than normally, the shoulders appear stiff and the head is carried rather high, while the lumbar region is arched.

Lameness behind is seen by trotting the horse from the observer, the croup being the essential point to be watched, since it falls or drops with the sound leg and rises with the lame one.

If lame in both hind-legs, the stride is shortened and awkward, the fore-legs are kept back of the vertical line and are apt to be raised higher than usual, while the head is 
lowered. Backing is difficult, and it is almost impossible to keep the animal at a trot when there is lameness in more than one leg at a time.

Horses lame in both fore or hind legs, show a wabbling gait behind, often mistaken for lameness originating in the lumbar region; this peculiar motion is simply due to the fact that the hind legs are unduly advanced under the body for their own relief or that of the fore-legs.

Lameness in two legs of the same side causes a seesawing of the head and haunch, due to the jerking up of the head, as the lame fore-leg comes down, and dropping of the haunch as the sound hind-leg touches the ground. Pacers, of course, form an exception to this rule. If lame in two legs of the same side, the body drops when the sound legs are planted and rises when the lame legs come to the ground.

Animals lame diagonally, for instance, in the right foreleg and left hind-leg, show a rising of the body as the lame legs are put to the ground, whereas the head and haunch drop as the left fore and right hind leg (the sound ones) touch the ground.

Close attention is to be paid to the animal's action as he turns while being trotted to and from the observer, as at this moment, - that is, while he turns, - any hitch becomes visible, as, for instance, in spavin or stringhalt lameness.

Sometimes lameness is so slight, and that only for a little while after leaving the stable, that the detection of the lameleg is quite impossible. Under these circumstances it is advisable to drive the animal briskly three or four miles, rest him one half hour, and then proceed with the examination. This treatment often materially increases lameness and the lame leg becomes more apparent. 
Exceedingly difficult to diagnose are complicated cases, that is, those where more than one leg is lame at the same time, calling for constant practice and keen observation. If there is any doubt as to the permanency of the lameness,it may be temporary from interfering, picking up stones, etc.,-examine the animal again in a day or two.

Lameness resulting from chronic disease of a joint, especially the hock joint, becomes more pronounced by passively flexing the joint supposed to be diseased for one or two minutes, trotting the animal immediately on releasing the leg. This method of examination, applied mostly to confirm the diagnosis "spavin," is known as the spavin test. Sometimes it is necessary to trot the horse in a circle, particularly if trotting him in a straight line gives negative results; but the circle must not be too small, as this produces irregular action of the legs. The horse is trotted to the right and to the left of the circle, as one direction is apt to bring out the lameness better than the other. For instance, if jogrging him to the left causes or increases lameness, the trouble is somewhere in the near leg. 
CHAPTER II.

\section{DETECTION OF THE SEAT OF LAMENESS.}

Slight lameness requires a thorough knowledge of the anatomo-physiological laws, with careful application of the same. Of great value is the history of the case, and absolutely necessary the local examination by inspection and palpation.

\section{History.}

In learning the history of a case ambiguous questions are to be avoided. The most important questions are :

1. How long is the animal lame?

2. Under what conditions did he go lame?

3. Was the lameness first seen while at work, or did it appear on rest?

4. Has the horse been shod recently?

5. Did it fall or sustain external violence?

6. Did the lame leg ever show any swelling?

7. Has the lameness increased or decreased since it first occurred?

8. Does lameness increase while working, or is it more pronounced after a rest?

9. Has the animal ever been treated, what part of the leg, and what was the treatment? 


\section{Examination of the Lame Animal.}

1. Observe the horse while at rest, see if the feet support the same amount of weight, or if the animal points; whether one fetlock is more upright than the other and whether he frequently shifts the weight from one leg to the other.

Some nervous horses, or those previously treated with blisters, setons, firing iron, etc., become restless at once on approach of a person; such animals therefore must be examined with great care.

2. Make the animal step from one side to the other, bestowing particular attention upon the action of the hind-legs. The spasmodic motion peculiar to spavin or stringhalt is often brought out in this manner.

3. The animal is now walked, trotted, ridden or driven, according to the degree of lameness. While moving the horse the nature of the faulty action must be studied. The important point lies in finding out whether the faulty action is more visible while the leg is supporting weight or when it is swinging; whether it is abducted or adducted, the toe pointing in or outward. In all doubtful cases the horse must be tried on soft and on hard ground.

4. If possible, place the animal's legs into a normal position, and inspect the various parts of the lame leg, always comparing them with the same parts of the sound leg, to find anatomical changes. Examine the hoof first, unless the seat of the lameness is sufficiently couspicuous to allow the omission of the examination.

\section{Examination of the Hoof.}

A thorough knowledge of the principles of shoeing, of the anatomy and diseases of the hoof, are essential to arrive at a correct diagnosis. The size and shape of the hoof is to 
be inspected. It is well to remember that the left hoof is frequently normally smaller than the right one; yet the writer has seen horses with the right hoof smaller than the left one, although they had never been lame. Compare the size, slope, depth and breadth of the heels of the two feet.

In cases of hoof lameness of long standing, the lame foot is usually smaller and narrower than the sound one. If inspection leaves any doubts, the eye may be greatly assisted by measuring the various parts with a compass.

Inspect the coronary region, the horny wall and the shoe. The latter immediately becomes of great importance if lameness follows recent shoeing; in such cases the fit of the shoe, its length and shape, as well as the seat of the nails, are to be closely examined.

One also tests the pulsation of the arteries on the fetlock, an increased throbbing invariably pointing to an acute inflammation of the podophyllous membrane. This latter symptom can also be produced to some extent by any pressure upon the blood vessels of that region, as, for instance, swellings of the skin or subcutis about the coronet or fetlock; but the pulsation thus brought on is never as intense as the one following an acute inflammation, and really is more a fulness of those vessels.

A positive diagnosis of an acute inflammatory process within the horuy box can be made if there is an absence of swelling along the phalanges and presence of increased. throbbing in the arteries along the fetlock. Even then the pulsation in the arteries of the lame foot is to be compared with that of the sound one. Of course the increased pulsation following exercise is not to be mistaken as an indication of disease. 
On the whole it is well to examine an animal for lameness after it has rested some time, while again a great many horses can be examined to advantage immediately on being presented for examination.

The temperature of the hoof is also of interest, remembering the fact that the posterior part of the hoof is naturally warmer than the balance of it, as that region is more richly supplied with blood and the horn is thinner. For this reason it is best to individually examine the various regions of the hoof, using the same part of the hand for each one. For instance, the one hand is allowed to rest upon the toe of the lame foot while the other hand rests on the same part of the sound foot, comparing the impression made upon both hands. In a similar manner all parts are gone over.

Palpation is also of value to detect pain. The instruments employed are a light hammer and hoof testers.

In order to avoid errors, that is, to interpret the obtained results correctly, quite some practice and judgment are required, as too strong a pressure may produce pain even in a sound hoof, while too light a pressure in a diseased hoof gives negative results. Generally speaking, the proper amount of pressure is then applied, when the horn yields just a little; if this is not productive of pain, evinced by the attempts of the animal to withdraw the foot, one may be reasonably sure that the spot borne upon is not the seat of pain.

As a rule, it is safest to begin testing the hoof where no disease is supposed to exist, thus to find out the degree of elasticity and sensibility of the region about to be examined. To complete the test, the various parts pinched by the hoof tester are lightly tapped with the hammer, in order to 
confirm the diagnosis made by the hoof tester; and under certain conditions a diagnosis can only be arrived at by the percussion sound of the hammer.

If the examination reveals disease, the shoe must be removed. If necessary, the sole should be pared, the condition of the white line being of particular interest, and all loose shreds of the frog are to be cut off. Foreign bodies are usually found when the sole is cut out.

If any portion of the sole indicates by its color or its friable consistency a diseased state, or if the painful spot pressed upon by the hcof pincer shows a nail-hole, further examination with the searching knife is imperative, and in the latter case the nail-hole is to be traced until either an abscess is found or that part of the white line where the nail entered the horny wall.

In all cases of hoof lameness the pulsation of the artery along the shin bone, or those along the fetlock, must be taken into consideration, and undue throbbing or fulluess of these vessels must be followed by a careful, systematic examination of the hoof.

Finally, it is well to remember that the swelling of the subcutis along the flexor tendons-the result of inflammation of the podophyllous membrane-being œdematous and painless, should exclude an error as to the diagnosis of inflammation of the flexor tendons.

Completion of the examination of the hoof is followed by inspection and palpation of the phalangeal articulations, bestowing special care upon the joints below the knee or hock, observing them from various points of view, always comparing them with the corresponding part of the sound leg.

Knee, fore-arm and shoulder receive similar attention. 
In the latter one looks for muscular atrophy, but this symptom must not be credited immediately as the seat of lameness, since in all chronic or severe forms of lameness atrophied muscles may be expected; but atroplyy of certain groups of muscles, especially the antea and postea spinatus, or the olecranian muscles, justly hints at the seat of lameness.

The examination of the hind-leg does not differ materially from that of the fore-leg. The inner surface of the hock requires close attention, a thorough knowledge of the anatomy of that region, a good deal of practice and discretion whenerer an attempt is made to locate a sparin, and it is essential that the observer takes the same position in viewing and comparing the contour of both hocks.

First, the anterior part of the inner surface of the tarsus is viewed by standing a little to one side of the fore-leg; then, by sighting the hock from between both fore-legs, the middle of the internal hock surface can be criticised, the posterior portion of the internal face of the hock being looked at from behind.

Sometimes the length or roughness of the hair interferes with the recognition of the contour of the joint; then the hair shonld be moistened to make it lie close to the skin. Horses with sickle-shaped hocks may mislead the observer, as the bones at the inner and posterior part of the hock are 11aturally enlarged; at the same time, in some horses one particular bone may be enlarged, and if the same bone is equally large in the other hock, spavin cannot be pronounced.

The middle and lower layer of hock boues are sometimes divided by distinct grooves, which give rise to ridges, and the greater development of the inner metacarpal boue must 
not be mistaken for a spavin. In these cases the ridges are found on both hocks, and as they are sitnated along the center of the bone and not its edge, this, together with the fact that other bones of the bony frame are naturally enlarged,--for instance, the knee bones, easily detected by inspection and palpation,--helps to avoid errors.

The gluteal region is inspected for muscular atrophy, changes in the shape of the external angle of the ilium and the postero-external angle of the ischium.

Whenever the animal is subjected to such a methodical examination, one rarely fails to find some pathological condition, as swelling, heat, pain, etc., subsequently to be examined by palpation.

In palpating, the situation, consistency, form and extent of the lesion require the attention of the one conducting the examination. To interpret pain, the possible result of palpation, demands great care, especially when palpating the flexor tendons of the phalanges, as even moderate pressure upon them causes some patients to flinch. By gliding the thumb and index finger over the flexor pedis perforans and perforatus from above to below, with the leg resting on the ground, enlargements, ruptures, etc., can be detected, but pain in these structures must not be considered a symptom of disease unless palpation is conducted with the foot raised from the ground.

In palpating the metacarpal bones, the thumb rests against the region of the external face of the bone, while the balance of the fingers touch the internal face; in this manner the pain of periostitis or exostoses, - that is, splints,_can be nicely felt, and mostly in the groove formed by the small and large metacarpal bones.

Certain precautions are necessary in palpating the region 
of the shoulder, as even moderate pressure with the hand against single muscles or groups of them produces flinching in animals perfectly sound; therefore, in the detection of pain by palpation, it is well to test the sensibility not only of the supposed seat of the lameness, but also the corresponding part on the sound leg.

Increase of temperature of any part is perceived by the palm, or, better yet, the dorsal portion of the hand. Of course the greater the inflamed area the easier the detection of it. A good deal depends on the condition of the examining hand, a cold hand being least adapted to appreciate differences of temperature. At the same time the hand must be rested gently upon the parts to be tested, keeping it there for a few seconds, remembering that any firm pressure decreases the chances to notice slight changes in temperature. The test is usually executed by resting both hands (equally warm), one on the diseased area and the other upon the corresponding one of the sound limb. Acute inflammatory processes of the skin or parts below it are recognized by an increase of temperature; increased heat of a part may be dne to prolonged resting of the hand upon the place to be tested.

Palpation is further of value to detect crepitation, as in fractures or inflammation of tendons and their sheaths. To examine for fracture, the parts just above the supposed broken bone are fixed, and the parts below the injury are abducted, adducted and rotated to bring out abuormal mobility and crepitation. In fractures of the pelvis one hand is placed upon the external angle of the ilium, the other one upon the postero-external angle of the ischium, then pushing toward the opposite side; or the animal is walked with the hands resting upon the above-named 
regions. Either method may bring ont crepitation and occasionally mobility. Examination per rectum also is of great value in these fractures.

In disease of the tendon of the glutens medius muscle or postea spinatus tendon, the crepitation peculiar to this trouble is differentiated from that of a fracture by its softer character. It is felt by placing the haud upon the tendon of the muscle while walking the animal. Pain on rotation of a joint indicates articular tronble, especially of the phalangeal articulations. In such a case the leg is picked up as in shoeing, one hand fixing it above the articulation to be examined and the other hand practicing a strong and steady rotation. If the pain in the joint or its ligaments is slight, passive rotation may give negative results; therefore the absence of pain on rotating a joint does not invariably exclude its being diseased.

Artificial movement of the upper joints, - that is, those above the knee or hock, - with a view to locate abnormal conditions, is of but little value, unless it be to test for limited mobility.

In examining the carpus for stiffuess, it is imperative to have the angle of the elbow and shoulder joint in both legs exactly alike, since a difference in their respective positions might lead to errors, as both knees must be testerl and the results compared.

Pain in the region of the shoulder occasionally is discernible by artificially extending the arm forward and backward, abducting and adducting it; but the impatient. motions of a nervous animal must not be confounded with pain the result of that test.

Examination of the pelvic cavity per rectum may become necessary to diagnose fractures of the pelvic bones or 
thrombosis of the posterior aorta and its branches. For this purpose the fingers of the hand are shaped like a cone, hand and arm moistened. The other hand pushes the tail to one side, and with a rotatory movement the moistened hand is introduced into the rectum; frces are removed by the hand. To feel for thrombosis of the posterior aorta, iliac and femoral artery, search first for the posterior aorta, the pulsations of which can be distinctly felt; now proceed along the course of the vessel on one side and then on the other. In cases of thrombosis pulsations are either absent or a slight trickling feeling is imparted to the fiuger, the obstructed vessel being abnormally hard. Here as elsewhere the ressel on the opposite side must also be examined and the results compared, to avoid errors.

To locate fracture of the pelvic bones the hand and fingers palpate the floor and sides of the pelvis; if no fissure can be found by simple palpation, it is well to let somebody push one hindquarter toward the other one, which may cause a displacement of the fractured parts, easily detected by the examining hand. In this manner crepitation may also be brought out. In luxation of the head of the femur into the foramen ovale its head can be felt, especially when the affected leg is moved.

An important question often arises while examining an animal for lameness, viz.: Is the abnormality found the cause of the present lameness? In answer to that question, the following points are to be considered :

1. Compare the degree of lameness with the pain resulting from palpation of the diseased part. If the lameness is out of proportion to the pain produced by the local examination, care is necessary to avoid mistakes. In such cases the examination is to be continued until another 
cause is found to explain the lameness, or the absence of such a cause is established beyond a doubt.

2. The duration of the lameness and the nature of any anatomical change are to be compared. If the lameness is of recent origin and the pathological condition an old one, or when the lameness is of long standing and the pathological condition of recent date, it is clear that one cannot be directly connected with the other.

3. Compare the influence which the present abnormality has upon the physiological functions of the limb with the nature of the existing functional disturbance.

Splints and thrush are frequently looked upon as causes of lameness, but an exostosis only causes lameness when periostitis is present, recognized by palpation, or when such an exostosis mechanically obstructs the movement of a joint. Thrush rarely causes lameness, excepting in contracted feet,-the latter, in my mind, being the main cause of lameness; but thrush itself will cause lameness whenever the horny frog is lestroyed to such an extent that it no longer protects the sensitive frog from undue pressure. Generally lameness is accompanied by distinct anatomical changes, and the seat of it can thus be located; but lameness depending on paralysis does not show any anatomical changes at first; the diagnosis therefore is based upon the functional disturbance and the absence of pain.

For a number of years hypodermic injections of cocaine over the plantar nerves at the fetlock have been resorted to, to help locating the seat of the lameness, especially in cases of mixed lameness, where doubt prevailed as to whether the pathological conditions above or below the fetlock caused the limeness. As a rule, 5 to 10 drops of a 10 per cent. solution of cocaine were injected on either side 
of the fetlock, the animal left to itself eight to ten minutes, and then trotted. If the lameness disappeared after such an injection, the seat of the trouble was necessarily below the point of injection. The writer has abandoned this practice, because the lame animal frequently becomes greatly excited, even when less cocaine is introduced, and in his opinion the results of the injection, which ought to be made aseptically to avoid complications, are not sufficiently satisfactory to warrant its use as a diagnostic agent in such cases. 


\section{CHAPTER III.}

\section{LAIIENESS IN THE FORE-LEG.}

\section{Anatomo-Physiological Review.}

The fore-leg supports the body while at rest, hanging from the boly and swinging forward during movement. In the former position it is known as the supporting leg, in the latter as the swinging leg. Aponeuroses and muscles interwoven with fibrous tissue,-and of these the serratus magnus is the most important one,-firmly unite the scapula and humerus to the body. A solid connection between the limb and body, entirely independent of purely muscular elements, exists. This fibrous union diminishes concussion, helps carry the weight of the body, and finally holds the limb in place. Some muscles of that region are traversed by a strong fibrous cord, especially the flexor brachii, and nearly all the muscles below the elbow show fibrous intersections from their origin to their movable insertion. In this manner union and harmonious working of the articulations is established.

Flexion of the shoulder joint is limited by the flesor brachii, it acting as a check to the joint in the supporting leg. The phalanges, so to speak, rest upon the flexor tendons, as they are firmly united to them at the lower part of the leg. Consequently tightening of the flexors immobilizes all joints below the elbow joint, without expenditure of muscular 
energy. The elbow joint is made immovable by the flexor muscles and their aponeuroses. Lateral motion of all joints below the elbow joint is inhibited by the shape of the articular surfaces and the ligaments; only the shoulder joint forms an exception, as ligaments are here replaced by the postea-spinatus muscle, flexor brachii, the large extensor of the fore-arm, teres minor, the short abductor of the arm, and, on the internal face, the wide and strong tendon of the subscapularis muscle and teres major. The elasticity of these muscles and their aponeuroses fix the shoulder joint sufficiently to prevent undue lateral motion.

The horse, as is well known, ean stand up for days without getting tired, since all the joints of the supporting leg can be fixed without the aid of muscular elements. During movement this mechanism, fixing all joints while at rest, has another important duty to perform, it receiving the shock coming from the weight of the body, which the elastic muscular elements could never stand. This inelastic check-apparatus therefore prevents collapse of the whole limb whenever weight is thrown upon it, and consequently the fibrous parts of the flexors, but never their muscular portion, sustain injury from concussion. The forward stride,-that is, the action of the swinging leg,-is partly due to the weight of the foot, but mainly depends upon the mastoido-humeralis, antea-spinatus, biceps brachii, and coraco-humeralis muscles. While these muscles advance and extend the shoulder joint the elbow joint is flexerl, this greatly facilitating the forward motion of the leg. The olecranian muscles extend the elbow joint; at the sams time they extend all joints below it, as the extensor muscles, like the flexors, have fibrous cords running through them, being also covered with aponeuroses. Whenever the elbow 
joint is flexed, the flexor muscles are tightened; extension of that joint is followed by tightening of the extensor muscles of the foot, and consequently extension of the phalangeal articulations. The action of the swinging leg takes place as follows: at the moment the supporting leg has finished its work it points obliquely downward and backward; now the weight borne by the one supporting leg is transferred to the other one, the strained tendons and aponeuroses of the first leg are relieved, the flexors and their check ligament become slackened, and the phalanges advance; this is partly brought about by the action of the flexors, greatly assisted by the elasticity of the fascir of the fore-arm; now the mastoido-humeralis and some of the pectoral muscles also act, the extensors of the shoulder joint and flexors of the elbow joint, principally the biceps brachii, coraco-humeralis, antea-spinatus muscles, and the leg swings forward. Thus the first half of the peudulum-like motion of the swinging leg is made. While the muscles moving the scapula and those extending the shoulder joint continue to act, the other joints are extended. A gradually increasing flexion of all joints from the elbow joint downward accompanies the first half of the swinging leg. The second half of the forward stride shows extension of all joints of the leg. The above indicates that the function of the swinging leg depends chiefly on the action of the muscles, the first part of the forward stricle on the muscles of the shoulder, mastoido-humeralis, biceps brachii, coraco-humeralis and antea-spinatus; in the second half, the olecranian muscles and extensors of the fore-arm assist the advancement of the leg by extending all joints, and gradually change the swinging leg into the supporting leg. In the supporting leg the muscular elements are more or less at rest, being 
replaced by the tendons, suspensory ligaments, aponeuroses and fibrous intersections of their muscles, which unite the

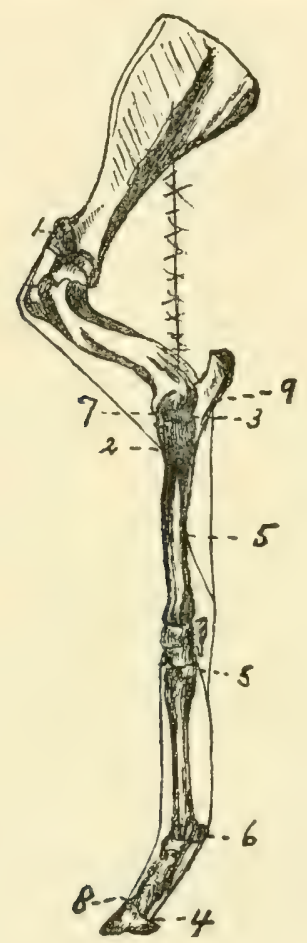

FIG. 1.

1, Upper Insertion of the Flexor Brachii; 2, Lower insertion of the Flexor Brachii ; 3, Axis of the Elbow Joint; 4, Lower Insertion of the Flexor Pedis Perforans: 5, Check Ligaments; 6, Flexor Pedis Perforatus and Perforans at the Sesamoid Bones; 7, Upper Insertion of the Extensor Muscles; 8, Lower Insertion of the Extensor Pedis; 9, Upper Insertion of the Flexor Muscles.

articulations so firmly that the entire leg becomes a solid colum able to sustain the weight of the body withont the aid of muscles.

Taking the above into consideration, it is clear that lameness must be divided into that of the swinging leg and 
that of the suprorting leg. The former alludes to diseased conditions of muscles mainly, the latter of bones, tendons, ligaments and the hoof. Diseases of joints, tendon sheaths and periosteum cause a mixed lameness, that is a combination of the above. Swinging-leg lameness refers to those lamenesses characterized by an imperfect forward stride, whereas supporting-leg lameness shows itself when the leg supports the weight of the body.

In quadrupeds one step consists of the distance between the foot-prints made by one and the same leg. The step of the horse, therefore, may be divided into two halves. The first half is in back of, or posterior to; the second half in front of, or anterior to, the foot-print of the opposite leg. Thus the normal step may be said to show two equal halves, as the distance of the foot-prints of one leg is equally divided by the other, the opposite leg.

Lameness does not alter the length of the stride, since the lame leg has to cover the same distance as the sound one; hence it must take an equally long step. But lameness causes a shortening of either the posterior or anterior half of the step. In swinging-leg lameness the lame limb does not advance in the regular manner, and does not step the the full distance beyond the foot-print of the sound leg. For this reason the second or anterior half of the step taken by the lame leg appears shortened. The reverse is true of supporting-leg lameness. Here the lame leg is advanced properly, but putting weight upon the lame leg is painful, inducing the animal not only to step shorter with the sound leg, but also to place it quicker to the ground. As a consequence, the posterior half of the lame legr's step is necessarily shortened. In order to see this, the lame animal is led by the observer at a distance of three or four yards, 
he closely watching the distance between both feet as they are placed before each other upon the ground.

Swinging-leg lameness can be divided into two main groups.

Swinging-leg lameness, with a retarded and apparently shortened stride, is present in:

1. Diseased states, usually of an inflammatory nature, of muscles, tendons or their sheaths, as of the mastoidohumeralis, coraco-humeralis and antea-spinatus.

2. Inflammatory processes of the shoulder and elbow joint.

3. Painful conditions in the region of the shoulder joint, as swelling of the prescapular and axillary glands.

4. Paralysis of the axillary nerve plexus.

5. Periostitis.

6. Inflammatory conditions of the skin of the phalangeal region, lameness lisappearing after a few steps have been taken.

Swinging-leg lameness, with irregular movement of the $\operatorname{limb}$, as incomplete extension, is present in :

1. Paralysis of the olecranian muscles.

2. Extensive lacerations of the olecranian muscles.

3. Transverse fracture of the ulna.

4. Rupture of the extensors of the metacarpus and foot.

Supporting-leg lameness is much more frequent than swinging-leg lameness, because all diseases of the hoo: give rise to it. It can be divided into three main groups :

Supporting-leg lameness, with shortening of the period of weight-bearing aud posterior half of the step, is present in:

1. Diseases of the bones, as fractnres, fissures and periostitis, especially of the phalanges; less so of other bones. 
2. Peri-arthritis, mainly of the phalangeal articulations; lameness is intensified by turning the animal quickly on the diseased leg or exercising it in a small circle. When at rest the horse puts the foot down cantiously, and it is gradually weighted.

3. Diseases of the ligaments, tendons and tendon sheaths of the inhibitory apparatus, especially the inferior and superior sesamoidal ligaments, the flexor pedis perforans and perforatus, and posterior ligaments of the coronet joint; also in navicular disease. In severe pain the fetlock becomes upright; this position is always seen when the tendons are shortened.

\section{Hoof diseases.}

Lamenesses of this group are characterized by an omission or shortening of the period of weight-bearing. When at rest the animal is apt to point, and, should both feet be affected, the weight is frequently shifted from one leg to the other one. The sound leg is brought forwasd quicker than normally, as the lame leg experiences pain in sustaining weight. Although the lame leg is alvanced at regular intervals, it is carried abnormally beyond the footprints of the somnd leg, the posterior half of the step) being shortened. This causes an apparently retarded action of the lame leg, which may lead to errors, mistaking supporting-leg lameness for swinging-leg lameness. In cases of doubt, the animal is moved in a circle, the lame leg being on the inmer side of the circle; the weight is thus increased on the lame leg, and supporting-leg lameness becomes more pronounced; for this reason going down hill increases lameness.

Supporting-leg lameness, with abnormal position of the entire limb, as abduction, is present in: 
1. Painful affections about the breast, as in disease of the superficial pectoral muscle, sternal fistula.

2. Formation of splints, between the inner small and large metacarpal bones, exostoses and periostitis close to. the carpal articulation.

3. Disease of the exterual lateral ligaments of joints, as in distortion of the coronet joint, ringbone, particularly when the outer wall of the hoof is longer than the inner one.

4. Painful conditions of the muscular or tendinous portion of the deltoid or postea-spinatus muscles, and paralysis of the same.

5. Diseases of the outer half of the hoof, such as corns, quarter crack, nail-prick, etc.

Supporting-leg lameness, with abnormal position of the entire limb, as adduction, is present in :

1. Disease of the shoulder joint; this often causes the tendon of the postea-spinatus to become quite prominent.

2. Diseased condition of the subscapularis and teres major muscles, which is often overlooked on account of the hidden position of these muscles.

3. Hoof diseases.

Supporting-leg lameness, with abnormal position of the entire limb, as pointing backwards, is present in :

1. Inflammation of the flexor brachii and its bursa.

2. Diseased conditions of the posterior section of the hoof, as corns, contracted heels, disease of the plantar cushion.

Supporting-leg lameness, with abnormal position of the entire limb, as pointing forward, is present in :

1. Hoof diseases, as founder and navicular disease.

2. Diseases of tendons and their sheaths. 
Supporting-leg lameness, with abnormal position and movement of individual parts of the leg:

1. Abduction of the shoulder at the moment the supporting leg is in a perpendicular position, as in paralysis of the teres minor, postea-spinatus and deltoid muscles. If the suprascapular nerve is paralyzed the animal cannot step sideways.

2. Abnormal flexion of the shoulder joint, as in rupture of the flexor brachii.

3. Abnormal flexion of the elbow joint, as in rupture of the flexors of the metacarpus and in fractures, causing a loosening of their insertion.

4. Abnormal extension of the elbow joint, as in contractions of the olecranian muscles.

5. Abduction of the leg from the elbow downwards, as in rupture of the external ligament of the elbow joint.

6. Volar flexion of the carpus, as in corns, contracted heels. In these cases the horse usually points backward and the fetlock is upright.

7. Dorsal flexion of the carpus, as in rupture of the flexors of the metacarpus, fracture of the pisiform bone and imperfectly healed fracture of one of the condyles of the humerus. It is usually seen at the moment the function of the supporting leg begins, or, more rarely, while the animal is standing quietly.

8. Dorsal flexiou of the phalanges, especially the fetlock joint, as in rupture of the flexor tendons. If all tear at once, the fetlock may descend to the ground; if the suspensory ligament only ruptures, the fetlock goes dow somewhat; if the perforatus, the toe is turned up a little; while rupture of the perforans causes the fetlock to descend materially, and the toe of the hoof is turned up decidedly, 
the hoof resting on the heel only. Horizontal fracture of the sesamoid bones, rupture of the inferior sesamoidal ligament.

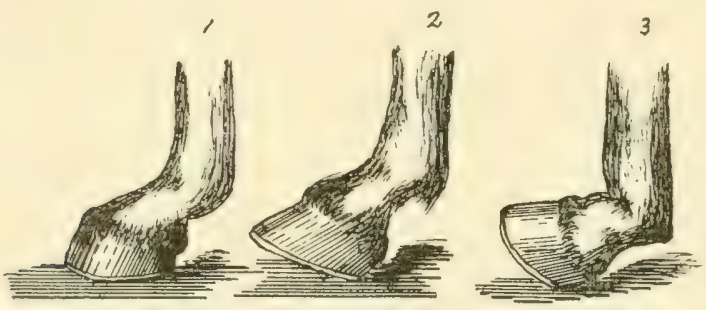

FIG. 2.

RUPTURE OF :

1, Suspensory Ligament; 2, Flexor Perforatus; 3, Flexor Perforans.

9. Volar flexion of the phalanges, as in shortening, and inflammation of the teudons flexing the phalanges; if pain and inflummation are not severe, volar flexion of the fetlock joint disappears on cessation of the inflammatory process, but if it persists a long time, volar flexion of the fetlock and carpus are permanent. Acute inflammatory processes in the sheaths of the flexors, especially the flexor pedis perforans; sesamoidal and navicular sheaths, inflammatory conditions of the phalangeal articulations, as synovitis, periarthritis, mainly about the coronet and pedal articulation; painful conditions in the posterior region of the hoof, as corns and similar affections; disease of these parts, often followed by wedematous swellings of the subcutis near the flexor tendons, may be mistaken for clisease of the flexor tendons. Volar flexion of the phalanges may or may not be accompanied by lameness. If it depends on chronic changes of the flexors, both legs are usually deformed, and a short and stumbling gait results. 


\section{CHAPTER IV.}

\section{LAMENESS IN THE REGION OF THE SHOULDER.}

\section{1.--Shoulder Lameness.}

This ambiguous term is applied to all those diseasea conditions of the region of the shoulder which camnot be clearly recognized clinically. Since the shoulder is covered by the main organs of locomotion, it is natural that there is more or less similarity in the symptoms shown.

Lameness is indicated, as a rule, by a limited motion when the leg is carried forward, the foot is advanced slowly and imperfectly, often lescribing an outward circle during the forward stride; when stauling still, the leg may or may not be flexed, resting on the toe. Moving on mneven ground, the toe is liable to trip; going up hill or trotting in a circle, with the lame leg on the outside of the circle, increases lameness. While trotting, the animal frequently nods decidedly with the hear, "going lame with its ears," as the Frenchman says. Backing is difficult, and the leg is usually dragged along the ground. Lameness on hard or soft ground is about the same, the animal possibly going it little lamer on soft than on hard ground. In disease of the levators of the fore-arm, passive movements in a forward, hackward and inward direction, produce pain. Atrophy of muscles in chronic lameness is not to be relied upon too much, for it does not always indicate the seat of the disease. From a 
clinical standpoint, it is well to classify this lameness according to its approximate seat, extent and nature.

DISEASED CONDITIONS OF THE SHOULDER JOINT AND ITS NEIGHBORHOOD.

Inspection.-Swinging-leg lameness or mixed lameness. Turning the animal suddenly upon the lame leg may increase lameness. In cases of long standing, atrophy of the shoulder muscles is noticed.

Palpation.-Pcri-articular exostoses may be felt about the scapulo-hnmeral articulation. Raising and lowering the foot may cause pain or show limited motion.

INFLAMMATORY SWELLINGS AND NEW GROWTHS.

Anatomy: Glands.-The prescapular glandis form a kind of chain along the ascending branch of the inferior cervical artery, beneath the mastoido-humeralis muscle, descending close to the attachment of the sterno-maxillaris muscle. The brachial glands aico situated insicle the arm, one gromp near the ulnar articulation, the other near the insertion of the teres major and latissimus dorsi muscle. (Chanvean.)

Inspection.-Lameness is most noticeable during the forward stride, the leg being abducted even when at rest. Acute or chronic swelling of the axillary and prescapular glands and local infections diseases can cause lameness.

Palpation.-Tumefaction of the axillary and prescapular glands may be felt, as in glanders, strangles and local infection.

THROMBOSIS OF THE BRACHIAL ARTERY.

History.-Lameness appears regularly as soon as the animal is sharply worked for ten or fifteen minutes, the horse sometimes being in danger of falling; after resting 
about half an hour the lameness clisappears, to return when again exposed to active work.

Inspection.-The animal is apparently all right when standing still or walking, but becomes very lame if trotted briskly for ten or fifteen minutes; the lame leg begins to tremble and can no longer support the weight of the body; the animal stumbles and may fall. The horse may perspire freely, yet the affected leg remains dry. When rested these symptoms disappear, to reappear on active work.

Palpation.-The lame leg, as a rule, is colder to the touch than the sound one.

DISEASE OF THE MUSCLES OF THE SHOULDER.

Histriy.-Lameness following falls, blows, stopping of the horse suddenly while going at a fast gait, etc.

Inspection.-True swinging-leg lameness, no pain being evinced while the leg supports weight. More or less swelling may be detected in one or the other muscle.

Palpation.-Almost invariably swelling and heat can be felt upon careful examination. One should bear in mind that even animals not lame almost always flinch when strong pressure is exerted on the shoulder, whereas in painful lameness sensation on pressure is not always expressed in a like manner, as handling, liniments, blisters, etc., on the actual or supposed seat of the lameness increase sensitiveness. In recent cases pain is caused by pressing upon or passively extending the affected muscles. Single muscles, as the mastoido-humeralis, or whole groups, as the pectoral muscles, when involved require careful palpation. Drawing the leg backward is frequently painful. Atrophy of the muscles of the shoulder occurs in cases of long standing, being particularly marked in the diseased muscles. 
Rhenmatic lameness, as mostly found in the mastoidohumeralis, is either remittent or intermittent. In this trouble, firm, steady pressure does not seem productive of much pain, while slight and sudden touches, as tapping the muscle with the finger, produces severe pain and even violent contractions of it; lameness often disappears on aciive sweating exercise, to return with more or less intensity aftex resting.

The writer has seen a case of rheumatism of the mastoidohumeralis which caused permanent lameness by involving later on the flexors of the phalanges, especially the flexor pedis perforans. At first the neck of the animal was bent downward and to one side, after some time this was relieved, but the flexors of the phalinges became diseased, until now the phalanges show excessive volur flexion, the toe barely touching the ground.

CONTUSIONS AND DISTORTION OF THE SCAPULO-HUMERAL ARTICULATION.

Ilistory.-Lameuess following falls, slips, and struggling with one or both feet entangled, -in fact, anything causing excessive movement of the joint.

Inspection.-When standing still, the leg is usually abducted and rests upon the toe. There is swinging-leg lameness, the stride is shortened, the leg is moved carefully and slowly, being abducted at the same time. Backing is comected with difficulty, the foot being dragged over the ground. There may be swelling about the articulation.

Palpation.-Heat, pain and swelling may be present together or separately. The exact location of this trouble is often hard to find, and the ambiguous diagnosis of "shonlder lameness" is made. 


\section{2.-Luxation of the Scapulo-humeral Articulation.}

History.-Sudden severe lameness following falls, slips and jumping.

Inspection.-Severe swinging-leg lameness, shortening of the leg, with more or less swelling about the articulation.

Palpation.-Passive movements of the articulation, as flexion and extension, are almost impossible; adduction and abduction are exceedingly free. Above and in front of the glenoid cavity of the scapula the head of the humerus can be felt, provided inflimmatory swelling does not interfere with palpation. Pressure upon this region is painful. This condition is often complicated with fracture of the scapula and humerus.

\section{3.-Inflammation of the Bursa and Tendon of the Postea-spinatus Muscle.}

Anatomy.-A wide and flattened muscle, having its fixed. insertion in the postea spinatus fossa, scapular spine and tuberosity, cartilage of prolongation and internal face of the scapular aponeurosis. It terminates inferiorly by two brauches; the extermal one, the strongest, is inserted in the crest of the external tuberosity of the humerus, first gliding over a synovial bursa situated above its point of insertion. This muscle is an outward rotator and abductor of the humerus. (Chauveau.)

History.-Lameness following kicks, falls, collisions and sudden turning while speeding.

Inspection.-Abduction of the entire leg with supportingleg lameness. The animal still supports the weight of the body, but while doing so abducts the leg as much as possible.

Palpation.-Usually increased heat and swelling can be felt over the external trochanter of the humerus. Pressure 
upon that part is productive of pain. At times crepitation can be found by walking the animal and resting the hand upon the course of the tendon and its insertion.

\section{4.-Paralysis of the Supra-scapular Nerve.}

Anatomy.-Formed by the sixth and seventh cervical pairs, this short and thick nerve runs backward between the levator anguli scapula on the one side, and the anterior deep pectoral, prescapularis and antea spinatus muscles on the other, gaining the space between the antea spinatus and subscapularis, entering it. Now it bends around the anterior border of the scapula, runs across the acromion spine, ascending to the postea spinatus fossa. It supplies the antea spinatus, poster spinatus and teres muscle. (Chauveau.)

History.--Lameness following runaways, colliding with trees, posts, etc.

Inspection.- Supporting-leg lameness, with sudden abduction of the shoulder. By walking the animal toward the observer it will be seen that the scapula, at the moment the leg supports weight and is perpendicularly under the body, suddenly is jerked away from the thorax. In disease of some standing the scapular spine becomes prominent, due to the atrophy of the paralyzed muscles, especially the antea spinatus and the two abductors, the postea spinatus muscle showing nothing abnormal.

\section{5.-Inflammation of the Bursa of the Flexor Brachii Muscle.}

Anatomy.-A long cylindrical muscle divided by many strong fibrous intersections, the middle one of which is of a tendinous nature, being continuous with the tendon of the muscle at the extremities. It originates at the base of the 
conacoid process of the scapula, to run obliquely downward and backward through the bicipital groove of the humertis, where it becomes fibro-cartilaginons, gliding over an extensive synovial sac, known as the bursa inter-tubercularis; the

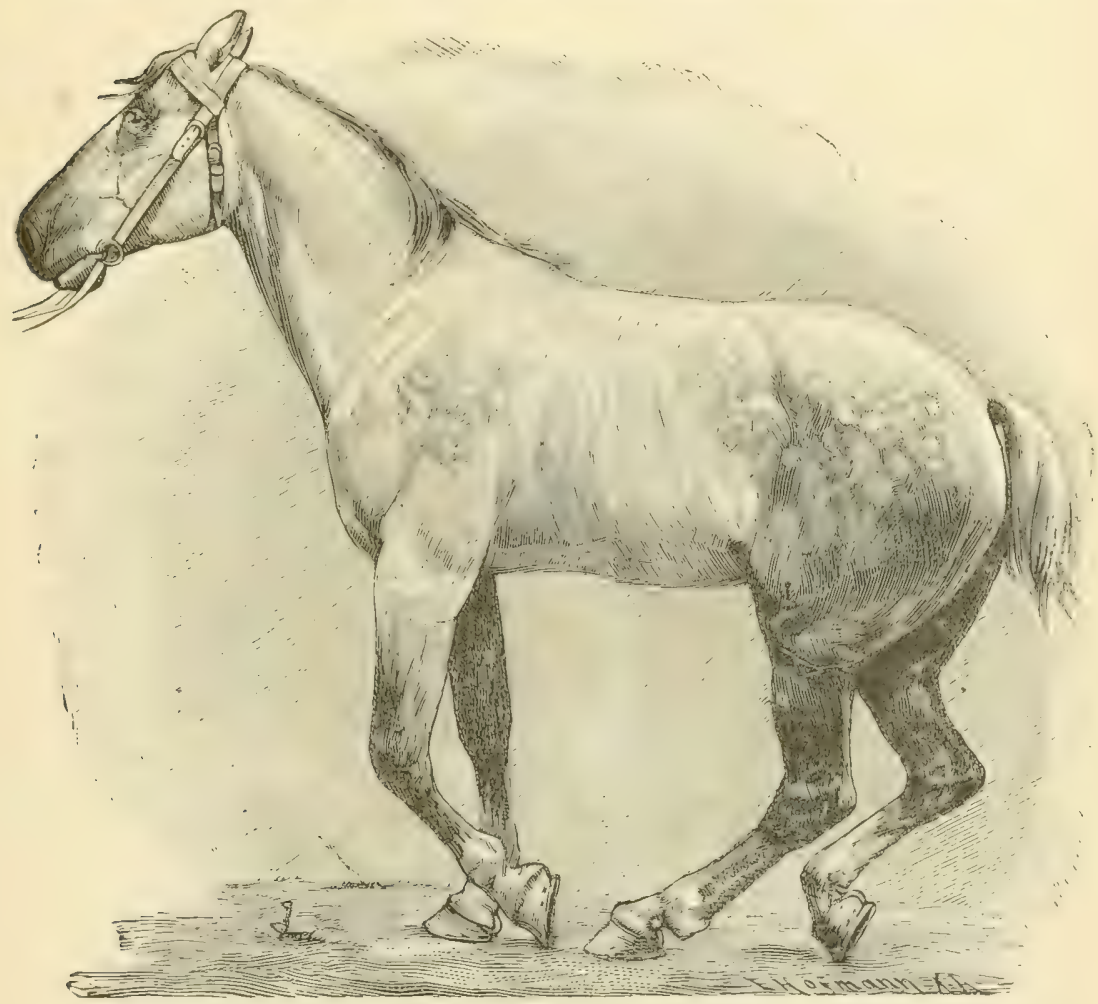

FIG. 3.

Lameness from Bursitis Inter-tubercularis.

inferior tenclon of the flexor brachii terminates on the bicipital tuberosity of the radius. This muscle flexes the fore-arm, renders tense the antibrachial aponemrosis, and mechanically opposes the flexion of the scapulo-humeral angle while the animal is at rest. (Chauveau.) 
History.-Lameness following collisions, blows and runaways.

Inspectim.-Severe swinging-leg lameness. When trying to walk it seems as though the foot could not be raised from the ground. On forced movement no weight is put upon the lame leg. Backing is done fairly well, the animal even picking up the foot. When at rest the lame leg is carried further back under the belly than the sound one, and often supports its share of the weight of the body in this position.

Palpation.-Entirely out of proportion to the intense lameness is the smail amount of pain and swelling about that muscle ; it is absent in chronic bursitis, where lameness is most marked when the leg is carried forward. In these cases wasting away and contraction of the muscle is occasionally noticed. Bilateral bursitis causes a groggy, stiff gait; the shoulders are apparently immovable.

\section{6.-Paralysis of the Radial Nerve.}

Anatomy.-This, the largest nerve furnished by the brachial plexus, runs downward and backward, crossing the inner face of the subscapularis and teres major muscles. Arriving at the deep humeral artery, it passes behind the humerus, entering between the large extensor of the fore-arm and the short flexor of the fore-arm; it runs along the posterior border of this muscle, gains the anterior face of the radio-ulnar articulation, runs on down to the oblique extensor of the metacarpus, terminating here by two branches. This nerve stimulates all the extensors of the fore-arm and foot and the external flexor of the metacarjus, endowing with sensibility the skin of the onter and anterior surface of the fore-arm. (Chauvean.) 
weight upon it. Therefore, when walking slowly on smooth ground nothing unusual can be noticed, but should the animal strike its toe against anything, stumbling is frequent, all joints from the elbow down are flexed and there is danger of falling. Sometimes lameness is only seen after exercising on heavy ground. Animals which have been lame and have improved acquire a peculiar gait, together with active contraction of the muscles of the shoulder, the leg is slung forward, the olecranian muscles being muble to exert the function fully.

Inspection (partial paralysis). - At the moment the lame supporting leg is perpendicularly under the chest, there is a sudden forward jerk of the scapula and humerus. This involuntary movement is clearly seen as the horse walks slowly past the observer.

Differential Diagnosis.-This lameness is liable to be mistaken for supra-scapular nerve paralysis, but is distinguished from it by the fact that in the latter the shoulder is abducted, whereas in partial paralysis of the radial nerve the shoulder and humerus are jerked in a forward direction. Transverse fracture of the ulna and rupture of the extensors of the phalanges show similar symptoms, yet palpation will settle the question.

\section{7.-Paralysis of the Brachial Nerve Plexus.}

History.-Sudden lameness following a severe fall, etc.

Inspection.-In complete paralysis movement is impossible, but when the leg is passively extended and brought into a normal position it is able to support the weight of the body, especially when the radial nerve is not paralyzed; while even then there is necessarily more or less difficulty 
in advancing the leg; whenever the olecranian muscles contract, all the joints, from the elbow down, become extended, to remain so during motion.

\section{8.-Fracture of the Scapula.}

History.-Sudden lameness following collisions, falls and kicks, etc.

Inspection.-Usually a mixed lameness. Any sudden severe lameness showing itself not only when the leg supports weight, but also when it is carried forward (mixed lameness), with an above history, creates suspicion of a fractured scapula, unless there is some other positive reason for the sudden lameness. The lame leg may be shortened, the animal thus walking on three legs; but in simple fracture of the scapular spine the leg often supports weight, there being a distinct swinging-leg lameness in this case.

Pulpation.-Crepitation may or may not be felt by resting the hand upon the external scapular muscles. When there is much swelling the diagnosis of a fracture becomes very difficult. In fracture of the scapular spine, dorsal and cervical angles, the broken fragments can geuerally be felt. Excessive adduction and abduction is noticeable in fracture of the neck of the scapula. Very difficult of diagnosis are fractures of the body of the bone; but if the humerus is intact and crepitation with the above mentioned symptoms present, the fracture of some part of the body of the scapula can be surnised.

\section{9.-Fracture of the Fore-arm.}

History.-Lameness following kicks, falls, collisions, etc. FRACTURE OF THE DIAPHYSIS.

Inspection.-Swinging and supporting leg lameness, with abnormal mobility in the region of the arm. 
Palpation.-Abnormal mobility and crepitation of these parts, with severe pain and perhaps swelling. This abnormal mobility is best detected by fixing the scapula and moving the bones below the humerus; it, together with crepitation, leaves no doubt as to the nature of the trouble.

FRACTURE OF ONE OF THE CONDYLES.

The foot is unable to support weight. There is severe swinging-leg lameness, and the leg from the elbow down is either adducted or abducted, the former in fracture of the external condyle, the latter in fracture of the internal condyle. When the external condyle is fractured, there is also excessive volar flexion of the phalanges, often to such an extent that the outer wall of the hoof touches the ground. 


\section{CHAPTER V.}

\section{LAMENESSES IN THE REGION OF THE ELBOW AND FORE-ARI.}

\section{1.-Inflammation of the Elbow Joint.}

History.-.-Lamenesses following wounds penetrating the joint, kicks, etc.

Inspection.-Supporting and swinging leg lameness. Lameness may be so intense that the animal will only walk on three legs, and studiously avoids any movement of the elbow joint. In the acute stage particularly, the elbow joint is extended, while the phalangeal articulations are in excessive volar flexion.

Palpation.-Usually there is severe pain and swelling about the articulation, with increased temperature.

\section{2.-Fracture of the Ulna.}

History.-Lameness following kicks and falls, etc.

Inspection.-Supporting and swinging leg lameness. If the olecranon is broken off entirely from the radius, symptoms of radial paralysis are apparent (see page 42); but as a rule the fracture takes place further down, going through the elbow joint, causing more of a supporting-leg lameness.

Palpation.-Crepitation may be detected. Abnormal mobility of the fractured parts is always present, usually accompanied by pain and more or less swelling. 


\section{3.-Fracture of the Radius.}

History.-Lameness following kicks, falls, slips and external violence, etc.

Inspection.-Inability to use the leg; possibly deformity.

Palpution.-Abuormal mobility of the parts, crepitation, pain and swelling. The ends of the fractured bone may stick through the skin.

\section{4.-Wounds and Bruises of the Fore-arm.}

History.-Lameness following kicks, blows from the wagon pole and falls, etc.

Inspection.-Generally the lameness is most marked on carrying the leg forward; there is swinging-leg lameness; the visible lesions, such as swelling, wounds, etc., with pain and increased heat, detecter on palpation of those parts, will bardly permit of a mistake. 
CHAPTER VI.

\section{LAMENESS IN THE REGION OF THE KNEE.}

\section{1.-Injuries to the Anterior Surface of the Knee.}

History. -Lameneas following falls and kicks, etc.

Inspection.-More or less swelling about the knee, excoriation of the skin, or even deeper wounds. Swelling is particularly severe when the sheaths of the estensor tendons are opened. The knee is held as stiffly as possible during motion. Weight may or may not be borne by the lame leg.

Palpation.-If the sheaths of the tendons are opened, synovia flows from the wound, often looking like jelly; in these cases severe pain and swelling are detected on palpation. Passive flexion produces intense pain. In cases where the articulation is opened, the finger or the probe can be introduced into the joint (under proper aseptic precautions). Articular surfaces, denuded of their cartilage, are rough to the touch.

\section{2.-Fracture of the Bones of the Knee.}

History.-Lameness following falls, external violence, etc.

Inspection.-The leg, as in radial paralysis, is kept flexed and is unable to support weight. Since this fracture is, as a rule, the consequence of a fall, there may be excoriations or wounds about the knee.

Palpation.-If the pisiform bone is fractured, as is usually the case, abnormal mobility and crepitation of that bone are present. 


\section{3.-Chronic Inflammation of the Knee.}

History.-Lameness following interfering, as in trotting horses, and excessive work in immature lymphatic animals.

Insprection.-Swelling about the knee, deforming the joint more or less. When at rest the knee is kept flexed; in walking there is often inability to flex the knee properly; the lame leg is brought forward slower than the sound one, the leg being abducted while supporting the weight of the body. In bringing the foot dowu the heels are apt to strike the gromud first; frequently the anterior half of the step is shortened. Lameness may be wanting, if both legs are diseased, or the carpo-metacarpal articulation only.

Palpution.-The swelling may be of bony hardness or soft and fluctuating; the latter is true in disease of the tendon sheaths. Passive flexion of the knee joint either produces pain, or demonstrates limited movement as compared with the other knee joint. (In making this comparative test the elbow joints must have the same position in both legs.)

Differential Diagnosis.-Since there is some similarity in this form of lameness and shoulder lameness, the following points are of importance in differentiating one from the other. In shoulder lameness the animal does not touch the ground with the heels first, as it often does in chronic inflammation of the knee joint; here also the leg is more frequently advanced with an outward swinging motion than in shoulder lameness. In chronic inflammation of the knee, passive flexion of the knee either causes pain or proves a limited movement of the knee joint, which in shoulder lameness is not the case.

\section{4.-Inflammation of the Carpal Bursa of the Flexor Pedis Tendons.}

History.-Lameness following, in the acute form, the introduction of some septic material, as in punctures with 
the dung fork, and extermal violence; in the chronic type, generally overwork.

Inspection: Acule Form.-Swelling around the entire joint. A wound may be seen and flowing from it synovia, alone, or mixed with pus, the discharge then having a straw-colored appearance. There is excessive lameness, the leg is carried forward stiffly and slowly.

Pulpation.-The swelling is very painful, hot and more or less firm, with a teudency to spreal. In septic inflammations, constitutional disturbances, as high fever, etc., are frequent.

Chronic Form.-Is not accompanied by lameness, unless movement is mechanically interfered with by the distended tendon sheath, extending as much as six to eight inches above and below the joint. As a rule this swelling is seen on the outside of the leg, but at times also on the inside. The superior swelling may attain the size of a cocoa-nut, whereas that on the metacarpus is mostly smaller.

\section{5.-Distension of Articular and Tendinous}

\section{Synovial Sacs.}

Acute inflammation of the synovial sacs of joints or synovial sheaths of tendons brings on lameness. When chronically inflamed, they sometimes produce limited motion by mechanically interfering with the working of a joint or tendon, and thus cause lameness. Usually bursal enlargements disappear when the leg is flexed, or when no weight is put upon it, while enlarged tendon sheaths, under those circumstances, become more distinct. Horizontal swellings suggest distended articular sacs; vertical or oblique swellings indicate distension of the synovial sheath, in which the tendon lies. 


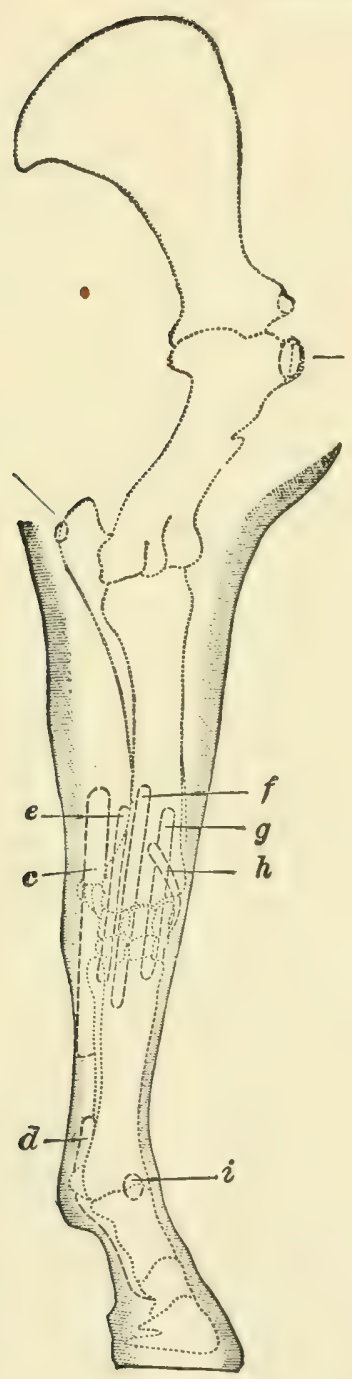

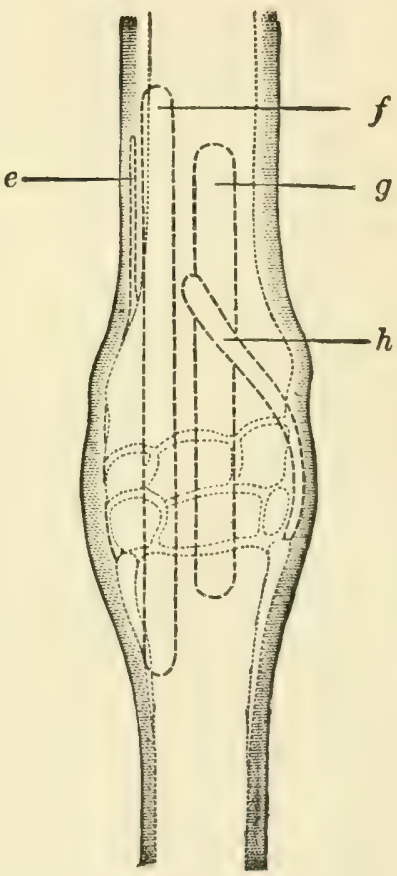

FIG. 6.

The same, as seen from the front.

Fig. 5.

Schema of the more important tendon sheaths and bursæe of the fore-limb seen from in front and without. $a$, bursa intertubercularis ; $b$, bursa olecrani; $c$, upper; $d$, lower tendon sheaths of the flexor pedis ; $e$, sheath of the flexor metacarpi ; $f$, upper sheath of extensor pedis; $g$, sheath of extensor metacarpi magnus; $h$, sheath of extensor metacarpi obliquus; $i$, bursa mucosa of extensor pedis. 
History.-Lameness following, in the acute form, distortions, contusions; fast and hard work in the chronic form.

Inspection: Acute Form.-Swelling (see further on), supporting-leg lameness, and sometimes mixed lameness.

Palpation.-Pain, increased heat, swelling, which fluctuates and corresponds to the shape of the affected joint or tendon sheath; occasionally the neighboring parts also swell to a doughy consistency.

Chronic Form.-Lameness is generally absent, especially when the swelling is soft, fluctuating and corresponding to the shape of the joint. Should the swelling be diffused, spindle shaped, tough or hard on palpation, without increased leat or pain of the parts, excessive work frequently results in lameness. In chronic inflammation of the flexor tendon sheaths, especially where the swelling is of an unyielding nature, lameness is permanent.

The following are the most commonly distended articular sacs and tendon sheaths:

1. Knee-gall.-The capsular ligament is situated between the lower extremity of the radius and upper row of carpal bones. When distended, it appears as a roundish swelling, subdivided by the extensor tendons of the anterior surface of the carpus, or on the outside, just over the pisiform bone and behind the radius; it rarely exceeds the size of a hen's egg.

2. Fetlock-gall. - This gall appears as a roundish swelling, seldom more than duck's egg size, between the suspensory ligament and metacarpus, on either side of the extensor pedis tendon, extending toward the anterior part of the fetlock.

3. Distension of the Carpal Sheath.-The synovial sheath on the posterior part of the carpus, in which the perforans 
and perforatus glide, extends about four inches above the joint, and rums down to the upper third of the metacarpal bone; when disteuded, a longish swelling above and below the carpus on the outside or inside is seen.

4. Wind-galls.-The metacarpal phalangeal sheath for the gliding of the perforans and perforatus tendons begins in the lower third of the metacarpus, extending down to the plantar cushion. Below the fetlock this sheath is surrounded by a strong, unyielding fibrous band; when distended, which is rare, a flat swelling is noticed. Distension of that part of the sheath above the fetlock is characterized by two longish swellings, one on either side of the perforans tendon, extending up to the lower third of the metacarpal bone. In the hind-leg this gall quite often becomes hard, the result of chronic changes in the tendon and its sheath.

5. Distension of the Sheath of the Extensor Suffraginis.-This swelling appears three to four inches above the knee on the outside of the fore-arm, runuing downwards, at times involving the anterior face of the carpus.

6. Distension of the Sheath of the Extensor Pedis.-This is rare. The sheath begins six inches above the knee; it runs in the outer groove on the inferior extremity of the radius over the knee joint to the upper part of the metacarpus.

7. Distension of the Sheath of the Extensor Metacarpi Magnus. - This sheath runs parallel with the one of the extensor pedis, but does not reach quite as far above the knee, runs through the middle groove on the inferior extremity of the radius, ending at the lower row of carpal bones.

8. Distension of the Sheath of the Extensor Metacarpi Obliquus. - This sheath begins on the outside, and three inches above the knee, runs obliquely downward and inward over the anterior face of the carpus, ending at the head of 
the inner small metacarpal bone. When distended, it forms a round, oblique swelling, runuing as described, being subdivided by the extensor tendons.

9. Above the fetlock, on the anterior face of the metacarpal bone, is a mucous bursa for the extensor pedis tendon, its upper wall resting against that tendon. When distended, it may become as large and even larger than a goose's egg. 


\section{CHAPTER VII.}

\section{LAMENESS IN THE REGION OF THE METACARPUS.}

\section{1.-Rupture of the Flexor Tendons and Sesamoidal Ligaments.}

History.-Lameness following sudden external violence and over-extension, as in galloping, jumping, etc.

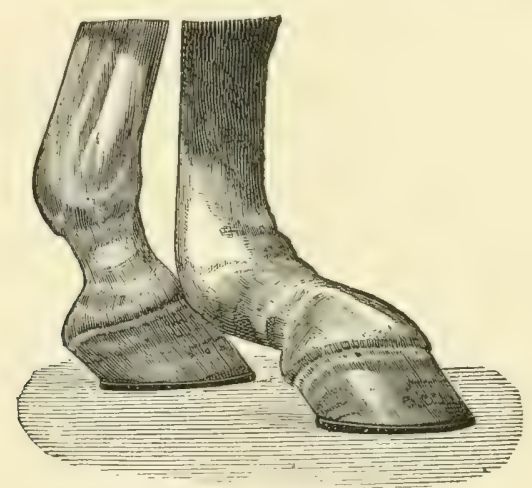

FIG. 7.

Rupture of the superior sesamoidal or suspensory ligament.

(From a photograph.)

Inspection.-In rupture of the perforatus tendon there is supporting-leg lameness, with some dorsal flexion of the phalanges, in consequence of which the toe is turned up a little, and the weight is mainly sustained by the heels. When the perforaus is ruptured all three phalangeal joints show decided dorsal flexion, causing the hoofs to rest upon the heels entirely, with the toes elevated from the ground. Rupture of the superior and inferior sesamoidal ligaments 
means abnormal dorsal flexion of the fetlock only, the position of the hoof being normal (see fig. 7).

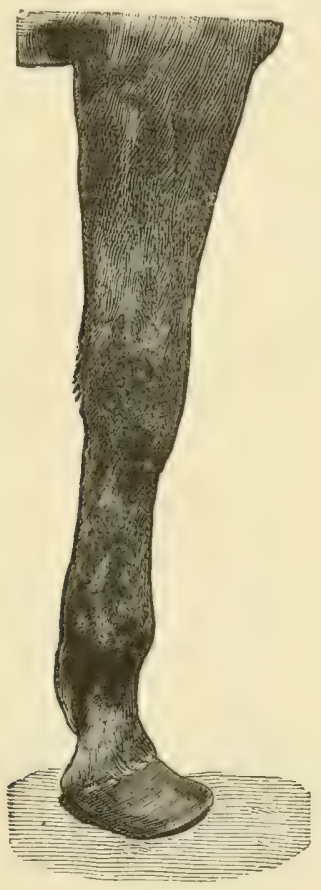

Fig. 8.

Excessive dorsal flexion after section of the perforans and perforatus tendons; the knuckling over at the fetlock is due to contraction of the suspensory ligament. (From a photograph.)

Palpation.-In recent cases the point of division of the tendon or ligament can usually be felt, while later inflammatory swelling prevents it. There is always more or less severe pain.

2.-Inflammation of the Flexor Tendons.

History.-Lameness following bruises, from kicks, prolonged hard work, jumping and galloping, etc.

Inspection.-Supporting-leg lameness, with shortening of 
the period of weight-bearing, particularly as the lame leg is perpendicularly under the body. While at rest the phalanges are kept in volar flexion. At times the animal attempts to support weight with the lame leg by putting the heel upon some elevation, but carefully aroids sustaining weight with the whole bearing surface of the hoof. Permanent volar flesion of all the phalangeal articulations indicates contraction of the perforans; but contraction of the suspensory ligament and of the perforatus only affects the position of the fetlock.

Palpation.-When the perforans is involved, the pain and lameness are severe, while inflammation of the perforatus and suspensory ligament either causes molerate or no lameness at all. Passive rotation of the various joints does not give any pain. Heat, pain and swelling, in the first stages, are present in varying degrees; but being often indistinct, great care is necessary in differentiating pain from mere nervonsness. Pain and swelling are best detected by raising the lame leg and flexing it, this being the only way, as already stated, to examine each structure separately. Of course, in clean legs, swelling can frequently be seen from a distance, otherwise most careful palpation is required to detect it. In cases of some standing there is often permanent volar flexion of the phalanges; this permanent volar flexion can be recognized as such by raising the sound leg, and thus the lame leg must support the whole weight at that moment. When volar flexion of the phalanges is due to chronic changes in the tendons-that is, contraction of the tendons-the upright position will persist under that test.

\section{3.-Fracture of the Metacarpal Bone.}

History.-Lameness suddenly following kicks, falls and external violence. 
Inspection.-Usually all three metacarpai bones are broken, there is inability to support the weight of the body, and generally, deformity with abnormal mobility of the fractured parts.

Palpation.-Crepitation, abnormal mobility, pain, and after some time hot and painful swelling about the broken parts. Fissures are difficult of diagnosis, and may be surmised when a tract of increased sensibility can be detected by careful palpation. The sound leg must also be examined in exactly the same way as the lame one, in order to compare results obtained. Fracture of one of the small metacarpal bones usually is difficult to recognize, especially when swelling has set in; but careful palpation occasionally reveals crepitation.

\section{4.--Splints.}

History.-Lameness following fast or continuous work on hard ground, interfering; lameness is more marked on hard than on soft ground.

Inspection.-At rest, the lame leg is abducted, especially when the splint is near the carpal articulation. Swinging-leg lameness is more pronounced on hard than on soft ground. The hoof is put down in the usual manner, the knee may be held stifly, while the leg is advanced. There is generally a greatly increased amount of lameness on changing the horse from a walk to a trot.

Palpation.-In the earlier stages, heat, pain and swelling are detected. Splints are chiefly on the inside of the metacarpal bone, especially in the groove formed by the small and large metacarpal bones; but in pigeon-toed horses they are mostly seen on the outside of the shin bone. The farorite location seems to be a little above the 
middle, between fetlock and knee. Splints interfering with the suspensory ligament and flexor tendons, do cause permanent lameness, as the writer repeatedly convinced himself. In those cases, the splint is situated about the middle of the posterior face of the large metacarpal bone,

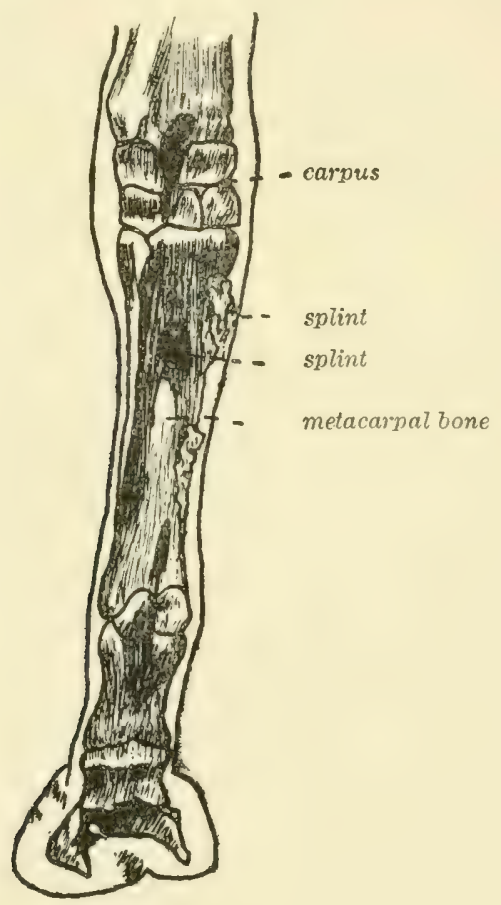

FIG. 9.

Location of Splints.

where it can be found by raising the leg and flexing it ; this causes a relaxation of the flexor tendons, which are pushed to one side, thus the posterior face of the large metacarpal bone can be palpated and enlargements felt. The swelling, which at first is slight, becomes somewhat soft on account of the oedema of the overlying skin, but later on it hardens. 
To examine the leg for splints, it must be pickeci up and the points of the fingers allowed to glide with gentle pressure over the metacarpal bone, to detect any pain or enlargements; care must be taken not to mistake the natural knob-like formation on the lower eud of the small metacarpal bones for a pathological condition. In order to avoid errors it is wise to test the sound leg in the same way and to compare the sensitiveness of the periostenm in both legs. Swelling of the skin in the metacarpal region may confuse, but the lameness is never so marked in this condition as it is in splints. One or two year old racers get, what is commonly termed, "sore shins." This periostitis is characterized by sudden lameness after hard and fast work. The lame leg is favored as much as possible; should the other one be diseased at the same time the animal shifts the weight from one leg to the other. There is decided swinging-leg lameness, the leg is raised slowly and imperfectly when moving. Soon a hot, painful swelling appears on the anterior face of the metacarpus of one or both legs. 


\section{CHAPTER VIII.}

\section{LAMENESS IN THE PHALANGEAL REGION.}

Anatomy.-The bones of the phalangeal region are:

1. Os suffraginis, also called first or metacarpal phalans and large pastern bone, with the two sesamoid bones.

2. Os coronae, also known as second phalanx or small pastern bone.

3. Os pedis, also called third phalanx, pedal or coffin bone, with the navicular bone.

These bones form three joints :

1. Fetlock joint: This is a perfect hinge joint. Its capsular ligament is reinforced by fibrous bands laterally. It also has two lateral sesamoidal ligaments, which, strengthened by the crossed ligaments, unite the sesamoids with the cannon bone and first phalanx. Between the sesamoid bones is the intersesamoidal ligament, which is of a fibro-cartilaginous nature. This ligament, together with the posterior face of the sesamoid bones, forms the groove for the flexor tendons to glide in. The superior and inferior sesamoidal ligaments inhibit excessive dorsal flexion of the fetlock-joint. The inferior sesamoidal ligament, situated at the posterior face of the os suffraginis, is divided into three separate branches: $(a)$ The superior arises from the middle of the fibro-cartilaginous mass behind the superior articular surface of the os coronae, runs up behind the first phalanx and is inserted into the base of the sesamoids, being 
confounded with the intersesamoidal ligaments. (b) 'The fasciculi of the middle ligament are fixed on the posterior imprints on the os suffraginis, and ascend to the base of the sesamoids, where they end. (c) The bands of the deep ligament are fixed to the base of the sesamoids and superior extremity of the os suffraginis. The superior sesamoidal ligament, also called the suspensory ligament of the fetlock, a powerful brace, is lodged behind the large metacarpal bone. It is inserted superiorly to the lower row of carpal bones and posterior face of the large metacarpal bone. Its inferior extremity is bifid, the branches being attached to the summits of the sesamoid bones.

2. Pastern joint: This is an imperfect hinge joint. The superior surface of the os coronae shows behind a glenoidal fibro cartilage, also two strong lateral ligaments passing downward and backward, which are inserted into the tubercles on the inferior extremity of the os suffraginis superiorly, while they are attached to the sides of the os coronae inferiorly. Their most inferior fibres reach the os naviculare and constitute the posterior lateral ligaments of the pedal articulation. This joint has a capsular ligament, related anteriorly to the extensor pedis, laterally to the ligaments; posteriorly, it touches the suspensory ligament.

3. Pedal joint: Is an imperfect hinge joint. There is one interosseous ligament which fastens the navicular bone to the os pedis. The anterior lateral ligaments are attached superiorly to the lateral imprints on the os coronae, and inferiorly into the cavities at the base of the pyramidal eminence of the pedal bone. The posterior ligaments are the continuation of the lateral ligaments of the pastern joint. The capsular ligament extends from the inferior extremity of the os coronae to the os pedis and navicular 
bone posteriorly; it expands, reaching the posterior face of the os coronae, being prolonged between the two lateral ligaments. (Chaureau).

\section{1.-Luxation of the Phalanges.}

History.-Lameness following jumping and violent struggles to free the foot, which has become entangled in some way or other.

Inspection.-Decided change in the relation of the bones of the joint. Excessive dorsal flexion of the fetlock suggests rupture of the flexor tendons, allowing the lower end of the metacarpal bone to descend; should the sesamoidal ligaments and the lateral ones be torn, the lower end of the metacarpal bone can be seen in front of the joint. When seen on the outside or inside of the joint, the lateral ligaments are ruptured.

Palpation.-Detects the abnormal position of the dislocated bone, and, unless swelling is too severe, the torn ends of the tendons or ligaments can be directly felt.

\section{2.-Distortion of the Phalangeal Articulations.}

History.-Sudden lameness following slips, and, in fact, anything stretching the ligaments excessively.

Inspection.-- While at rest the phalangeal articulations are in volar flexion,- that is, the animal kunckles over at the fetlock. After some time the lame leg may support weight when standing on level ground, but any sudden move, such as turning him around, immediately causes pronounced lameness. There is Jameness, both when the leg is carried forward (swinging-leg lameness), and when weight is put upon it (supporting-leg lameness); the latter type, as a rule, predominates, especially when turning. 
Palpation.-Usually the coronet joint and pedal joint are affected, although the fetlock may also be sprained. Heat, pain and swelling are more or less apparent. Artificial rotation of the diseased joint is important to attain a correct diagnosis. For this purpose the leg is raised, the fetlock fixed, and the other hand rotates the coronet or pedal joint. In case the fetlock is sprained, it is well to remember that artificial rotation of this joint does not always give perfect results on account of the stability of the fetlock joint. Very often the animal evinces decided pain as the various parts of the articulations are pressed upon while palpating. It is very difficult to differentiate between sprain of the pedal and coronary joints.

\section{3.-Inflammation of the Posterior Ligaments of the Coronet Joint.}

History.-Lameness following excessive dorsal flexion of the coronet joint, as slipping, jumping, and hard work on rough ground.

Inspection.-In the standing posture, the lame leg does not support any weight, and rests either upon the toe with the foot pointing forward, or, if the pain is severe, the foot may be held above the ground. There is severe supportingleg lameness, with a decided shortening of the posterior half of the step.

Palpation.-Local examination is of great value. The leg is raised and pressure exerted upon the posterior part of the pastern, about where the flexor tendon runs, and a little to each side of it; swelling and pain may thus be recognized. If there is more than a slight amount of swelling, it will be best detected by compelling the animal to stand on the diseased leg only,-done by picking up the 
sound one. It is also advisable to take up the foot and extend it, at the same time pushing the toe upward, thereby exerting an extra strain upon the ligamentous apparatus of the diseased parts. The sound leg should be manipulated in the same way, and the results compared; in this way errors are better avoided.

Differential Diugnosis. - This lameness resembles laminitis somewhat; but in the latter one finds excessive pulsation in the digital arteries, which is absent in inflammation of the posterior ligaments of the coronary joint. It differs from chronic navicular disease by the fact that contraction of the hoof and pain on compressing the horny box, over the region of the navicular bone, are wanting. (See page 76).

\section{4.--Sesamoid Lameness.}

History.-Lameness following anything straining the flexor apparatus excessively, as jumping, or stopping a horse suddenly when going fast, etc.

Inspection: Acute Form.-The animal, at rest, points forward, with the phalanges in volar flexion. There is supporting-leg lameness.

Palpation.-More or less swelling and pain over the region of the sesamoid bones.

Inspection: Chronic Form.-Forward pointing, with marked volar flexion of the phalanges when the animal stands quietly, is met with. There is supporting-leg lameness, more pronounced when first starting out, increasing on rough ground, and decreasing on prolonged rest. In severe cases, the horse is even lame at a walk. Permanent volar flexion of the fetlock, combined with swelling of the perforans tendon, is found where this lameness is of long standing. 
Palpation.-Pressure over the region of the sesamoid bones is painful. After a time a swelling of bony hardness appears in that region; it may also be at the side of the

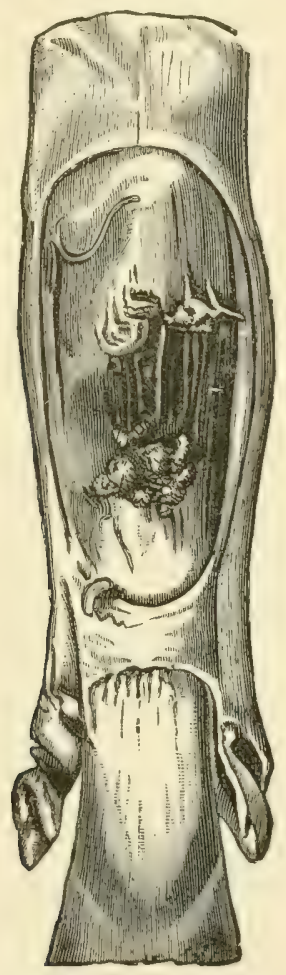

FIG. 10.

The flexor pedis perforans and perforatus tendons in a case of sesamoid lameness; at the point where it passes over the sesamoid bones the perforans tendon is fibrillated. (After Brauell).

fetlock joint next to the metacarpal bone. Passive flexion of the diseased joint quite often shows limited movement. Later on, sometimes after years, the flexor tendons enlarge at the sesamoids; in such cases there is also permanent volar flexion of the fetlock joint. Symmetrical swellings are 
now and then seen on the lateral aspect of the joint on one or both legs, causing no lameness whatsoever, and some skill is necessary to differentiate this condition from enlargements consequent upon chronic arthritis, as seen in sesamoid lameness. Whenever there is any doubt, sesamoid lameness may be diagnosed, if diseased conditions of the flexor tendons and chronic navicular disease are wanting. The examination of the sound leg should never be omitted, to compare results.

\section{5.-Fracture of the Sesamoid Bones.}

History.-Instantaneous lameness following galloping, jumping and sudden work after continued rest.

Inspection.-Horizontal fracture of the sesamoid bones shows severe supporting-leg lameness, with excessive dorsal flexion of the fetlock joint; later on, swelling of that region.

Palpation.-In recent cases a depression may be felt between the broken pieces, with great pain on pressure. Crepitation is occasionally detected.

Differential Diagnosis. - Rupture of the suspensory ligament, perforans and perforatus, offer somewhat similar symptoms, but are differentiated from fracture of the sesamoid bones as follows:

In rupture of the suspensory ligament the torn ends can be felt, and the lameness is not so intense, nor the pain so great on palpation, as in fracture of the sesamoid bones. Rupture of the perforans and perforatus tendons is followed by excessive dorsal flexion of the fetlock, the toe of the hoof not touching the ground. In fracture of the sesamoid bones, particularly in horizontal fractures, there is only dorsal flexion of the fetlock, while the position of the hoof is normal - that is, the toe is on the ground and not elevated, as in rupture of the perforans, for instance. 


\section{6.-Fracture of the Os Suffraginis.}

History.-Lameness following falls, slips, mis-steps, galloping, jumping and sudden turning of the animal when at a rapid gait.

Inspection.-Severe supporting-leg lameness, with rolar flexion of the fetlock when at rest. Shonld the fracture be complete the broken parts may show abnormal mobility, and on account of their dislocation deformity is brought on, with subsequent swelling. When the bone is only fissured, the animal is still able to support some weight with the lame leg.

Palpation.-Pronounced crepitation and usually abnormal mobility. When the lateral prominences are broken off, mobility is marked from sicle to side. Great pain is also present. In absence of crepitation artificial rotation must be resorted to; if it is not productive of crepitation, careful palpation of the anterior surface of the suffraginis must be practiced, by starting at the middle of the anterior part of the superior extremity of this bone, going down aloug the extensor pedis tendon. Any increased sensibility, along the course of the tendon, running to one side or to the other (usually the outer one), suggests a fissured condition of the os suffraginis. To correctly estimate the degree of pain resulting from such a palpation the leg must be kept quiet during the examiuation, and it is advisable to test the sound leg in the same manner, thus comparing pain and conformation.

\section{7.-Fracture of the Os Corona.}

This fracture is diagnosed in the same way as that of the os suffraginis, and the rules given under Sub. 6 can be equally well applied in recognizing this fracture. Whenever 
there is crepitation about the os corons, and no fracture of the os suffraginis present, the diagnosis of "fracture of the os corona" is in all probability the correct one.

\section{8.-Fracture of the Os Pedis.}

History.-Same as in Sub. 6, but can alsc be the consequence of a nail puncture.

Inspection.-Excessive supporting-leg lameness, with volar flexion of the phalanges while at rest.

Palpation.-Crepitation, in the majority of cases, is absent, even on artificial rotation. Compression of the horny box, usually, but not invariably, is painful. Within the first twenty-four hours after the bone has been broken there are no symptoms of acute inflammation of the flexor tendons or hoof, but after that time increased pulsation of the digital arteries sets in. A good deal of discretion therefore is required to diagnose this trouble. If crepitation and marked pain on compressing the hoof are absent, the history of the case, the sudden severe supporting-leg lameness, with excessive volar flexion of the phalanges and a careful general examination, to detect another cause, with failure to do so, make the diagnosis of "fracture of the os pedis" tolerably certain.

\section{9.-Ringbone,}

History.--Severe or slight lameness; when slight, the animal is apt to drive out of it, and the amount of lameness is likely to diminish after prolonged rest.

Inspection.-More or less severe supporting-leg lameness, increased by short turns or moving the horse in a small circle, especially in the peri-articular form. Lameness is more decided on hard than on soft ground. In stepping, the 
affected joint is held stiffly and the foot is picked up in a snatching fashion. While at rest, the lame leg is inclined to be abducted, as the phalanges are usually kept in rolar flexion. Swelling may be seen either on the inside, outside, or in front of the large or small pastern bone. When on the inside or outside of the large pastern bone, it is called "peri-articular high ringbone"; should the swelling extend

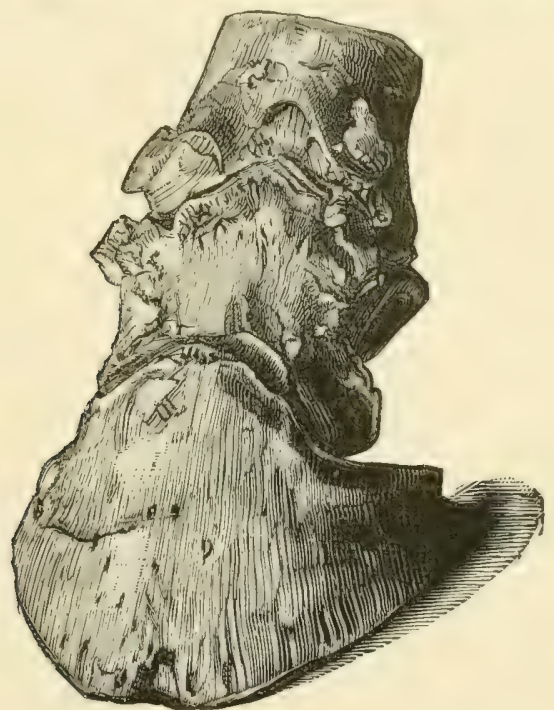

FIG. 11.

Articular Ringbone.

from the inside or the outside to the anterior surface of this bone, it is known as "articular high ringbone". The same is true of the small pastern bone, only it is termed either "peri-articular" or "articular low" ringbone. In the first instance the swelling is on the inside or outside of the bone, in the latter the swelling extends to the anterior face of that bone in the shape of a ring,-that is, the enlargement encircles the bone. Atrophy of the muscles of the leg,-a 
natural consequence of their inactivity, - is the more developed the older the case. During inspection both legs must, if possible, support the same amount of weight. Lateral swellings are best seen from in front. Swellings involving the anterior portion of the bone are more readily detected by sighting the bone from above or sideways.

Palpation.-In cases where the enlargement is as yet small it is difficult to diagnose ringbone. In the articular, as well as the peri-articular form, either high or low, the

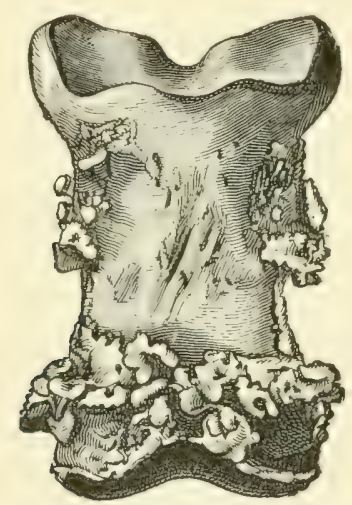

FIG. 12.

Peri-articular Ringbone.

swelling is of a bony hardness and painless, the skin on top of it is movable. In high ringbone the inferior extremity of the os suffraginis is most frequently attacked, while in low ringbone the enlargement is somewhere about the inferior extremity of the os corona. Passive flexion, extension and rotation show limited mobility of the diseased joint, indicating anchylosis; there is also permanent volar flexion of the phalanges. A positive diagnosis can, is a rule, only be arrived at after the enlargement has fully developed. 
Differential Diagnosis.-In colts, on account of the incomplete growth of the hoof, the coronet joint lies higher and the phalangeal extremities are more prominent; but the absence of lameness, and the fact that the young animal supports weight with all its feet normally, will settle any doubt. Sidebones onght not to be mistaken for low ringbone when palpation is properly conducted. Careful palpation will also differentiate thickened conditions of the skin about the regions usually showing ringboue, but some trouble may be experienced in differentiating sprain of the coronet joint from ringbone. In these cases the increased temperature of the part upon pressure and the history will usually suffice to recognize this as distortion of the coronet joint, bearing in mind that no increased heat or pain is noticed on palpation in true ringbone.

\section{0.-Fracture of the Navicular Bone.}

History.-Sudden severe lameness following jumping, stopping the animal suddeuly while going at a rapid gait, nail punctures, etc.

Inspection.-The lame leg is constantly kept in the air, or rests on the toe. When the animal is obliged to support weight with the lame leg it will do so most cautiously, with excessive volar flexion of the phalanges, the toe being held obliquely downward and backward. Later on swelling appears in the hollow of the heel.

Palpation.-Intense pain is produced by raising the foot and practicing forced dorsal flexion of the phalanges, by extending the toe and pushing it in an upward direction. In the one case met with by the writer, which was in a trotting horse going at a 20 gait, and suddenly stopped on the track to avoid a collision, seen about four hours after 
intense lameness appeared, the abore symptoms, with increased throbbing of the digital arteries of the lame foot, were evident. The diagnosis was confirmed by a post mortem examination.

\section{1.-Navicular Disease.}

History.-The horse points forward whenever standing still. Later on he seems stiff when first taken out of the stable, going lamer on hard than on soft ground, and gradually drives out of the lameness.

Inspection.-In the standing posture the animal shows volar flexion of the phalanges, pointing forward. When both feet are involved, he frequently shifts the weight from one foot to the other, and keeps them in advance of the chest, or first points with one foot and then with the other. When going, there is a tendency to dig the toes into the ground, and the animal is apt to stumble, especially in disease of both feet. In these cases the gait is stilty, the shoulders appear stiff, and the feet remain on the ground as little as possible. Little exercise is necessary to bring on sweating and exhaustion. In the early stages of the disease, the animal may drive out of the lameness; nevertheless, hard work intensifies it. Resting the horse entirely for a long time often diminishes the lameness to such an extent that it is barely visible. It is a distinct supporting-leg lameness. Backing is difficult. Lameness is usually increased by travelling on hard and rough ground. In cases of some standing, inspection of the hoof shows an apparently swollen condition of the coronet, ridges on the horny box, the hoof seems lengthened, the heels are long, the quarters diminished in size, the concavity of the sole is greatly increased, and the frog more or less atrophied. The toe of 
the hoof or shoe shows more wear than any other part of the hoof or shoe. Contraction in itself must not be relied upon too much in the diagnosis of navicular disease, even in cases of some standing. For instance, it is well to know that the left foot naturally is often smaller than the right one, although the writer is accuainted with a three-year-cld trotting horse and a five-year-old carriage horse, in both of which the right fore foot is perceptibly smaller than the left one; neither of these horses have ever been lame.

$P$ cilpation.-Heat in the hollow of the heel and increased pulsation of the collateral artery of the cannor or digital arteries, according to most authorities, is not detected in true navicular disease. In cases of navicular disease seen by the writer, some of which were coufirmed as such by post mortem examinations, increased pulsation of the arteries or increase of temperature about the hollow of the heel were absent. The deep-seated pain may be detected by pushing the thumb firmly into the hollow of the heel in the direction of the navieular bone; at the same time the toe is forced upwards. When this does not give satisfactory results, one jaw of the hoof-tester is placed upon the middle of the frog, while the other one rests upon the wall in the region of the toe, and now gradual pressure is exercised. Sometimes the sole and bars are too thick to permit of positive results with the pincers; in such cases the bars and sole must first be pared before the test with the pincers is made. Should there still be a doubt existing after this test, the animal can be shod with a bar shoe, the bar of which presses upon the frog. In true navicular disease, lameness will then increase. My personal experience taught me that a tip with a toe piece,-thus raising the toe and bringing the heels abnormally low,-gives better results and is more 
easily made than the bar-shoe. In case both feet are affected at the same time, diagnosis often becomes exceedingly difficult, and main reliance should be placed in palpation. A good deal of discretion is required, as the animal experiences pain by standing upon one leg, which is necessary during the examination; therefore his attempts to draw away the foot to be examined cammot always be looked upon as pain resulting from the hoof-testers, etc.

Differential Diagnosis: 1. Sesamoid Lameness.-Careful examination of the region of the sesamoids is sufficient to avoid errors. (See page 66.)

2. Thrush.-In bad cases of thrush, where the greater part of the frog is diseased, a supporting-leg lameness is sometimes produced, which in some respects resembles navicular lameness. In thrush, volar flexirn of the phalanges and forward pointing are not so persistent as in navicular disease. In severe forms of thrush, lameness, more acute on soft than on hard and level ground, with a tendency to increase when working, is apparent. Pressure upon the diseased frog with the hoof-tester must be done carefully and slowly, as less pressure is required to produce pain in thrush than in navicular disease. In doubtful cases it is advisable to practice forced dorsal flexion of the phalanges, which, as already stated, usually causes pain in true navicular disease, but not in thrush.

3. Sprain of the Posterior Ligaments of the Coronet Joint.The eximination of the horny box and its contents with the hoof-tester is painless; but palpation of the region of the posterior ligaments of this joint will in all probability locate pain and perhaps swelling of the ligaments in question. Lameness resulting from sprain of the posterior ligaments 
of the coronet joint is usually much more severe than navicular lameness.

4. Contracted Sole.-This condition is rare, and often exceedingly difficult to differentiate from navicular disease. The generally accepted points of difference are as follows: While there is throbbing in the digital arteries in contracted sole, there is none in navicular disease; in the latter the entire hoof atrophies; in contracted sole there is only a narrowing of the inferior border of the hoof. Little red spots are found in the white line in contracted sole, but not in navicular disease. (See page 152.)

5. Contracted Quarter's. - Are easily mistaken for navicular disease; in contracted quarters there is usually throbbing in the digital arteries and pain on compressing the quarters, which is not found in uavicular disease. Should contracted quarters be a consequence of navicular disease, the pressure upon the frog, to demonstrate pain, must decide. 


\section{CHAPTER IX.}

\section{LAMENESS IN THE HIND-LEG.}

\section{Anatomo-physiological Review.}

The ruuctions of the hind-leg, like those of the fore-leg, may be divided into the swinging and supporting leg. The supporting leg sustains the weight while the animal is at rest, but during motion it is also concerned in the propulsion of the body. The function of the supporting leg is executed principally without the aid of muscles, it being equipped with a check apparatus which fixes the joints. Under these circumstances an expenditure of muscular energy becomes at once unnecessary, provided the joints from the stifle down are fixed, the ilium being immovable and sustained by the head of the femur. The flexor metatarsi unites the stifle and hock joints, the gastrocnemii, the posterior face of the femur and os calcis. As the flexor metatarsi is in front and the gastrocnemii behind the axis of the stifle and hock joints, the femur is connected with the metatarsus in such a manner as to make the movements of these two joints dependent on each other,-that is, if one is extended or flexed the other undergoes the same movement at the same time. The phalanges are fixed similarly as in the fore-leg by the flexor tendons; the check ligament of the perforans pulling the hock downward and backward, just as the carpus is fixed in the fore-leg. While the check ligament just 
mentioned is less developed in the hind-leg, it, together with the flexor pedis perforans and perforatus, helps to fix the stifle and hock joints, sustaining the equilibrium of the limb. Whenever the weight of the body causes the fetlock

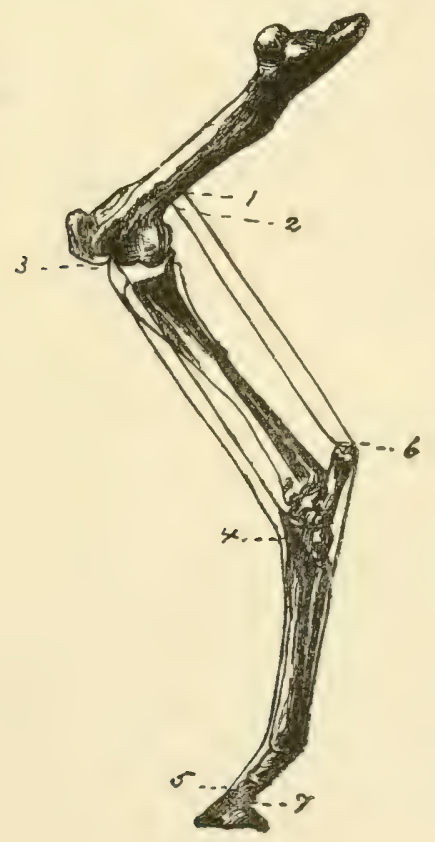

Fia. 13.

1. Upper insertion of flexor perforatus; 2 , do. of gastrocnemii ; 3, do. of flexor metatarsi ; 4 , lower insertion of flexor metatarsi ; 5 , do. of extensor pedis ; 6 , do. of gastrocnemii ; 7, do. of flexor perforans.

to descend, and thus tightens the check apparatus, the inferior extremity of the femur is pulled down and backward. This same act has also a tendency to extend the stifle joint and to fix it; the supporting leg, therefore, is provided with a fixed stifle joint, which in return means that all other joints are also fixed. The stifle joint is fixed by the tightened 
perforatus, perforans and tendinous intersections of the gastrocnemii, which pull the femur backward. In front the flexor metatarsi envelopes the stifle, also assisting in its extension. In this manner the equilibrium is almost perfect, very little help of the muscles inserted about the patella being required to maintain it. The propulsion of the weight of the body depends on the three upper joints and their powerful muscles. Vigorous extension of these joints produces decided tightening of the flexor tendons of the foot, pressing the toe and sole of the hoof against the ground. This stretching of the flexors results in an elastic gait and facilitates the beginning forward stride. If the extension of the hind-leg takes place slowly, as in a walk, the body, so to speak, is pushed forward. Trotting and galloping, calling for a more powerful and sudden extension of the hind-leg, throws the body forward.

At the moment the function of the supporting leg is finished, all fascia are tense, this being the primary factor in introducing the function of the swinging leg,-that is, the beginning of the forward stride. Now the ilio-psoas, tensor fasciæ lata, pectineus and sartorius act to advance the leg, taking place under gradual flexion of all joints. As soon as the hoof is perpendicularly under the hip-joint, the further advance of the leg is accompanied by gradual extension of all joints from the stifle down; while the above named muscles continue their action, the triceps femoris, similar to the olecranian muscles of the fore-leg, assists in the extension of the stifle and hock joints and forward movement of the limb. The extensors of the hock and foot are also concerned in this motion; thus the hoof reaches the ground, and the function of the supporting leg begins once more. The function of the supporting leg is based upon 
the tightening of the tendinous apparatus fixing the joints, it being assisted by the triceps femoris. There is at first a gradual increasing flexion of the joints, due to the relaxation of the patellar muscles, the joints of the limb flexing as the weight of the body is received by the leg, until the hoof is about perpendicularly below the hip joint; now the energetic contractions of the extensors of the hip, stifle and hock joints, which means practically all the muscles of the leg, lengthen it and more the body forward.

Swinging-leg lameness of the hind-leg can be divided into three main groups.

Swinging-leg lameness in general depends on diseased conditions of the active organs of locomotion, primarily the muscles; but disease of the joints, tendons and their sheaths may also produce it.

Swinging-leg lameness, with retarded movement and shortening of the anterior half of the step, is present in :

1. Inflammation and rupture of the ilio-psoas. 'The hind-legs are dragged, rising and lying down is painful, and therefore cautiously done.

2. Painful states in the tensor fasciæ lata.

3. Inflammatory processes in the gluteal muscles, especially the tendon of the middle gluteus.

4. Contraction of the muscular elements of the limb, due to severe and continued work, bring on a dragging gait; it is characterized by the fact that the phalangeal muscles are also affected, causing the fetlock to be upright and to kuuckle over at the moment the function of the supportingleg sets in.

5. Paralysis of the sciatic nerve and its collateral branches. 
6. Diseases of joints, as upward luxation of the patella, inflammation of the hip and stifle joints.

7. Painful conditions of tendon sheaths, as that of the flexor pedis perforans on the inner surface of the hock joint, or perforatus on the os calcis. As long as this condition is acute and painful it causes an apparently spasmodic and frequently repeated flexion of all joints, the hoof often being raised as high as the hock. Disease of the lower tendon sheaths produces an upright fetlock.

8. Painful states of bones, as fracture of the trochanter of the femur, fracture of the pelvis in front of the acetabulum, in periostitis and fissures of the tibia.

9. Painful diseases in the neighborhood of the upper thigh, as in inguinal hernia, scirrhous cord, swollen inguinal glands.

Swinging-leg lameness, with irregular action of the limb, is present in :

1. Excessive flexion of all joints, as in stringhalt; spavin and painful conditions of the skin about the phalanges, as in grease or injuries to the anterior portion of the coronet; in the latter the excessive flexion soon disappears after a few steps have been taken. The stifle joint is continually flexed in inflammation of the stifle and paralysis of the tibial nerve.

2. Upward luxation of the patella, which is followed by excessive extension of all joints.

Swinging-leg lameness, with abnormal motion of some joints, is present in :

1. Hip joint. Excessive flexion, as in spavin.

2. Stifle joint. Excessive flexion of this joint, with extreme extension of the hock joint, is seen in rupture of the tendinous part of the flexor metatarsi. Occasionally 
outward luxation of the patella produces abuormal flexion of the stifle joint; upward luxation of the patella causes excessive extension of both the stifle and hock joints. Rupture of the gastrocnemii or their tendons gives rise to abnormal extension of the stifle and the hock joint, flexing as weight is put upon the leg.

3. Hock joint. Paralysis of the tibial nerve, which is rare, produces excessive flexion of this joint in the swinging as well as in the supporting leg; abnormal extension of the hock joint, as in rupture of the flexor metatarsi, fractures of the femur and tibia.

4. Phalanges. Paralysis of the tibial nerve and rupture of the extensor pedis, especially its tendon, is manifested by volar flexion of that region.

Supporting-leg lameness of the hind-leg can be divided into eight main groups.

The supporting action of the hind-leg depends on the resistance offered by its long bones and the fixing of the different joints, which is mainly done by the triceps femoris and the tendon of the gastrocnemii.

Suspension of the function of the supporting leg, with inability to support the weight of the body, collapsing in the attempt, is present in:

1. Paralysis of the triceps femoris, or crural nerve.

2. Animals suffering with thrombosis of the iliac arteries after active exercise.

3. Rupture of the patellar muscles and of the straight ligaments of the patella.

4. Complete outward luxation of the patella.

5. Rupture of the gastrocnemii or their tendon.

6. Fracture of the long bones. 
Shortening of the period of weight-bearing and posterior half of the step is present in :

1. Diseases of the hoof.

2. Painful states in the tendons and tendon sheaths of the flexor muscles, especially the perforans.

3. Painful diseases of the joints; short turns increasing the lameness, as in spavin.

4. Inflammatory conditions of the fascix.

5. Fractures of the pelvis and painful diseases of the muscles of the internal crural region, especially the gracilis muscle.

Abduction of the whole leg, is present in :

Painful states in the outer half of the hoof, in animals spavined on both legs.

A bduction of the entire leg, is present in:

Fractures of the pelvis, especially pubis, and in the cotyloid cavity; thrombosis of the iliac arteries, and occasionally in spavin.

Inward and outward rotation of the whole leg is presentin:

1. Inward or outward rotation, as in fractures of the long bones.

2. Inward rotation, in rupture of the internal ligament of the patella and in inflammation of the bursa and tendon of the middle gluteus muscle. In backward luxation of the femur, the leg is also adducted.

3. Outward rotation, with abduction, in forward luxation, and with lengthening of the leg in inward luxation (obturator foramen) of the femur.

Abnormal flexion of all joints of the leg, is present in : (See pages 82-83.) 
Abnormal exteusion of all joints of the leg is present in : (See pages $82,83$. )

Abuormal position of individual joints in the supportingleg, is present in :

1. Exaggerated flexion of the hip joint, with forward pointing of the limb in order to relieve pain in diseases of the fore feet, as founder; abnormal extension of the hip joint, as in bilateral chronic inflammation of the stifle joint.

2. Stifle joint. Abnormal flexion of this joint is seen in the disease mentioned on page 82 , also in outward luxation of the patella. Abnormal extension, as in upward luxation of the patella.

3. Hock joint. Abnormal flexion of the joint, as in paralysis of the crural nerve, disease of the patellar muscles and rupture of the gastrocnemii or their tendon. Paralysis of the tibial nerve causes abnormal flexion of the stifle and hock joints. Excessive extension of the hock joint is sometimes due to spavin.

4. Phalanges. On the whole, the same causes, bringing about abnormal positions in the fore-leg, are also active in the production of similar conditions in the hind-leg. An upright fetlock is produced by inflammations of the flexor tendons and their sheaths, or shortening of their muscular or tendinous portion. Although these symptoms are about the same as in the fore-leg, the hock joint is less influenced than the carpus, but muscular contraction results in knuckling at the fetlock at each step. An upright fetlock also follows diseases of the phalangeal joints, chiefly the fetlock and coronet joints; inflammatory changes in the skin on the posterior face of the phalanges; in the hoof, as a secondary symptom, all such conditions as paralysis of the 
crural and tibial nerves and rupture of the gastrocnemii and their tendon.

Dorsal flexion of the phalanges accompanies anything increasing the angle of the hock, such as dislocation of the flexor pedis perforatus, rupture and stretching of the flexor tendons, sesamoidal ligaments, and finally horizontal fracture of the sesamoid bones. 


\section{CHAPTER X.}

\section{LAMENESS IN THE GLUTEAL REGION.}

\section{1.--Hip Lameness.}

The symptoms in hip lameness are sufficiently pronounced to establish the region of the hip as the seat of the lameness. Nevertheless, it is an ambiguous diagnosis, which immediately points out that the exact seat of the lameness is only known approximately. Nor is it to be wondered at, that diagnostic difficulties are met with, since the thick layers of muscles necessarily interfere with palpation and the results of phathological processes, as heat, pain and swelling, etc., are ill-defined; therefore, morbid conditions about the hip joint or upper region of the hind-leg will occasionally escape the closest observer.

History.-Lameness following falls, collisions, kicks, slips, etc.

From a clinical standpoint it is of value to divide this lameness into three main groups: $(a)$ In the bones of the pelvis or femur, as old fractures; (b) diseased conditions of the muscles of that region, this being undoubtedly the most frequent cause; (c) peripheral nerve paralysis, especially in paralysis of branches of the great sciatic, crural and obturator nerves.

Inspection.-It is clear that the nature of a lameness depending on so many causes will not be alike in all cases; 
at the same time there is a certain similarity in the symptoms offered. Swinging-leg lameness, with retarded movement of the leg, or even dragging of the whole leg. If the hip joint is diseased supporting-leg lameness is noticed, while diseased conditions of the muscular elements do not, as a rule, interfere with the function of the supporting leg. Lameness is apt to increase on hard work, backing and abrupt turning. Sometimes the animal starts out lame, gradually driving out of the lameness; or the reverse is true.

Palpation.-Swelling, increased heat and pain may be detected, and serve as valuable guides in locating the seat of the lameness.

\section{2.-Infiammation of the Tendon and Tendon Sheath of the Middle Gluteus Muscle.}

Anatomy. -This, the largest of the glutei muscles, is attached superiorly to the internal face of the gluteal fascia, the aponeurosis of the longissimus dorsi, the superior face and anterior angles of the ilium and the two ilio-sacral ligaments. Inferiorly, it is inserted by means of two branches on the trochanter major of the femur; one tendon is fixed on the summit; the other, after gliding over the cartilaginous surface of the convexity, where it forms a large bursa, is inserted into the crest. (Chauveau.)

History.-Lameness following falls, collisions, heavy work, etc.

Inspection.-When at rest the leg is usually flexed, or it may support its full share of weight, this referring especialiy to recent cases. During motion the animal trots obliquely, like a dog, 一that is, the hind-legs swerve from the straight line, the forward stride being shortened. In chronic cises 
the lameness becomes most noticeable when a heary load is

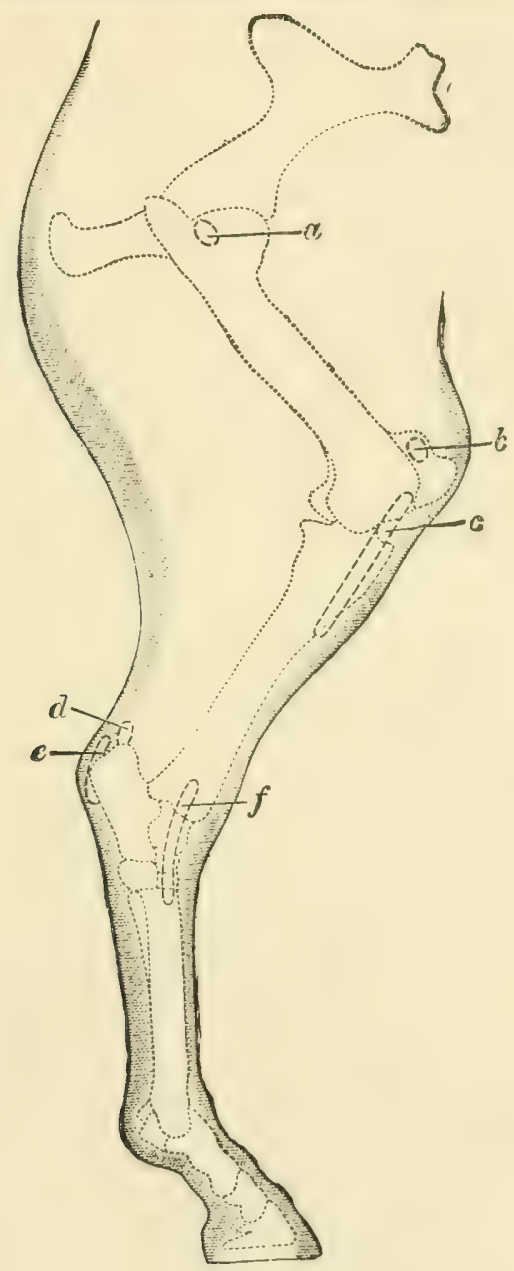

FIG. 14.

Tendon sheaths and bursæ of the hind-limb of the horse, seen from without (semi-diagrammatic). - $a$, Trochanteric bursa; $b$, prepatellar bursa; $c$, bursa of the extensor pedis; $d$, bursa calcanea; $e$, bursa of the flexor pedis perforatus tendon; $f$, bursa of the peroneus tendon.

pulled, the horse starting with the sound leg, shortening the 
period of weight-bearing of the lame leg as much as possible; then, again, lameness is most apparent when turning. In these old cases wasting of the gluteal muscles is present.

Palpation.-In acute cases pain on pressure over the great trochanter, increased heat and swelling in that region, are quite marked. The detection of crepitation over the middle trochanter, best felt by resting the hand upon that region and walking the horse at the same time, is to be mainly relied upon. The writer has seen a number of these cases in draft-mules obliged to do heavy and prolonged backing. Crepitation with local changes must be looked upon as pathognomonic, as mere swelling and pain in that region, and even an oblique trot, may follow other diseases, -for instance, old cases of fractured pelvis. 


\section{CHAPTER XI.}

\section{LAMENESS IN THE REGION OF THE HIP JOINT.}

\section{1.-Luxation of the Femar.}

History.-Lameness following slips, falls, unexpected turning, and blows, etc.

Inspection.-Swinging-leg lameness is, as a rule, pronounced, although supporting-leg lameness is present to some extent. Depending on the kind of luxation, visible changes in the form of the joint are present, and the leg may appear longer or shorter than usual.

Palpation.-Either per rectum or over the region of the hip joint one may encounter abnormal conditions ; passive movements are exceedingly free in one direction, and limited in another one, this differentiating a fracture from luxation almost invariably. In fracture, passive movement is generally unobstructed and accompanied by crepitations. At times the friction of the end of the dislocated bone against the soft parts, as muscles, tendons, etc., causes a soft crepitation, easily distinguished from the harsh, grating sound of a fracture.

(a) Forward LUXATION OF THE FEMUR.

If weight is put upon the leg the trochanter becomes plainly visible, stretching the skin which lies in folds over the thigh and stifle, which is turned outwards; the leg appears shortened, the femur is perpendicular. 


\section{(b) BACKWARD LUXATION OF THE FEMUR.}

Swinging and supporting leg lameness. The leg is advanced in an outward swinging fashion, the toe possibly dragging over the ground. Standing still, the skin over the gluteal region is tightly stretched; a depression will be noticed about the trochanter and a groove in front of the biceps muscle. The leg is abducted, but the stifle is turned inwards. Striking the trochanter, or pushing the extended leg suddenly back, gives rise to a dull sound as the head of the femur strikes the ischium.

(c) INWARD LUXATION OF THE FEMUR.

If the head of the femur rests against the transverse portion of the os pubis, the animal shows an unsteady, wabbling gait, a depression is seen over the region of the hip joint; of passive movements, alduction is excessively free while adduction is limited. If the head of the femur is in the obturator foramen, the symptoms are very much like those in the just described condition, but the head of the femur can be felt in the obturator foramen by rectal or vaginal examination, particularly when the leg is pushed upwards at the same time.

\section{(d) OUTWARd LUXATION OF THE FEMUR.}

It is quite difficult for the animal to walk, as the leg is materially shortened. In a case of a mule, seen by the writer, the trochanter was plainly visible, and could be readily identified as such by palpation directly in front and above the cotyloid cavity. Whenever the mule took a step and put weight upon the lame leg, deciled upward movement of the trochanter and stretching of the skin could be readily seen. The characteristic points therefore are: shortening of the leg with adduction, limited passive movements, 
swelling over the hip joint, recognized by palpation to bo the trochanter of the femur.

\section{2.-Inflammation of the Hip Joint.}

This disease is rare in the horse, and seldom recognized as such. More or less severe lameness when the leg is brought forward, it being advanced in an outward swinging manner. If the animal is suddenly turned on the diseased leg, it is liable to collapse. When purulent inflammation of the joint is present, symptoms of cellulitis in the region of the joint can be discovered, consisting, in the first stages, of a hot, painful, doughy swelling, becoming harder later on, with abscess formation.

\section{3.-Fracture of the Femur.}

History.-Sudden lameness following falls, kicks, struggling while cast, with inability to rise, etc.

Inspection.-Swinging-leg lameness is seen, as well as supporting-leg lameness. The tottering, dangling motion of the thigh, even at a distance, suggests fracture of the femur or tibial. Should the lower portion of the fractured bone slip into the cotyloid cavity, thus enabling the animal to support weight on that leg, it may become difficult to diagnose it, but, as a rule, the leg is then perceptibly shortened. Severe swinging-leg lameness, - that is, a shortened and retarded forward stride and abduction of the leg,-together with swelling over the region of the trochanter, follows fracture of the latter. Fracture of a condyle is accompanied by severe swinging and supporting leg lameness; all the joints are kept flered, and symptoms of acute inflammation of the stifle joint set in in $\approx$ few days. (See page 101.) 
Palpation.-In fracture of the neck or head of the femur, abnormal abduction is possible, and crepitation is, as a rule, well marked, unless the parts are too much displaced. Manipulations, such as passive movements, produce severe pain. In fracture of the trochanter, a painful swelling in that region will be noticed. Localized and painful swelling, together with the above symptoms, are found in fracture of a condyle of the femur. 


\section{CHAPTER XII.}

\section{THROMBOSIS OF THE POSTERIOR AORTA AND ITS BRANCHES.}

History.-An intermittent lameness of more or less severity when engaged in active work, disappearing while resting, and reappearing on brisk exercise.

Inspection.-In the standing posture, and before any active exercise has been taken, nothing abnormal is seen, but as soon as the animal is given a good trot of a few to several hundred yards, supporting-leg lameness or swingingleg lameness, depending on the vessels obstructed, promptly sets in.

Palpation.-Now and then the lame leg is colder than than the other one, and rectal examination of the worta or its branches locates the obstructed ressel.

\section{(a) FEMORAL ARTERY.}

Shortened and retarded forwird stride combined with dragging of the leg. (Swinging-leg lameness.)

(b) ILIAd ARTERy.

Supporting-leg lameness, with collapse of the leg when an attempt is made to sustain weight. When both arteries are obstructed the hind legs sway to and fro. Should exercise be continued, the hind legs rapidly hecome powerless, and the animals falls. In such cases, as well as in thrombosis of the posterior aorta, inability to sustain any weight, even when standing, is a consequence. These severe cases are frequently accompanied by violent beating of the heart, difficult respiration and cramps in the muscles of the hind leg. The animal may sweat profusely, yet the lame leg remains dry. 


\section{CHAPTER XIII.}

\section{PERIPHERAL NERVE PARALYSIS.}

Anatomy.-The lumbo-sacral plexus furnishes the nerve supply for the muscles of the hind-leg. The anterior portion of the plexus has two important branches-the crural and obturator nerves. The former supplies the triceps femoris muscle, pectineus and long adductor of the leg; the latter provides the adductors of the thigh, gracilis and obturator externus. The important part of the posterior portion of the plexus is the great sciatic nerve and its collateral branches; of these the small femoro-popliteal nerve is distributed to the flexor metatarsi, anterior and lateral extensor of the phalanges, while the tibial nerve supplies the adductors, gastrocnemii and flexors of the foot,-in fact, all the muscles on the posterior surface of the lower portion of the leg. (Chauveau.)

\section{1.-Tibial Nerve.}

Inspection.-The animal supports weight with the lame leg; both hock and phalanges are excessively flexed. The hock cannot be extended, the leg is advanced by raising the foot unusually high, and it is put to the ground in a groping manner. Trotting is impossible.

Palpation.-The lower portions of the hind leg are wanting in sensibility. The gastrocnemii and perforans are flabby and atrophied, in paralysis of some standing.

\section{2.-Ischiatic Nerve.}

Inspection.-While walking, the leg is trailed over the ground. The animal is mable to advance or elevate the leg, 
which appears lifeless, and the phalanges are excessively flexed. When the leg is artificially placed in a normal position it is capable of supporting weight.

Prilpation.-The muscles are flabby, and the sensibility of the skin of the leg is absent.

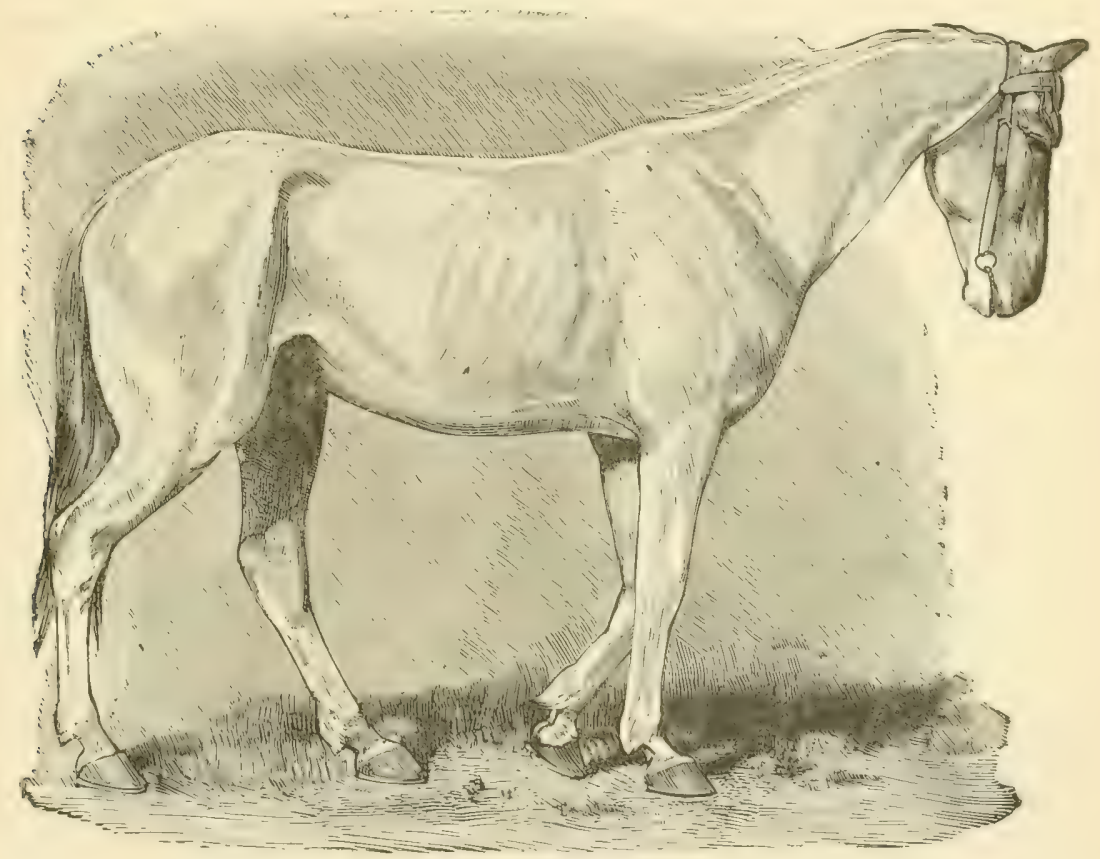

FIG. 15.

Incomplete crural paralysis. From an instantaneous photograph.

\section{3.-Crural Nerve.}

Inspection (complete paralysis). - It is impossible for the animal to support any weight with the lame leg, and any attempt in that direction is immediately followed by extreme flexion of all joints, - that is, the leg collapses.

Prlpation.-The skin on the inside of the thigh loses its sensibility. 
Inspection (incomplete paralysis).-The posterior half of the step is shortened, all joints are somewhat flexed, and the croup of the affected side sinks down a little. In older cases, the animal accustoms himself to a peculiar gait, seen to advantage when the horse is led slowly by the observer. The animal makes use of the abductor and adductor muscles of the leg to aid immobilizing the stifle joint, as the triceps femoris is powerless. The superior extremity of the tibia is drawn up and backwards, and the patella remains fixed on the condyles of the femur.

Differential Diagnosis.-Rupture of the muscles of the triceps femoris and outward luxation of the patella give rise to similar symptoms. The diaguosis of the former is very difficnlt; a gap may possibly be found between the separated ends of the muscles. The fact that crural nerve paralysis is usually a sequel to hromoglobinæmia and that rupture of the muscles follows falls or slips, etc, may facilitate the diagnosis of rupture of a muscle. Outward luxation of the patella is recognized by careful palpation.

\section{4.-Incomplete Paralysis of the Hind-leg.}

History.-Lameness following exposure to wet and cold, unaccustomed hard and continued work, and struggling when cast and unable to rise, etc.

Inspection.-LLoss of strength and irregularity of movement are apparent. Such animals appear weak behind and tire rapidly. The feet are raised incompletely, the toes are dragged, and the corresponding part of the horny box is worn excessively. The animal finishes the step by lifting the feet up rather suddenly and carrying them to an abnormal height; quite frequently the leg makes a swinging outward movement as it advances. In the next step the horse takes, 
the feet possibly cross each other, the hind-quarters execute a sort of rolling motion, and the animal is in dauger of falling. The awkward movement is plainly seen when the horse is suddenly turned. Reflex irritability is occasionally increased. Slight bilateral atrophy is liable to be met with. 


\section{CHAPTER XIV.}

\section{LAMENESS IN THE REGION OF THF FEIMORO-TIBIAL ARTICULATION.}

Anatomy.-This is an imperfect hinge-joint. It has two semi-lunar fibro-cartilages interposed between the condyles of the femur and tibial facets. The patella is united to the tibia by three ligaments, situated in front of the articulation. The exterual patellar ligament is attached to the anterior tuberosity of the tibia; superiorly it is fixed to the anterior face of the patella. It is also joined to the internal ligament by an aponeurotic extension of the fascia lata. The internal patellar ligament is attached inferiorly to the immer side of the anterior tuberosity of the tibia. Superiorly it is fixer to a prominence inside the patella. The middle patellar ligament, between the other two, leaves the anterior face of the patella, and is lodged in the fossa in the middle of the anterior tuberosity of the tibia. The femoro-patellar capsule, a membranous expansion, maintains the patella against the femoral trochlea, covering above and laterally the superior synovial membrane. This capsule is attached to the borders of the trochlea and periphery of the patella. The femorotibial ligaments consist of two lateral ones, the exterual one rumniug between the external condyle of the femur and fibula, the internal one between the internal condyle and tibia. The posterior ligament is a capsular one, formed by two layers; the superficial layer is fixed above to the posterior face of the femur, and below to the gastrocnemii ; the deep layer surrounds the condyles of the femur. After being 
united, these layers are attached close to the posterior portion of the superior articular face of the tibia. The crucial ligaments run between the tibial spine and the femoral condyles. The superior synovial membrane, strengthened by the femoro-patellar capsule, facilitates the gliding of the patella. The two lateral synovial membranes facilitate the gliding of the articular surfaces of the femur and tibia. The external synovial membrane also lines the tendon of the popliteus muscle, and its expansion descends into the anterior groove of the tibia, enveloping the tendon of the extensor pedis and flexor metatarsi. The two lateral femoro-patellar synovial ligaments lie against that of the femoro-patellar articulation, and not infrequently communicate with it. (Chauveau.)

\section{1.-Acute Inflammation of the Stifle Joint.}

History.-Lameness following external violence and wounds, ete.

Inspection.--Severe supporting and swinging-leg lameness are evident. The animal carefully avoids any movements, and the whole leg is kept flexed. A diffuse swelling around the stifle, and in case of a wound purulent synovia will be seen to flow from it.

Prlpation.-Great pain on palpation, with hot swelling in the region of the patella. (See fig. 14).

\section{2.-Chronic Inflammation of the Stifle Joint.}

History.-Gradually developed lameness in draught horses exposed to heavy and fast work.

Inspection.-In the earlier stages of the disease lameness often escapes notice, especially when both stifle joints are affected. Swinging-leg lameness, with retarded morement 
and shortened anterior half of the step in walking, particularly when starting out, is pronounced. The leg is advanced stifly, and is apt to trip on rough and uneven ground. The gait reminds one of spavin lameness, but it lacks the peculiar hip-jerk of the latter. In the standing posture, the lame leg, if one only is affected, is kept flexed, but when both joints are diseased the weight is frequently

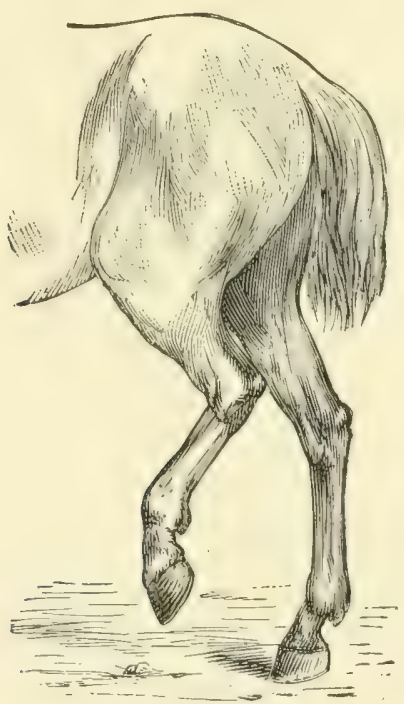

FIG. 16.

Left-sided chronic inflammation of the stifle joint (Gonitis chronica).

shifted from one leg to the other, the resting one being flexed.

Palpation.-Pain is rarely produced by pressure upon the diseased parts, but the distended capsular membrane can, as a rule, be plainly felt, and perhaps seen. In old cases the enlarged internal condyle of the femur can be readily detected, clearly noticeable when standing behind the 
animal, placing the hands over the stifle and comparing the two joints. Occasionally abduction and inward rotation of the diseased parts cause severe pain.

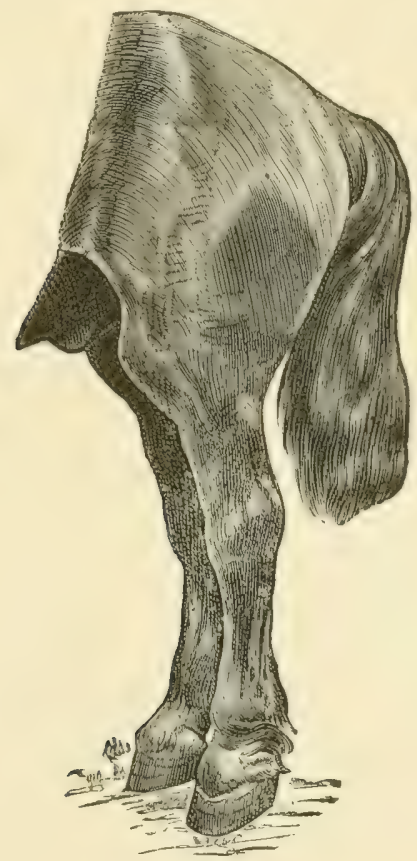

FIG. 1\%.

Bilateral chronic inflammation of the stifle joint (Gonitis chronica bilateralis). From a photograph.

\section{3.-Luxation of the Patella.}

History.-Lameness following slips, falls, kicks, etc.

Inspection.-In momentary upward luxation lameness may be so little that it is apt to be orerlooked, or at the moment the foot leaves the ground and is carried forward a sudden upward jerk of it is seen, similar to stringhalt. This peculiar movement can appear in one or both legs; it is best seen when the animal is turned around, or it is 
conspicuous only during the first few steps when beginning to work, losing itself later on. Close observation is therefore necessary to detect the momentary stop of the patella, while again it may be plainly seen to stop and suddenly jump down. The sudden flexion, following the momentary stop of the patella upon the inner lip of the femoral trochlea, must not be mistaken for a cramp of the muscles of the anterior femoral region. In stationary

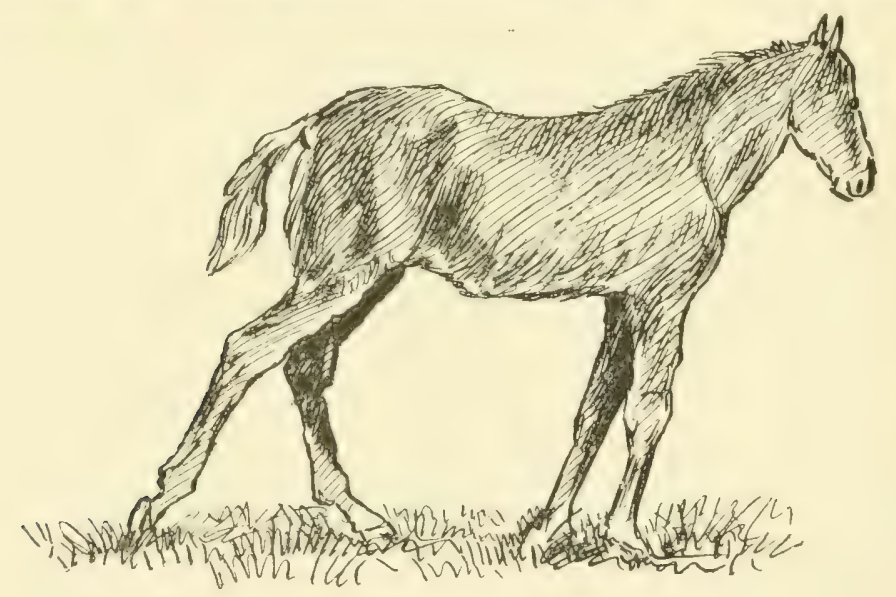

FIG. 18.

upward luxation of the patella there is swinging-leg lameness, with extreme extension of all joints, - that is, the leg is stretched backwards, and no assistance rendered can flex the joints. In cases where both joints are affected the animal is unable to move and apparently fastened to the ground.

OOTWARD LUXATION OF THE PATELLA.

Inspection.-There is supporting-leg lameness, with unusual flexion of all joints, similar as in crural nerve paralysis. 
Palpution.-Generally the patella can be readily felt in its abnormal place, while the capsular ligament is rather prominent below the knee.

Differentiul Diugnosis. - Crural nerve paralysis and rupture of the muscles, extending the stifle joint, shows similar symptoms, but careful palpation and the abnormal position of the patella usually suffice to settle the question. (See page 97.)

\section{4.-Rupture of the Straight Ligaments of the Patella.}

History.-Lameness following external violence, jumping and slipping.

Inspection.-In rupture of the outer straight ligament, which seems to be the one most frequently involved, decided supporting-leg lameness is the result. At first it is so severe that no weight at all is borne by the lame leg, but later on some weight is sustained.

Palpation.-Dnless swelling has set in, which is hot and very painful, mainly below the patella, the presence of the internal and the middle straight ligaments can be established. The gap in the external straight ligament suggests rupture.

\section{5.-Fracture of the Patella.}

History.-Lameness following falls and external violence. This trouble is rare in the horse.

Inspection.-Severe supporting-leg lameness. Any movement is carefully avoided, apparently causing intense pain. After a while swelling about the patellar region is noticeable.

Palpation.-Crepitation is usually absent, and unless the swelling interferes, the broken pieces can be felt. Manipulation of the parts is painful. 


\section{CHAPTER XV.}

\section{LAMENESS IN THE REGION OF THE TIBIA.}

\section{1.-Fracture and Fissure of the Tibia.}

History.-Lameness following external violence, falls, slipping and struggling while cast, with inability to rise.

FISSURE OF THE TIBIA.

Inspection.- When the bone is only fissured, there is severe supporting and swinging leg lameness.

Palpation.-Splitting of the bone usually shows a tract of increased sensibility, rumuing in a certain direction, on the inner face of the tibia, provided that the fissure is on that part; if on any other portion of the tibia, this tract of increased sensibility cannot be letected, as the heavy layers of muscles interfere with palpation. But any severe lameness, immediately following some external violence exerted upon the interual face of the tibia, with an absence of marked periostitis, - that is, excessive pain upon palpation,-suggests fissuring of the tibia.

FRACTURE OF THE TIBIA.

Inspection.-The tottering, dangling appearance of the leg, the inability to sustain any weight, the wabbling of the leg as the foot is raised, and possibly traces of external violence and wounds (the result of penetrating bony splinters), characterize it.

Palpetion.-Crepitation, as well as abnormal mobility, can aiways be detected. Soon after the occurrence of the fricture more or less hot and painful swelling sets in. 


\section{2.-Rupture of the Flexor Metatarsi Muscle.}

History.-Lameness following collisions, kicking violently and struggling while cast, with inability to rise.

Inspection._Swinging-leg lameness, with abnormal flexion of the stifle and excessive extension of the hock joint.

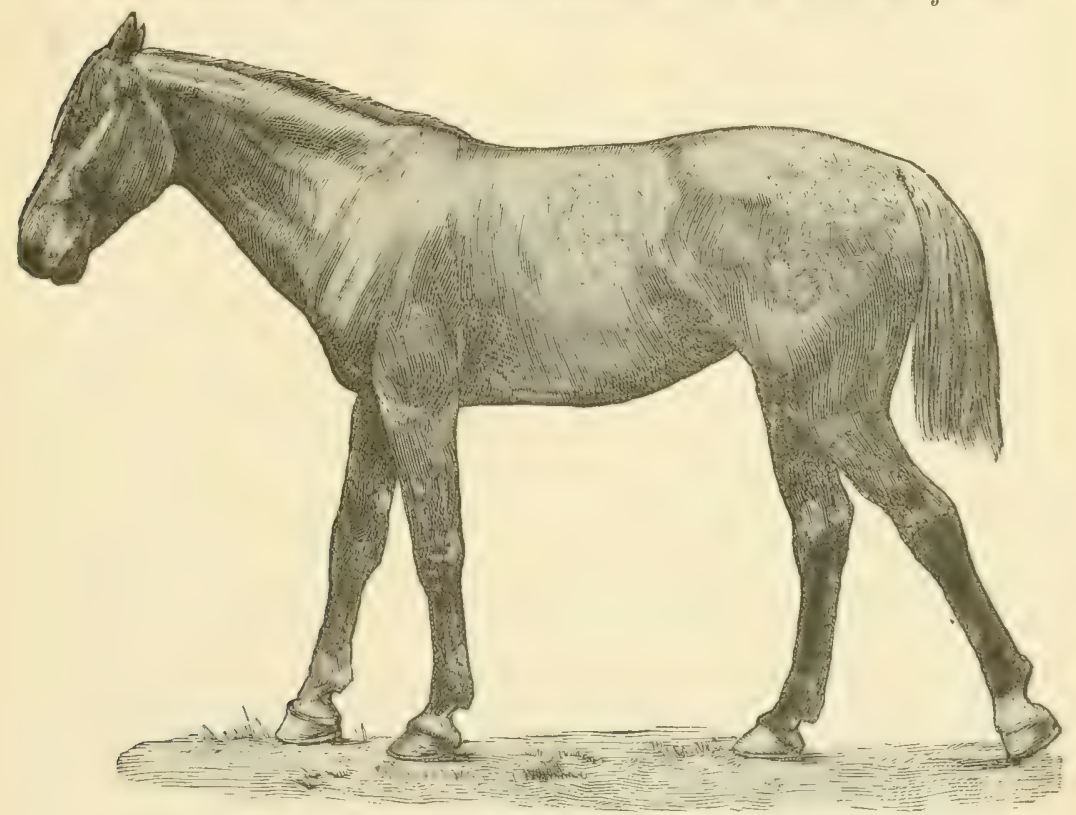

Fig. 19.

Rupture of flexor metatarsi muscle. From a photograph.

During the forward stride the hock and parts below it are not advanced in the usual manner, but remain hehind, the stifle joint at that moment being exceedingly tlexed. The thigh totters and the two hocks sometimes beat against each other, simulating a fracture of the tibia; yet any doubts in that direction can at once be banished, since weight is supported by the lame leg in rupture of the flexor metatarsi, but not in case of fracture. Then this muscle is ruptured the tendo-Achilles is perfectly slack. 
Palpation.--Sometimes a slight tumefaction can be detected about the anterior surface of the lower thigh. Passive movement of the leg permits of abnormal extension of the hock joint, and the tendo-Achilles is visibly relared.

Differential Diagnosis.-Fracture of the tibia and rupture of the tenlo-Achilles offer similar symptoms. The former is easily differentiated from rupture of the flexor metatarsi. In fracture of the tibia, severe supporting-leg lameness,that is, total inability to sustain weight,-is met with, which is not the case in rupture of the flexor metatarsi. (See page 106.) Rupture of the tendo-Achilles shows marked supporting-leg lameness; rupture of the flexor metatarsi swinging-leg lameness. (See page 108.)

\section{3.-Rupture of the Tendo-Achilles.}

History.-Lameness following falls, slips, etc.

Inspection. - Severe supporting-leg lameness, with inability to sustain weight and flexion of all joints. Unless swelling along the gastrocnemii is too prominent, the flabby condition of the tendo-Achilles is apparent.

Palpation.-As a rule a gap can be detected along the tendon. Passive movement of the hock joint allows of excessive flexion. 


\section{CHAPTER XVI.}

\section{LAMENESS IN THE REGION OF THE HOCK JOINT.}

\section{1.-Spavin.}

History-Lameness comes on gradually. In the beginuing the animal goes lame only when just starting out, soon driving out of the lameness, as a rule.

Inspection. - The nature of the lameness is by no means characteristic, in spite of the general opinion to the contrary. A spavin can only be positively diagnosed when an exostosis is evident. At the same time it cannot be denied that the nature of the lameness and certain attitudes of the lame leg are valuable guides in the diagnosis of spavin. When standing, the lame leg is apt to be carried forward and inward, its heel resting upon the wall of the opposite hoof. The animal exhibits unwillingness to move from one side to the other, and when compelled, especially towards the sound side, it does so with a decided hop. Spavin lameness, particularly in the first stages, is best seen during the first few steps the animal takes, when stepping over from the lame side to the sound one and when turning suddenly. The lame leg at that moment shows a jerky movement, similar to stringhalt, which loses itself after a little work. But in cases of some standing the animal rarely drives entirely out of the lameness; on the contrary, work is liable 109 
to increase it. As a rule, lameness is present both when the leg is carried forward and when supporting weight. The leg is not properly extended, the posterior half of the supporting leg is cut short, especially when anchylosis is present. It is quickly carried forward with a jerk and a conspicuous movement of the hip joint, there is more or less a tendency to knuckle over at the fetlock and to walking on the toe, which is usually excessively worn. Generally,

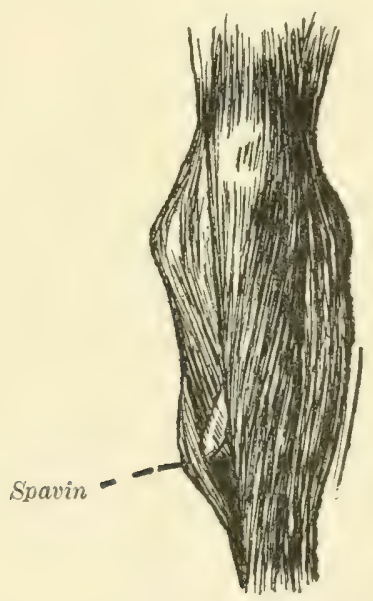

FIG. 20.

Spavined Hock.

lameness and the bony tumor appear together, yet either one can be evident before the other one. The term "coarse hock," so often employed to describe a want of symmetry of the hock joint, shows that the mere fact of one joint being of a different conformation from the other one, does not entitle to diagnosis of spavin. For this reason any visible difference in the two hock joints indicates either disease at that moment, or at a previous time. 
The principles involved in diagnosing spavin lameness, are:

1. The presence of any exostosis, particularly about the antero-internal part of the hock joint.

2. The peculiar lameness described above.

3. Certain pathological conditions, due to lameness of some standing, as atrophied muscles.

Pulpation.-Heat and pain on pressure upon the supposed seat of the spavin, unless the result of external violence, are not of much importance in the diagnosis of spavin. The enlargement is of bony hardness. In some cases, which are a little doubtful, the so-called spavin test can be employed to intensify lameness. Yet it must be remembered that this test is not infallible, and a good deal of judgment is required to interpret the result correctly. Old horses, which are merely stiff, often go lame after the test. The same refers to cases of hip lameness, which also increases after the test, as the writer has frequently observed. The test consists in raising the leg and keeping it flexed for about one minute; if the animal is then trotted, lameness usually is more pronounced than originally.

Differential Diagnosis.-1. Curb. This does not usually cause much lameness unless accompanied by a spavin. (See page 115.)

2. Inflammation of the flexor pedis tendon. Careful palpation will discern it from spavin.

3. Chronic inflammation of the stifle joint. In this affection the leg is kept flexed, when trotting there is no jerk, and the whole leg is carried forward stifly.

4. Hip lameness. As a rule the lameness is only seen while the leg is swung forward, and the animal often trots obliquely, like a dog. Lameness the result of sparin is seen 
both wlien the leg is carried forward and when supporting weight. At the same time the animal is not liable to drive out of the lameness, as it frequently does in spavin. (See page 87.)

5. Hoof lameness. Careful examination of the hoof settles the question. (See page 14.)

6. Ringbone. Ringbone lameness may be quite difficult to distinguish from spavin lameness, but the fact that ringbones are less frequent in the hind leg, together with careful palpation of the parts, will help to establish a correct diagnosis. (See page 70.)

7. Sprain of the coronet joint. Here rotation of that joint causes pain; the history and the local examination will usually determine the nature of the case. (See page .)

8. Stringhalt. In stringhalt, the animal seldom walks upon the toe, as it usually does in spavin. In spavin, when turning or stepping from one side to the other, the animal steps lightly upon the toe, and for about one-third of the stride the toe is almost dragged over the ground; whereas in stringhalt the leg is jerked up and the foot is put down firmly. In spavin the leg is nsually dragged when first starting, while in stringhalt the action is spasmodic from the very beginning.

\section{2.-Acute Inflammation of the Hock Joint.}

History.-Lameness following external violence, and wounds penetrating the joint.

Inspection.-Devere supporting and swinging leg lameness are noticed from the very outset on. Since it is mostly a consequence of a wound about the tarsus, severe swelling, with a tendency to spread abore and below the hock, and and perhaps discharge of synovia, is apparent. 
Palpation.-The swelling about the hock, which in the earlier stages is of a doughy nature, is hot and painful upon pressure.

Differential Dingnosis. - 1. Subfacial cellulitis. In cases where wounds penetrate the joint, fever, swelling and abscess-formation follow; the differentiation between this trouble and inflammation of the hock joint is at times impossible, and some time has to pass before the exact diagnosis can be arrived at. In either affection there is severe mixed lameness, with swelling about the hock and of the regional lymph glands, also deep-seated abscesses. If the opening of the abscess is followed by lessened lameness, it is reasonable to presume that the hock joint is not punctured.

2. Fracture of the bones of the tarsus. Differentiation is rather difficult unless crepitation is present, which, of course, would point to a fracture.

\section{3.-Fracture of the Bones of the Hock.}

History.-Severe sudden lameness following slipping, falling, external violence and struggling when cast, with inability to rise.

FRACTURE OF THE OS CALCIS.

Inspection.--Severe supporting-leg lameness, with excessive flexion of the hock joint especially, as well as the other joints, and collapse of the entire leg when an attempt is made to sustain weight. In compound fracture the wound and bony splinters may be seen. When the animal walks, the slackness of the tendo-Achilles is readily perceived, while all that portion of the leg below the hock is dragged over the ground. 
Pulpution.-Crepitation can usually be detected on careful palpation, and the torn-off piece of the bone is frequently felt on the end of the tendon of the gastrocnemii. There is always marked pain on manipulating the injured parts.

Differential Diagnosis.-Rupture of the tendo-Achilles offers allied symptoms. The main point of difference lies in the fact that, on palpation, crepitation and decided pain are brought out in the fracture, and a piece of the os calcis can usually be felt on the end of the tendon of the gastrocnemii.

\section{FRACTURE OF THE ASTRAGULUS.}

Inspection.-Severe lameness, followed by swelling about the astragulo-tibial joint.

Palpation.-The soft and yielding swelling is very painful. Excessive mobility, particularly abduction and adduction, as well as rotation, may be present. When the hock joint is encircled by the hands and the phalanges moved to and fro, crepitation can occasionally be felt.

Differential Diagnosis.-Sprain of the hock joint. The fact that this is very rare, the subsequent improvement, the absence of crepitation and abnormal mobility, differestiate it from fracture of the astragulus.

\section{SUBFACIAL CELLULITIS.}

The history, and the traces of a recent injury, as stabs with a manure fork, etc.; the presence of swelling of the regional lymph glands will exclude errors.

FRACTURE OF OTHER BONES OF THE TARSUS.

This is somewhat rare. The abnormal mobility, chiefly abduction and adduction, the very perceptible crepitation, the inability to support weight, and the pain on manipulation of the injured region, will at once establish the diagnosis 
of fracture of a hock bone, even though the exact location of the fracture can only be surmised.

\section{4. - Curb.}

History.-Lameness following heavy work in young animals, jumping, rearing, and stopping suddenly while going swiftly.

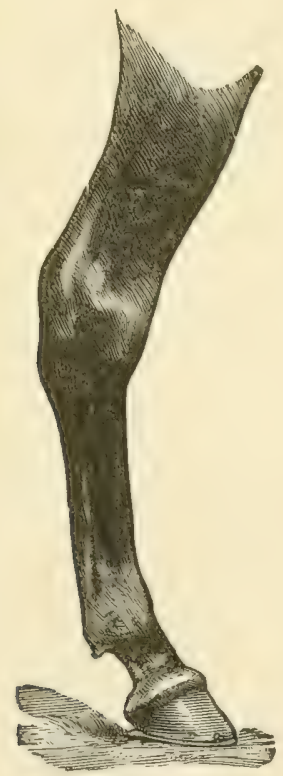

FIG. 21.

Curb.

Inspection.-A gradually developed curb hardly ever creates lameness. Should lameness be present, it is due either to a severe sprain of the calcaneo-cuboid ligament, the reinforcing ligament of the perforans tendon, or spavin. When inflammation of the above-named ligaments is present, supporting-leg lameness of varying intensity, with abnormal flexion of the metacarpo-phalangeal articulation, will be 
observed. To locate a curb, the hock is viewed from the side. Instead of a straight line from the point of the os calcis to the fetlock, a convex downward swelling, three to four inches below the point of the os calcis, is seen.

Differential Diagnosis.-Abnormal thickness of the skin in that direction may lead to errors; but here the skin is movable, while in curb the swelling is stationary. Enlargement of the reinforcing ligament of the perforans tendoin generally extends further down the tendon, thus differing from curb. The so-called bony curb is really a spavin, situated in that region, almost invariably accompanied by erostoses on the inner surface of the hock joint.

\section{5. - Luxation of the Flexor Pedis Perforatus Tendon.}

History.-Sudden lameness when pulling a heavy load, and external violence.

Inspection.-In the standing posture the phalanges show abnormal dorsal flexion, but the hock joint is extended. The slight lameness and tottering, unsteady gait are striking. Whenerer an attempt is made to extend the hock, it will be seen that the perforatus tendon slips off the point of the os calcis, usually gliding back into its place as soon as the leg is flexed. Swelling of that region and lameness are pronounced, especially when the luxation is the result of an external injury, such as a kick.

Palpation.-Unless swelling, which is hot and painful, is severe, the perforatus tendon can be felt in its abnormal position. 


\section{CHAPTER XVII.}

\section{LAMENESS IN THE REGION OF THE METATARSUS.}

\section{1.-Chronic Thickening of the Sesamoidal Sheath.}

Inspection.-In this condition the flexor tendons are often diseased. Lameness is most evident when weight is supported by the lame leg, and has a tendency to increase after exposure to hard work. The fetlock is upright.

Palpation.-The swelling is immovable and firm. Pressure upon it excites pain. The thickening can be so great that the flexor tendons are not felt through it.

\section{2.-Acute Septic Inflammation of the Flexor Tendon Sheath.}

Inspection.-More or less diffuse swelling in that region (sesamoids); wounds discharging pus may be seen. Of diagnostic value is the peculiar position in which the animal holds the suffering leg, viz.: the lame leg is similarly flered as in inflammation of the stifle joint, but the elevation of the foot is more pronounced, and the toe of the flexed leg is advanced towards the corresponding fore-leg as much as possible.

Palpation.-The swelling, which is hot and painful, may be of a doughy or firm nature. 


\section{3.-Stringhalt.}

Inspection.-In the standing posture nothing abnormal is observed; but when walking, the leg at the beginning of the forwari stride is raised with a jerk abnormally high, and quickly brought to the ground, which it strikes rather

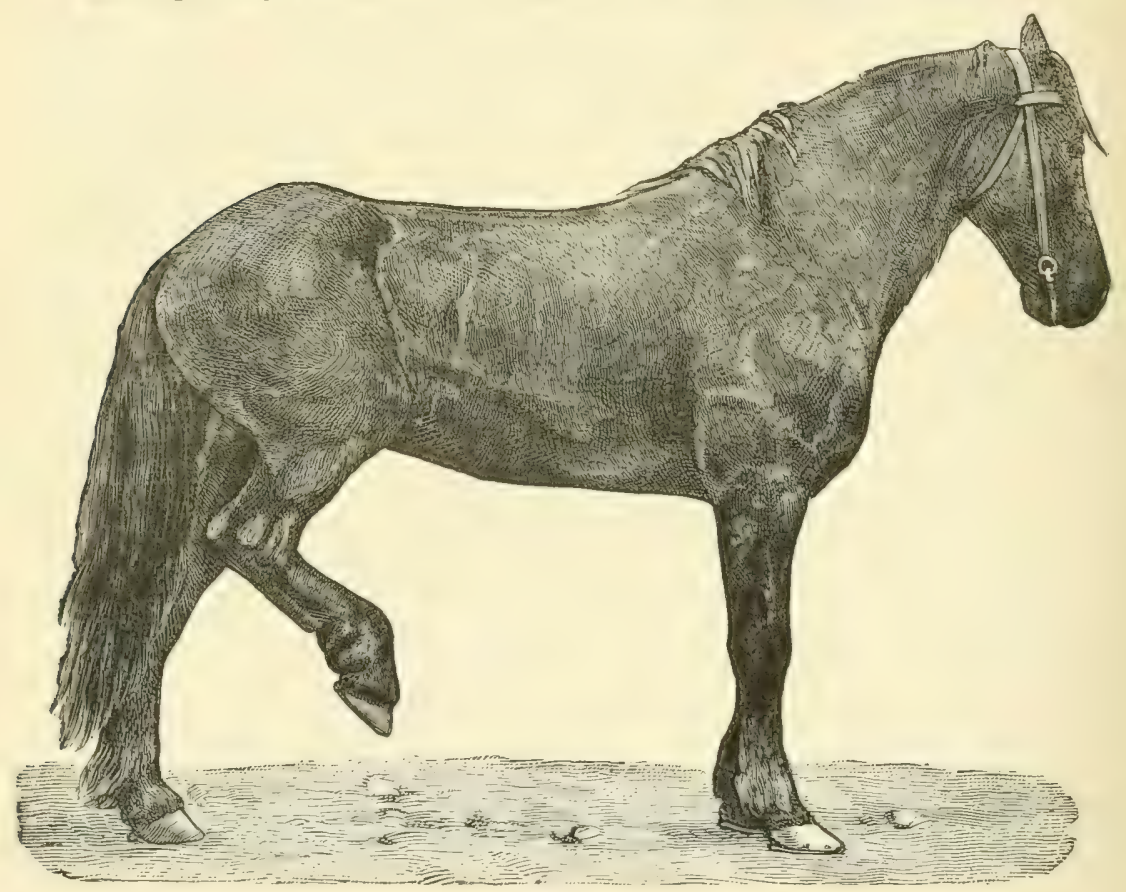

FIG. 22.

Position of the limb, in infectious inflammation of the flexor pedis perforatus sheath in the fetlock region. (From a photograph.)

hard. As a rule, this spasmodic action is most visible while trotting; in bad cases also in walking, continuing during work. In rare instances it disappears with work, to return when resting. Some animals only show the jerky action when turued in a narrow circle or forced to step over from one side to the other.

Differential Diagnosis.-(See page 112.) 


\section{4.-Lameness Resulting from Interfering and Its Complications.}

Inspection. - It is more frequently met with in the hind legs; usually the inner face of the fetlock or coronet are struck; but in the fore-legs the inner region, just below the knee joint, the metacarpus and fetlock are most liable to injury. Lameness is either severe or slight, and sometimes only momentary. In simple abrasions of the skiu, little, if any, swelling or lameness follows the injury; but infection of the subcutis, characterized by diffuse swelling and later abscess-formation, produces considerable lameness, often so severe that no weight is borne by the diseased leg. When the sesamoidal tendon sheath is involved, the leg is held in a diagnostic position. (See page 118.)

Pulpation.-The swelling is hot, painful, of doughy or firm consistency; when the sesamoidal sheath is infected, passive dorsal flexion produces intense pain. 


\section{CHAPTER XVIII.}

\section{LAIMENESS FOLLOWING FRACTURE OF THE VERTEBRAE.}

History.-Falling over backwards, starting and stopping an animal suddenly, violent struggling when cast and unable to rise, and also jumping.

\section{Fracture of the Body of the Vertebræ.}

Inspection.-The animal lies upon the ground stretched out, or sits upon his haunches like a dog, able to move the fore-legs, but the hind-legs are paralyzed. Sometimes the vertebra is only fissured; in these cases the animal can still walk, the back is arched and held stifly, and in a few days paraplegia sets in. Then again the vertebræ may be fractured, yet the animal stands; in these cases the sciatic nerve, but not the crural nerve, is involved; walking is impossible. Such symptoms are due to a fracture somewhere behind the fourth to the sixth lumbar vertebræ.

Palpation.-Deformity and crepitation are rarely detected; pressure upon the supposed seat of the fracture may give rise to pain. Insensibility of the hind-quarters, sharply defined, is noticeable, the animal not offering any resistance when pricked with a needle, etc. Under such conditions the fracture is in the lumbar region, or behind it; but in fracture of the dorsal vertebræ, or anterior to it, reflex irritability is present, and may even be exaggerated, as by pricking the paralyzed muscles active clonic and even tonic 
contractions are excited. Here, as in a good many other affections, it is of importance, in order to form a correct diagnosis, to differentiate between actual pain, resulting from the examination, and mere nervousuess of the animal, which in these cases is particularly difficult.

Differential Diagnosis.-1. Hæmoglobinæmia. Differs from the above in the history, the appearance of the urine often being of a coffee color, or hæmoglobin or albumin may be found on chemical analysis. In hæmoglobinæmia the muscles of the croup are also hard, while paralyzed muscles are soft and flabby.

2. Thrombosis of the posterior Aorta. The history of the case or rectal examination will be decisive. (See page 95.) 


\section{CHAPTER XIX.}

\section{LAMENESS RESULTING FROM FRACTURE OF THE PELVIS.}

History.-Sudden lameness following unexpected turning of the horse, falls, jumping, slipping and collisions.

\section{1.-Fracture of the External Angle of the Ilium.}

Inspection.-Lameness (swinging-leg lameness) is hardly ever wanting, and the thigh is adducted. Standing on level ground the animal is able to bear an equal amount of weight upon both legs. A bruise may be seen about that region in recent cases, swelling appearing later. The angular shape of the tuberosity is changed into a rounded one, best seen by comparing both sides from above, the affected being the narrower.

Palpation.-There is no crepitation, lout pain on pressure over the fracture.

\section{2.-Fracture of the Shaft of the Ilium.}

Inspection.-Swinging-leg lameness. The affected croup is lower than the other (the sound one); especially the external angle of the ilium of the fractured side appears sunken. This is seen by putting both hind legs into the same position, if possible, and comparing the gluteal regions, either by standing a little behind the animal or by looking at them from above.

Palpation.-Occasionally pressure upon the external angle of the ilium excites mobility and crepitation, but this 
fracture is most satisfactorily diagnosed by rectal examination. The hand, in the rectum, easily detects abnormal mobility, crepitation and possibly swelling aloug the shaft of the ilium, either by walking the horse or by moving the leg otherwise. (See fig. 23.)

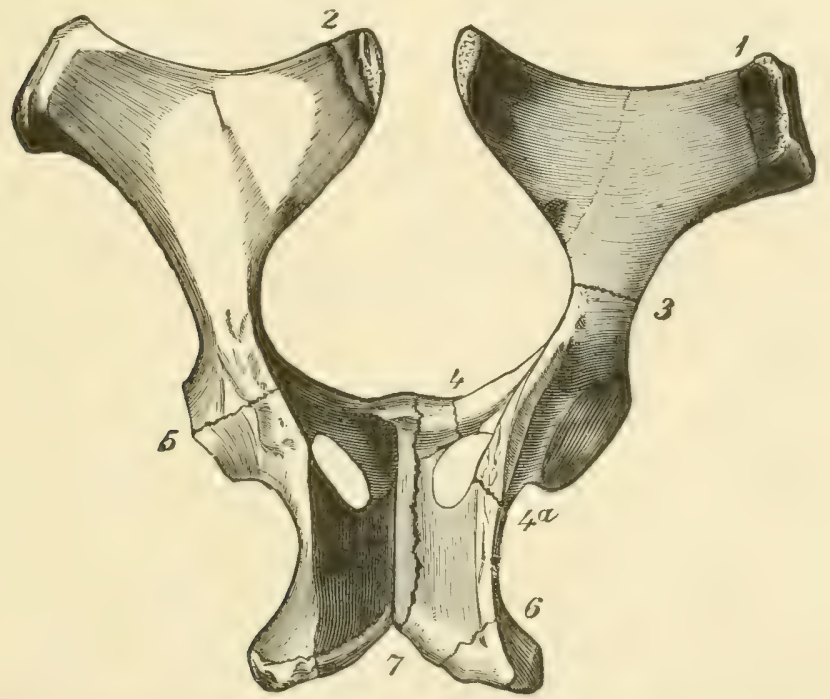

FIG. 23.-Schema illustrating fractures of the pelvis in the horse.

(1) Fracture of external iliac angle ; (2) internal iliac angle; (3) slaft of the ilium; (4) transverse portion of the os pubis; $(4 a)$ external portion of the ischium; (5) cotyloid cavity; (6) tuber ischii; (7) symphysis pubis.

\section{3.-Fracture Through the Obturator Foramen.}

Inspection.-Supporting-leg lameness. Usually no external deformity, but now and then one sees an adematous swelling about the scrotum, udder, or belly, together with symptoms of internal hemorrhage, as blanched visible mucous membranes, hurried breathing, etc.

Palpation.--Rectal examination gives positive results as to crepitation and location of the fracture. (See fig. 23.) 


\section{4.-Fracture of the Os Pubis.}

Inspection.--Tendency to adduct the leg, with marked supporting-leg lameness. Backing and stepping sideways apparently cause great pain. Occasionally there is a swelling under the belly, and possibly bleeding from the vagina in mares, if a bony splinter perforated the vagina.

Pulpation.-Abduction of the leg produces pain. Rectal examination will settle all doubts. Crepitation is slight or pronounced. (See fig. 23.)

\section{5.-Frature in the Cotyloid Cavity.}

Tnspection.-Severe mixed lameness. At the slightest disturbance the animal groans with pain. When the ligamentum teres is torn an uncertain stumbling gait is noticed, the leg being adducted in one step and abducted in the other one; the horse is liable to fall. Now and then a slight depression over the region of the hip is discernable.

Palpation.-Crepitation can be felt by resting the hand almost anywhere about the gluteal region, but is usually most perceptible on the exterual angle of the ilium. Abduction and adduction are abnormally free if the ligamentum teres is torn. (See fig. 23.)

\section{6.-Fracture of the Tuberosity of the Ischium.}

Inspection.-Lameness when the leg is carried forward (swinging-leg lameness); perhaps the thigh is abducted. In recent cases, where swelling of the surrounding muscles has not yet taken place, the fractured buttock seems broader and does not extend as far back as the other one. The first deformity is best seen by standing at the back of the animal, while the latter is most noticeable by standing at a right angle from the animal's haunch. A lameness sometimes 
remains after the fracture has healed, which resembles partial lumbar paralysis, but is differentiated from it by the deformed condition of the buttock. The animal in either case is affected with an unsteady, wabbling gait behind, the toes of the feet being excessively worn.

Pulpution. - Swelling of the muscles of that region, sometimes of the vagina, and even of the rectum. There is more or less crepitation, best detected by resting one hand upon the extermal angle of the ilium and the other upon the region of the ischial tuberosity, and pushing these parts toward the other side, thus weighting first the one and then the other leg. (See fig. 23.)

\section{7.-Fracture of the External Branch of the Ischium.}

Lameness slight or even absent, with usually pronounced crepitation. The region of the hip joint bulges out risibly, the ilium seems lowered, and the region of the ischial tuberosity appears fattened. If the above-named and described conditions are present, the diagnosis of fracture of the pelvis can safely be made, provided fracture of the femur is excluded. (See fig. 23.) 


\section{CHAPTER XX.}

\section{HOOF LAIMENESS.}

\section{Anatomo-Physiological Review.}

The hoof consists of the horny box and its contents. The horny box shows three portions. The wall is all that part of the horny box which is seen when the foot rests upon the ground. The anterior middle region of this crust is designated the toe, its two sides the outside and inside toe respectively; the lateral regious constitute the quarters. The heels are formed by the angles of inflection of the extremities of the wall; these extremities pass along the inner border of the sole and are called bars. The inner face of the wall shows white leaves, which dovetail with the laming of the podophyllous membrane.

The sole is a thick, horny plate, occupying the inferior face of the hoof. It is united to the inferior border of the wall, forming with it the white line. Its internal border shows a deep $\mathrm{V}$ notch corresponding to the bars, also lodging the frog. The frog is an elastic horny pad between the two re-entering portions of the wall. Its external surface shows a shallow excavation in the centre, known as the middle lacuna, separating the two branches of the frog which join the heels. Laterally the frog is attached to the sole and bars.

In the interior of the horny box are located, besides the blood ressels, lymph vessels and nerves, the os pedis, 
with the navicular bone, the inferior extremity of the os corona, ligaments uniting the pedal articulation, the tendon of the extensor pedis and of the perforans; the former in front of the pedal articulation, the latter supporting it from behind.

The fibro-cartilages, one on each side of the os pedis, are united posteriorly and below to the plantar cushion, a fibrous elastic wedge-shaped mass, on which the navicular bone rests by means of the perforans tendon.

The keratogenous apparatus covers the parts just mentioned like a stocking. This apparatus is a continuation of the outer skin of the phalangeal region. It shows the coronary cushion, a rounded prominence situated at the junction of the hoof and skin, and is covered with little prolongations known as papillæ.

The coronary cushion is the matrix of the wall. The podophyllous tissue, or sensitive laminn, line the anterior face of the os pedis. These are very vascular parallel leaves, separated from each other by deep channels, into which the horny leaves of the inner face of the wall are dovetailed. (Chauveau.)

The diagnosis of the seat of the pain, viz., lameness in the hoof, requires primarily a knowledge of the physical properties of the hoof and anatomo-physiological peculiarities of the keratogenous membrane.

The diagnosis of the seat of lameness only too often is difficult, since the horny box, enveloping the sensitive soft parts, is opaque and unyielding. A happy circumstance,at least from a clinical standpoint,-is encountered with, namely, disease of the podophyllous membrane, is always painful, therefore producing lameness.

The soft parts within the hoof, lying between the 
muyielding horny box and the os pedis, are very apt to be pressed upon even when but slight changes in the crust occur. As a consequence of such pressure, pain results and the animal goes lame. Nevertheless this horny box is a powerful protection to the parts enclosed by it, effectually resisting a great many destructive agents. Should separation of any part of the horny box occur, thus establishing a direct communication between the soft parts contained in it and the external world, a favorable condition for the entrance of septic material is created, and inflammation is likely to follow.

Inflarnmation of the podophyllous membrane can be septic, asceptic, acute or chronic, and the latter superficial and deep, also designated parenchymatous. To appreciate inflammation of this membrane, especially its seat and extent, means to be familiar with its structural arrangement. Uuless the one examining a horse for hoof lameness is thus acquainted with it, his diagnosis, as to the seat of the lameness, is only guess work.

'The podophyllous membrane is related in its make-np to the skin. It shows a strongly developed rete malphigii, which covers the cutis proper. The papillary body of the cutis is exceedingly prominent. The sole, frog, and especially the coronary cushion, are closely studded with large papilla. In the region corresponding to the wall of the hoof, an enormons development of the papillary body is met with in the shape of the primary and secondary lamine, protected by a strong rete malphigii. Next to the papillary body and below it is the vascular layer, composed of many vessels imbedded in a loose connective tissue. The deepest layer ensheathes the os pedis, representing the periosteum. The subcutis, the basis for all these layers, is irregularly 
distributed. It is only found underneath the coronary cushion, sensitive laminæ of wall and sole (excepting over the os pedis), fibro-cartilages, tendon of the extensor pedis, and finally in the shape of the plantar cushion.

Superficial inflammation of the podophyllous membrane involves the rete malphigii and the npper region of the papillary body. Parenchymatous inflammation of this structure attacks the deeper layers, especially the vascular layer, the papillary body, and frequently extends to the rete malphigii and subcutis. 


\section{CHAPTER XXI.}

\section{DIAGNOSIS OF HOOF LAMENESS.}

The nature of the fanlty action is in itself not characteristic of hoof lameness, as diseases of joints, ligaments and tendous resemble it closely. For this reason, the diagnosis of hoof lameness is necessarily based upon the results obtained by inspection and, above all, palpation, with percussion of the hammer or application of the pincers. Wherever possible the history of the case should be learned. Of particular interest is the question, "When was the horse shod last, and what treatment did the hoof receive by the farrier?" A correct answer to this may save disappointment. Lame horses are only too often taken to the blacksmith to be treated for lameness. Some farriers have a perfect mania to "cut out corns," thus frequently laying the foundation for inflammation of the podophyllous membrane. That, under such conditions, a correct diagnosis as to the seat of the lameness is sometimes for a while impossible, is clear. Inspection of the hoof-lame animal shows more or less supporting-leg lameness, intensified as a rule on hard ground or by going down hill. Should both feet be attacked, the gait is stiff and the feet are kept close to the ground. In the standing posture the animal usually points with the lame leg forward, or rests the foot upon the toe. Generally the former suggests disease of the anterior half, the latter of the posterior half of the hoof. When both feet are affected the weight is alternately sustained by one and then 
by the other leg. Inspection of the shape and condition of the horny box is exceedingly important, since the physical nature and the size of the hoof must be in proportion to the weight and work of the animal. Any changes of the foundation of the horse interfering with its duties must create suspicion, and palpation is a necessity in leciding whether the present change is directly or only indirectly concerned in the production of lameness.

1. Inspection of the Flat Hoof.--The bearing surface of the hoof is round aud the angle of the wall of the hoof at the toe is sometimes as little as 30 to 40 degrees. The heels are low and the frog usually of a good size; the sole is extensive and flat. Such a loof in itself does not cause lameness, but materially predisposes to it, as bruised sole, corns and interfering are common sequelae.

2. The Narrow and Upright Hoof.-The angle of the wall of the hoof at the toe is 50 degrees or more, the walls are upright, the shape of the hoof somewhat oval, and the narrowest portion lying between the quarters. Unless the above conditions are not exaggerated,- that is, contraction present,-no lameness is apparent. In heavy horses one quite often finds a hoof like this. Since the size is so out of proportion to the demands of the weight of the body, lameness follows work on hard ground and the animal becomes "pavement sore"; this painful sensation generally disappears after a little rest. Sprain of the lateral ligaments of the lower joints is mostly encountered in auimals having this sort of a hoof.

3. Crookerl, Hoof.--In this kind of hoof, the wall, instead of running in a straight line from the coronet to the bearing surface, deviates perceptibly from its normal course, the wall either being concave or convex. Quite frequently one 
finds one-half of the wall convex and the other half concave. This malformation usually occurs in the developing hoof,that is, the one of the colt,-mainly due to improper or neglected paring and faulty shoeing. If, for instance, the outer half is allowed to grow too long, the wall of the inner half in due time becomes convex, the outer one concave. Lameness is wanting, but may set in at any moment, following improper shoeing and drying of the horn. The dislocated wall presses upon the underlying sensitive parts, and pain, expressed by lameness, quite pronounced on hard ground, is the consequence. Animals with this form of hoof are subject to corns, sandcracks, loosening of the sole or wall and distortion of the phalangeal articulations.

4. The Club Foot.-This sort of hoof, natural to the mule, shows an angle of 60 degrees or over. The wall at the quarter is very high, occasionally having the same height as at the toe. The frog appears too small for the size of the hoof, and the sole is decidedly concave. While this hoof form does not directly canse the animal to go lame, it predisposes it to sauderacks, bruised heels and lisease of the flexor tendons.

Certain deviations in the physical nature of the horny box, when pronounced, are accompanied by lameness. Thus the hard, brittle and dry hoof frequently is cracked, especially when contracted. This hardness is not confined to the horn of the wall alone, but that of the coronary region, frog and sole also participate. The horn of the coronary region, when thus diseased, is whitish in color, full of little fissures and covered with scaly fragments. Horses with such a hoof frequently show lameness on hard ground when trotting, their movements are limited and the entire animal seems stiff. This condition is often wrongly interpreted as 
rheumatism. The reverse is true of the soft hoof with its yielding horn. The horn has a constant tendency to break, not in the direction of the horn tubules, as in the dry, hard hoof, but at a right angle to them. Disintegration of the horn at the bearing surface, especially when shod at short intervals, is seen, pieces of the wall crumbling off. As the horn often yields under the weight of the body, dislocation of the wall, with pressure upon the seusitive parts, results, and is subsequently followed by an intractable lameness, particularly on hard ground. Corns and ridges are common in hoofs having this quality of horn.

Hoof lameness in colts, which should be a rare sight, but is not, is probably due to the fact that the little hoof is chiefly treated with contempt while developing, instead of receiving the care this important structure demands. In this country, where the interchange of horses from one section to another is so frequent and extensive, hoof lameness in the young horse is not uncommon. Undoubtedly difficulties are constantly met with in deciding the normality or abnormality of the physical nature of the horn and form of the hoof. Therefore any conclusions as to whether the hoof is within physiological limits or not, are to be based upon these points. Moist pastures predispose to flat feet, as the moist and elastic horn muder the weight of the body has a tendency to spread, thus furthering sole formation; upright and narrow hoofs are the result of the contrary influences, as the hard, dry ground renders the horn unyielding and sole formation is interfered with. The same follow improper or neglected paring, too early shoeing and faulty positions of the limbs.

The surface of the wall of the hoof is often covered with ridges, generally running parallel with the coronary band. 
These ridges may be physiological or due to disease. The physiological ridges are of no moment, appearing on the surface of the hoof when the hair is shed, or the nature of the food suddenly and radically changed, and in the pregnant female. Ridges, following dislocation of the papillse of the coronary cushion, indicate dislocation of the os pedis, for instance, in founder, and also inflammatory processes of the coronary cushion. In the former, the coronary cushion is sunken in and the horny wall growing from it lies below the surfice occupied originally; but in the latter the coronary cushion rises and the ridges are therefore above the level of the wall. Corns invariably produce them, as also injuries of the coronet. In flat feet, contraction of the wall in the coronary region sometimes irritates the papilln, and ridge formation follows.

Pulpation.-One way to recognize inflammatory processes, at least of an acute nature, within the horny box consists in resting the hand upon the toe, the quarters, the heels and the coronary region, first of the diseased hoof and then of the sound one, to compare the temperature of the two. The point is to find out whether one heel or quarter is warmer than the other heel or quarter of the same hoof, or whether both parts are warmer than the corresponding ones in the other hoof. As previously stated, the heels are normally warmer than the region of the toe. Then the pincers or the hammer is employed to detect a spot which, upon pressure or percussion, is painful, as demonstrated by the flinching of the animal at that moment. Some animals flinch as soon as pressure is brought to bear upon the sole. In such cases it is advisable to move the pincers a little away from the apparently painful spot, gradually working them back to the original place. Should the animal again 
evince pain, the spot pressed can safely be looked upon as the seat of the trouble, provided pain is not found anywhere else. The jerking of the leg, following pressure upon a painful spot in the hoof, is chiefly a reflex action. The short, spasmodic contraction of the shoulder muscles and extensors of the fore-arm may therefore serve as a guide. Jerking of these muscles synchronously with the application of pincers or hammer to a certain spot suggests pain in the region the pressure is exerted upon. As to the relative value of pincers or hammer, it is well to say that the hammer, on the whole, is of more use than the pincers, and in such cases as separation of the wall from the laminæ, it is invaluable.

To examine the white line, so important in the diagnosis of the seat of hoof lameness, the shoe must be removed and the sole and frog freed of all loose and ragged horn, to allow of a minute examination of these parts. Any place which has been previously established, beyond a reasonable doubt, to be diseased, by the hammer and pincers, should now be traced with the searching knife. But nothing is more unjustifiable than to dig into the sole here and there in hopes of finding something abnormal, for in that way the horn is destroyed and newly injured. In following up any diseased locality near the wall, it is of importance to remember that the wall is principally concerned in bearing weight, and therefore is to be spared as much as possible, while any portion of the sole can be replaced by artificial means. 


\section{CHAPTER XXII.}

\section{LAMENESS FOLLOWING ACUTE SUPERFICIAL AND PARENCHYMATOUS INFLAMMATION OF THE PODOPHYLLOUS MEMBRANE.}

History.-Usually lameness is the result of wounds of the horny box and underlying tissues, as caulking, pricking, nail-puncture, cutting out of corns, poorly fitting shoes, leaving the shoe on too long, prolonged rest on hard ground, and empirical treatment with oil of turpentine, acids, etc.

Inspection.-More or less supporting-leg lameness, increasing on hard ground and going down hill. In superficial inflammation one may see discharge of a thin, grayish or blackish matter flowing from a wound, as in nail-puncture, artificial openings; or the liquid, by burrowing, appears between the coronary cushion and the horny wall, at the heel or at the frog. At the point of perforation no swelling is noticeable. In parenchymatous inflammation, inflammatory products of a thick, yellowish nature are apt to perforate the skin at the coronet or heel. The point of perforation is surrounded by severe swelling. Whenever the product of the superficial inflammation appears on the coronet or heel, the seat of the trouble is readily found by following the direction of the horn tubules, from the point of perforation to the white line, where further examination reveals the seat of lameness. The animal points, and it is tolerably safe to say that resting upon the toe means disease somewhere in the posterior half of the 
hoof, most evident in purulent cellulitis of the plantar cushion. Forward pointing and weighting the heels, chiefly or exclusively, suggests disease in the anterior half, particularly the region of the toe of the hoof, as in founder (see fig. 25). Swelling in the hollow of the heels or the coronet and along the course of the flexor tendons is, as already stated, of value in coming to a conclusion. (See page ).

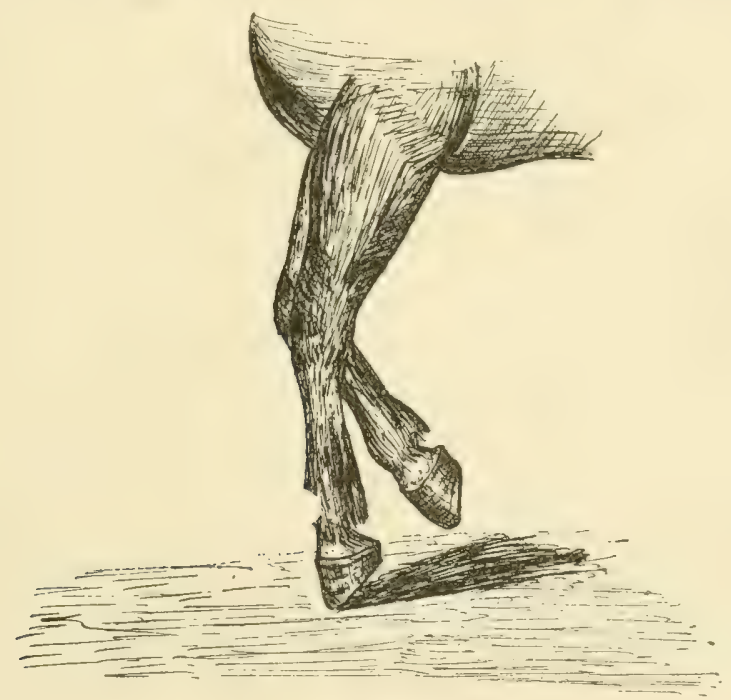

Fig. 24.

Position of the hoof in disease of the plantar cushion, respectively flexor pedis perforans tendon.

Palpation.-The hoof-tester or the hammer reveals painful spots, which, when cut out with the searching knife, are found to be either red or black, occasionally yellow, and matter, either thin, of gray or black color, or thick and yellowish. One may detect separation of the sole from the wall, or even of the wall from the lamine. The trace of a. misdirected nail or a foreign body, as a nail, etc., is found. Increase of temperature in certain regions, as the toe, 
coronet, heels, etc., and violent throbbing of the collateral artery of the cannon or digital ateries, which always accompanies inflammatory changes of some extent in the hoof, are met with. Whenever the animal shows volar flexion of the phalanges, supports weight cautiously and only upon the

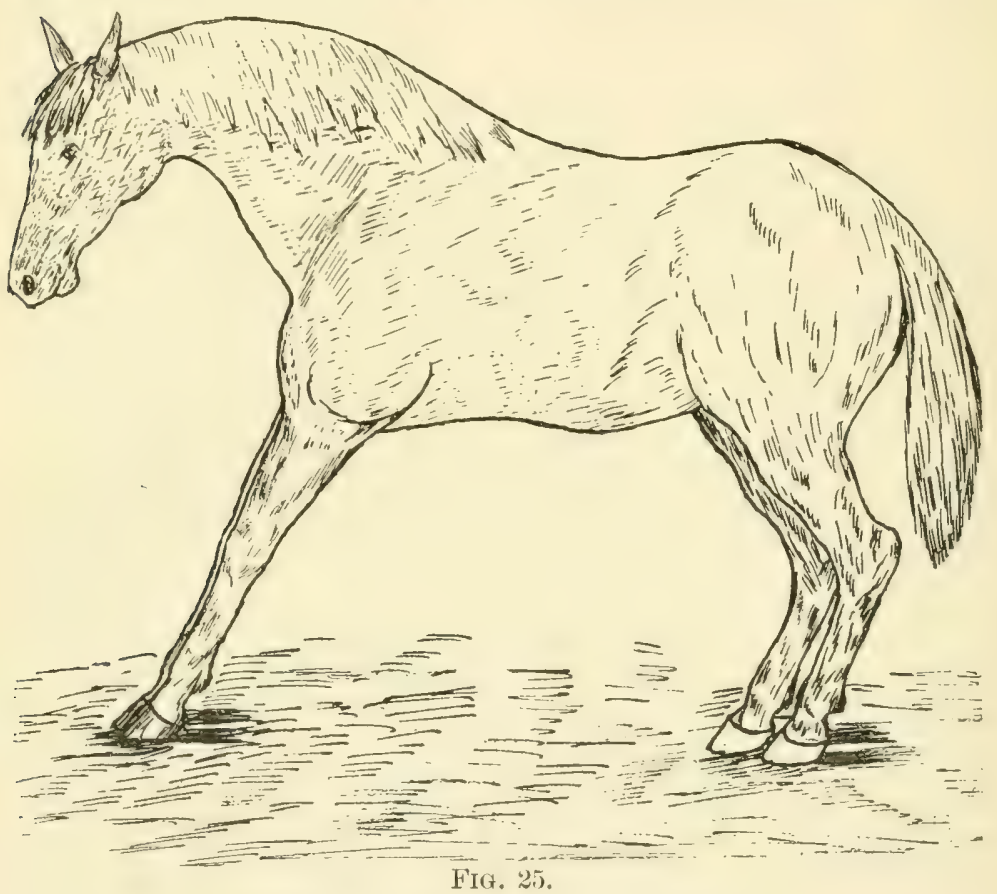

Position of anterior limbs in laminitis.

(Hind legs ought to be more advanced.)

toe, it is advisable to practice dorsal flexion; pain, as a consequence of it, indicates purulent cellulitis of the plantar cushion and often disease of the flexor tendon. (See fig. 24.)

Differential Diagnosis.-From a clinical point of view it is difficult unless pus formation or cellulitis are present.

1. Parenchymatous inflammation comes on gradually and lameness may increase to great severity. Superficial inflam- 
mation usually gives rise to sudden and unexpected lameness, which is apt to disappear quickly.

2. The product of parenchymatous inflammation, which is thick and yellowish, perforates the skin; swelling and pain in that region are pronounced. The product of superficial inflammation, which is thin and black in dark hoofs, and gray in light colored ones, only separates the coronary cushion from the horny wall at the point of exit, unattended by swelling or much pain in that region.

3. Parenchymatous inflammation, especially when septic, has a tendency to spread and to lead to fatal complications. Superficial inflammation is not so liable to terminate in this way.

4. Parenchymatous inflammation is usually the result of infection with pus producing bacteria, introduced by deeply acting irritants. Superficial inflammation is the result of less detrimental influences. 


\section{CHAPTER XXIII.}

\section{LAMENESS FOLLOWING INDIVIDUAL HOOF DISEASE.}

\section{1.-Laminitis.}

Inspection.-Usually the fore-feet are diseased. In the standing posture the body may sway back and forth, an expression of pain and fatigue. The hind-legs are unduly advanced under the belly and the fore-legs are kept in front of the chest, with the phalanges in abnormal dorsal flexion. The weight of the body is chiefly sustained by the heels of the hoof, and the head and neck are elevated. When forced to move, the fore-feet take short steps as if anxious to get out of the way of the hind-legs. The hind-quarters sway to and fro, the fore-feet touch the ground, heels first, and the sole of the hoof can be seen plainly by standing in front of the animal as it walks. The foundered hoof produces a double hoof beat, the first being dne to the striking of the ground with the heels, the second to the coming down of the toe. If the hind-feet are foundered, which is rarely the case, all four feet gather under the belly in a bunch. Foundered horses when lying down require some persuasion to get up. When down they occasionally groan, look to one side, and draw up first one and then the other foundered leg. In slight cases the animal, when walking, is merely stiff, and such animals in resting frequently hold up the foundered feet alternately. Such cases, turned quickly on hard ground, show 
an immediate and material increase of lameness. Should all four feet be foundered, the animal lies down constantly. In cases of chronic founder, - that is, those where the os pedis is dislocated,--distinct changes in the form of the hoof are evident. The coronary region is depressed, and, as a consequence, the anterior region of the wall of the hoof becomes more or less concave and is covered with ridges diverging toward the quarters. Such a hoof after some time is longer than wide, the sole is convex, and there is supporting-leg

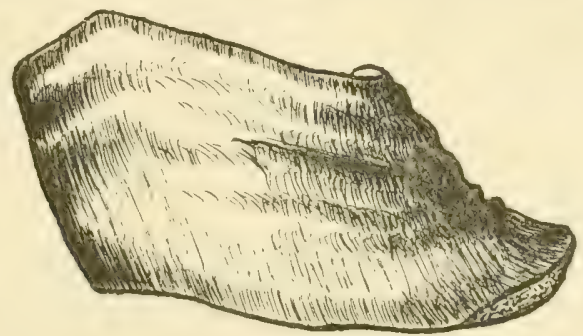

FIG. 26.

Hoof deformed by chronic laminitis.

lameness with permanent forward pointing of the leg; the heels always touch the ground first, and thus in walking slowly the double beat, mentioned before, is quite evident.

Pulpation.-Increase of temperature of the whole hoof, especially about the toe; pain upon pressure over the entire toe region, and exaggerated throbbing of the collateral artery of the cannon or digital arteries, form the diagnostic points of founder.

Differential Diagnosis.-Muscular rheumatism: It cannot be denied that after a superficial examination this affection is easily mistaken for founder ; still the characteristic points of founder, viz., throbbing of the digital arteries, pain on pressure and increased heat over the toe, region of the hoof, are absent. In rheumatism the animal does not rest so 
persistently upon the heels of the hoof; the muscles often quiver, may be warmer than normally, slightly swollen, tense and hard; tapping them lightly excites severe pain. Constant crackling of the joints almost invariably accompanies rheumatism in the beginning, and sometimes the flexor tendons are also involved; they are then painfuliy swollen. Such animals, when lying down, hold their legs perfectly quiet, not drawing them up as in founder. When exercised, lameness diminishes.

Injuries of the sole: Here the local examination will be decisive. Horses, especially flat-footed ones, occasionally wear off the hoof to such an extent that the sole becomes bruised, and lameness, similar to that seen in founder, results.

Pumiced foot: This formation and the hoof of chronic laminitis are often confounded. This is probably due to the convexity of the sole which is present in both; but the convexity of the former extends over the entire sole surface, while that of the pumiced foot is chiefly confined to the posterior half of the sole. The white line of the foundered hoof is much wider than the one of the pumiced foot. The deformity of the foundered foot is the consequence of laminitis, whereas the pumiced foot is nothing but an exaggerated flat foot with excessive sole formation during its development.

\section{2.-Wounds of the Coronet.}

Inspection.-Depending on the depth of the wound, the lameness is either absent, slight or severe. All stages of injury, from a mere abrasion of the skin to a deep infected wound with swelling of the coronet, of the heels, and perhaps of the phalangeal regions, are seen. The animal 
may refuse to support weight, or it is only sustained by the toe; the phalanges at the same time are held in excessive volar flexion.

Palpation.-The contusion is mostly found on the coronary cushion in the region of the extensor tendon. The degree of lameness and the swelling, which is hot and painful, are sufficient to give an idea of the extent of the injury. Should it be necessary to probe at all, a sterilized probe may be introduced by a steady hand. The latter is of great moment, as any sudden movement of the horse may endauger the pedal articulation of being punctured. It is useless to probe for an open joint, since the discharge of synovia settles that point, also confirmed by the severe supporting-leg lameness, swelling of the entire coronary cushion with abscess formation, and great pain on passive rotation of that joint. Deep injuries in that region, not opening the pedal articulation, excite more of a swingingleg lameness, and weight is often readily supported by the lame leg.

\section{3.-Quittor.}

Inspection.-More or less lameness, depending on the extent of the morbid process and the complications therefrom. Intense supporting-leg lameness and the extreme volar flexion of the phalanges, weight only being borne by the toe of the hoof, characterize purulent cellulitis of the plantar cushion and inflammation of the pedal articulation. (See fig. 24). When a quittor is forming, usually only a firm swelling in the internal lateral region of the coronary cushion and the corresponding heel is visible. In a few days a discharge, $-a$ mixture of blood and pus,-breaks through and the swelling goes down. One or more small openings, regularly discharging pus, remain. 
Palpation.-Probing is of little value, as the winding fistulous tracts interfere with the progress of the probe; but nevertheless it establishes the presence of a fistulous canal, thus helping to differentiate quittor from simple injuries to the coronet and superficial inflammation of the podophyllous membrane. After a while the first fistulous opening heals. Swelling, pain and lameness increase, and in dne time another fistula, usually anterior to the first one, makes its appearance. This process repeats itself from time to time until proper treatment checks it.

\section{4.-Punctured Woundis of Sole and Frog.}

Inspection.-The iutensity of the lameness depends on the seat and depth of the puncture. In inspecting the sole of recent cases, the foreign body, a drop of blood, or mothing at all, is apt to be found. In cases of some standing, a discharging wound is met with.

Palpation.-The application of the hoof-tester reveals a painful locality, which, when traced, shows the exact course of the puncture, or even the foreign body. The groove between the bars and the branches of the frog is the part most frequently involved. Careful paring of the sole and frog are essential to the detection of a punctured wound. Not long ago the writer was called several hundred miles to diagnose a case of lameness in a very valuable trotting mare, which went lame shortly after a race and had been treated for hip lameness, while she was actually suffering from a punctured wound, rumning from the middle lacuna of the frog obliquely upwards and backwards, as the writer found on making his examination. The attending veterinarian also. examined the hoof when she went lame first, but omitted the examination of the frog. The offending body in this 
instance was a piece of a darning needle. In probing a punctured wound of the sole or frog, none but a sterilized probe should be employed and that only after the wound has been disinfected.

\section{5.-Pricking in Shoeing.}

Inspection.-When the nail is driven into the deep layers of the podophyllous membrane, lameness is either immediate or may be severe within the next twenty-four hours. Such a case, seen soon after the shoe has been nailed on, generally shows a little blood around the clench of the pricking nail. If the nail is only driven too close to the rete malphigii, thus simply exerting pressure, three to five days may elapse before sudden lameness, with all the symptoms of a superficial inflammation of the podophyllous membrane, becomes apparent.

Palpation.-Lightly tapping the head or clench of the offending nail immediately makes the animal flinch, and upon removal, the nail will show pus or blood achering to it. Paring of the white line reveals a black spot (the stain is chiefly due to precipitated sulphide of iron), extending somewhat into the sole. This discoloration always indicates that the nail entered the podophyllous membrane.

\section{6.-Corns.}

Are reddish, or occasionally yellowish spots, situated chiefly in the angle formed by the bars and the wall, which do not produce lameness unless the bruising agent continues to act,-the product of the resulting contusion pressing upon the sensory nerves of the podophyllous membrane,or septic inflammation takes place. The septic material enters at the place where the so-called corns are located, so often the case when they are cut ont. This inflammation is 
usually designated as dry, moist and suppurating corns respectively,-terms of exceedingly doubtful value. Hoofs continuously afflicted with corns are quite characteristic in their conformation. The wall at the quarters is often covered with ridges, which do not run parallel with the coronary cushion, and the heels of such a hoof are wanting in uniformity. Two other conditions closely related to corns are bruised sole and bruised heels ; both are frequently met with in flat-footed horses when going barefooted or improperly shod. Bruised sole is identified by the same reddish spots in the white line or sole as corms, the only difference being the location. Lameness accompanying corms or bruised sole is the consequence of either a superficial or a parenchymatous inflammation of the podophyllous memdrane.

\section{7.-Side Bones.}

Irsprection.--W When walking, weight is chiefly borne dy the toe, which is put to the ground first; the animal steps lightly upon the posterior half of the hoof, and the phalanges show more or less volar flexion. When both feet are diseased the gait is stiff and the animal takes short steps. Inspection of the shoe shows least wear over the diseased quarter. Quite often contraction of the wall at the quarter of the aftlicted side is apparent, and the wall is ridged.

Palpation.--The seat of the lameness is readily recognized when ossification is complete. To test the elasticity of the cartilages the foot is raised, the thumbs placed upon the inside and outside quarters respectively, and the other fingers, resting against the upper border of the cartilages, pull them in an outward direction. Any difference in the elasticity of the cartilage is thus easily detected. This test is of no value when only the lower portion of the fibro 
cartilage is ossified, and the diagnosis then often becomes uncertain. If pressure upon the corresponding portions of the wall fails to produce pain, the diagnosis of side bones can only be pronounced when all other lesions, which might excite similar lameness, are excluded.

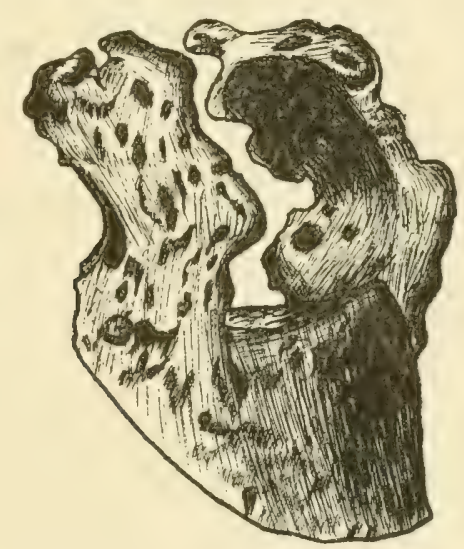

FIG. 27.

Ossification of the lateral cartilages.

\section{8.-Thrush.}

Rarely gives rise to lameness, unless the horny frog has been destroyed to such an extent as to no longer be a protection to the sensitive frog, which may even become visible. Such animals go lamer on soft than on hard and level ground. Ordinarily a thrushy frog looks ragged, and a greasy, grayish matter, having a disagreeable odor, oozes from the middle lacuna, where the disease starts, to possibly undermine the entire frog. Sometimes superficial inflammation of the podophyllous membrane follows the entrance of septic material into the spaces formed in the disintegrating frog, producing what is generally known as abscess of 
the frog. Thrush of long standing is occasionally followed by a characteristic ridge formation of the wall, the ridges running in all directions, even crossing each other.

\section{9.-Sanderacks.}

Inspection.-Cracks in the horny wall do not frequently cause lameness, except those which begin one or two inches below the coronary cushion extending iuto it; in such cases lameness is quite common. Animals with cracked hoofs occasionally show a periodic lameness when the hoofs are exposed to prolonged drying or moisture, the lameness simply resulting from the drying or softening of the edges of the crack, with subsequent irritation of the underlying sensitive parts. Any serious lameness in cracked hoofs is dne to the introduction of septic material into these cracks, which frequently causes superficial, or eveu pareuchymatous, inflammation of the podophyllous membrane. Brittle, contracted, crooked and flat hoofs are particularly predisposed to sanderacks.

Palpation.-It is always aclvisable to carefully search the hoof for cracks in cases of hoof lameness, and since such cracks may be hidden by mud, wax, gutta-percha, etc., miuute inspection is necessary.

\section{0.-Loosening of the Sole from the Wall.}

Inspection.-Lameness, chiefly on hard ground, accompanies separation of the sole from the wall only when the break extends into, or close to, the sensitive sole, or if, as at cousequence of septic material entering this space, inflammation of the podophyllous membrane sets in. This trouble is mostly seen in the fore-legs of flat footed horses. In old cases, with extensive separation of these structures, one 
occasionally sees a bending in of that part of the hoof lying between the clenches of the nails and the bearing surface of the hoof. It is advisable to consider this concavity of the wall in examining animals for hoof lameness, it being the only visible indication of this condition as long as the shoe is left on the hoof.

Palpation.-After the shoe has been removed, one or more dark streaks on one or both sides of the sole of unequal

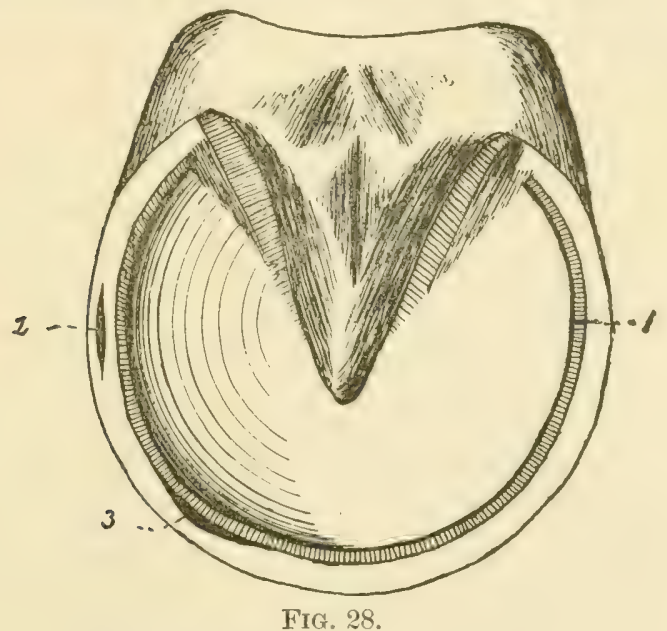

1, Loose wall ; 2 and 3 , hollow wall.

length are seen, and when cleansed a longish cavity in the white line, which, as further examination shows, extends into, or close to, the sensitive sole, is found.

\section{1.-Seedy Toe.}

Inspection.--This condition, following chronic changes in the laminæ, results in formation of a cavity between the sensitive and horny laminæ. Lameness is generally wanting, but the superficial or even parenchymatous inflammation of the podophyllous membrane, which may follow seedy toe 
at any time, causes lameness. Sometimes the wall bulges out visibly over the cavity, especially when the latter is extensive. After the shoe has been pulled off, black streaks in the white line, similar to those seen in loosening of the sole from the wall, are met with.

Palpation.-Percussion of the hoof produces a hollow sound. Probing reveals the fact that the cavity extends up into the sensitive structures, occasionally as far as the coronet. The cavity is either empty or contains crumbly disintegrated horn. The shape of the cavity is generally conical, with its apex toward the coronet and its base at the sole. Such a cavity rarely extends further than half-way up the wall, having a width of from one-eighth to one and one-quarter of an inch.

\section{2.-Contracted Hoof.}

All deformities of the hoof, which by their pressure upon the sensitive soft parts of the hoof cause lameness, are known as "contracted hoof." From a clinical standpoint it is of value to subdivide them according to the various regions in which the contraction may occur. Lameness is more noticeable when only one hoof is involved. When standing the animal points, and when both feet are contracted the weight is frequently shifted from one leg to the other. This is especially apparent when first getting up after having been lying down for some time, of which the animal, under these conditions, is very fond. Upright fetlocks and sprung knees are often seen in the lame leg. When contraction sets in gradually, lameness is occasionally absent or very slight; high strung animals frequently drive out of the lameness. Lameness, the result of contraction of the hoof, is in many instances periodical. 
CONTRACTION IN THE REGION OF THE QUARTERS.

A keen eye and a thorough knowledge of the various forms of the hoof are essential to diagnose contraction in its earliest stages. Upon inspection of the contracted hoof, in its various stages, one will see that it gradually becomes longer and narrower and that the heels approach each other more and more. The sole is more concave, the frog atrophied and often thrushy, and the ordinarily shallow middle lacuna is transformed into a deep and narrow cleft.

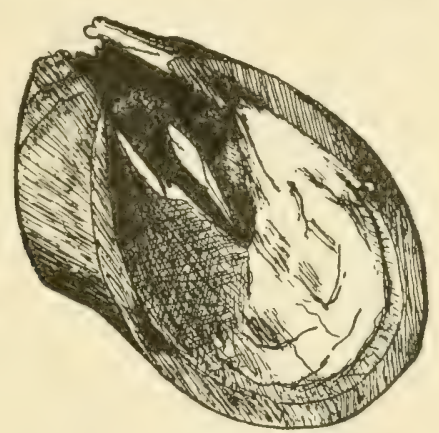

Fig. 29.

Complete bilateral contraction.

The bars, instead of running from the heels to the point of the frog in a straight line, Iie close to it, often forming an arch with its convexity toward the wall. In contraction of one quarter only (see fig. 30) the angle formed by the bar and the corresponding portion of the wall is of great diannostic value. If that angle and the branch of the frog next to it are smaller than the opposite ones, and the corresponding heel extends further up than the other heel, one-sided contraction can safely be diagnosed. In these cases the white line is also of some assistance, as it is narrower than the one on the other side, the normal one. Ossification of the lateral cartilage of the contracted side, sandcracks, 
corns, thrush and rigidity of the horny box are common complications in old cases of contraction. To test the rigidity of the horny box, of some moment in diagnosing this tronble, the thumbs are rested upon the bars, the palm and the other fingers upon the region of the heels, and a gradual compression will give one a fair idea of the elasticity of the horny box at the quarters.

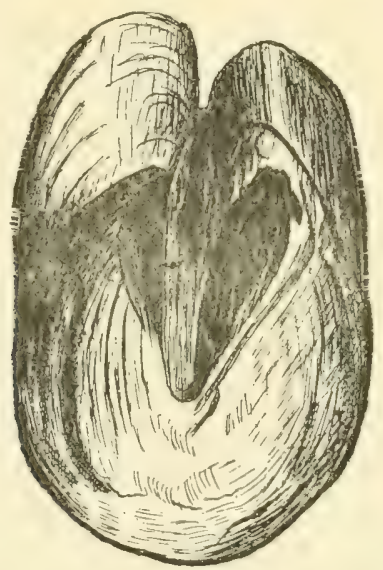

FIG. 30 .

Unilateral contraction.

CONTRACTION OF THE SOLE ONLY.

This condition is rather uncommon. Lameness is more apt to increase on soft than on hard ground, and generally follows musual exertion or recent shoeing. The application of the hoof-tester reveals no pain unless the centre of the sole is pinched. When only one hoof is thus affected, the difference in the concavity of the sole is readily noticed, the contracted one being more concave. Upon inspection the outer edge of the inferior border of the wall shows one or the other portion, usually at the toe or ruarters, to be bent 
inwardly,-that is, in the direction of the sole. Examination of the white line at that place will in all probability reveal little red spots, like those in corns. Abuormal throbbing in the digital arteries is present, and this is the

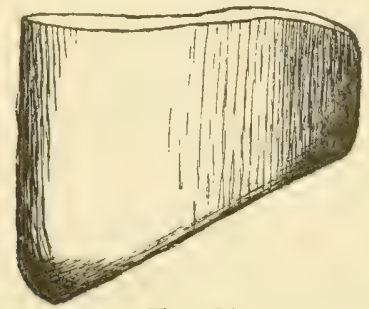

FIG. 31.

Contracted sole and dislocation of the wall at the toe.

principal point of difference between this condition and a badly defined case of navicular disease, in which abnormal pulsation of the digital arteries is wanting.

CONTRACTION IN THE CORONARY REGION.

This form of contraction is mainly seen in flat-footed animals, immediately below the coronary cushion. Tliere

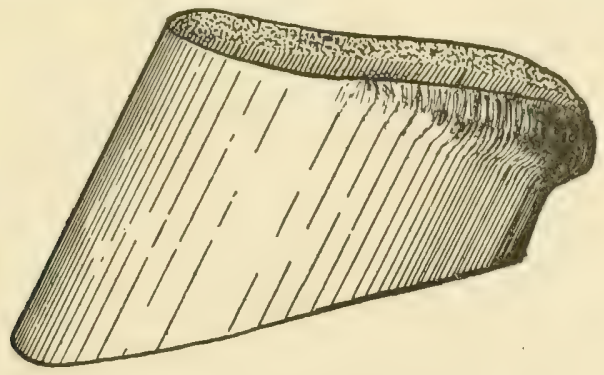

FIG. 32.

Coronary contraction.

is either a slight concavity, usually confined to the region of the quarters, or the wall is abruptly bent in. The pain excited by pressure with the pincers upon the contracted parts leaves no doubt as to the seat of the lameness. 


\section{CHAPTER XXIV.}

\section{LAMENESS RESULTING FROM DIFFERENT CAUSES NOT DESCRIBED IN THE FOREGOING PARAGRAPHS.}

In the previous discussions on the Clinical Diagnosis of Lameness in the Horse, all the common and important lesions have been considered, which are primarily concerned in lameness. The scope of this work is too limited to allow of full consideration of the majority of those conditions which interfere with locomotion; but even a compendium is not quite complete without alluding, at least, to some of those morbid conditions which secondarily produce lameness.

1. Glanders and Farcy.-The presence of glanderous processes in the neighborhood of aponemroses, in the subcutis and lymph glands, produces more or less lameness; but here, as in all other diseases mentioned further on, other symptoms are, as a rule, sufticiently prominent to call for a general examination.

2. Influenzu-Dropsical swellings of the legs interfere with locomotion, but the visibly lowered vitality, the pinkish and oedematous conjunctivil, the circulatory and respiratory disturbances, characterize this affection.

3. Malatie th Coit.-This disease causes certain locomotory irregularities, expressed by knuckling over behind in walking. Later symptoms of incomplete spinal paralysis 
are seen. The odematous spots on the skin from the size of a quarter of a dollar to a saucer, the great weakness and the ring-like swelling of the glans penis, the oedematous swelling about the vulva extending to the udder, the vaginal discharge, etc., diagnose the disease.

4. Purpura Hcemorhagica.-The more or less sharply defined swelling of the skin or subcutis is so painful that locomotion is materially interfered with, but the nature of the swellings, the petechix from millet seed to bean size in the nasal mucous membrane, etc., sufficiently define this specific disease.

5. Inflammatory Contitions of the Shin.-Especially when the flexor surface of a joint, the hock and phalangeal articulations are involved, as for instance, grease. The swelling and pain cause lameness more or less marked, which almost invariably loses itself after a few steps have been taken. The local examination, revealing the fact that no other cause is present to warrant lameness, is decisive.

6. Shoulder Aliscess.-Lameness occasionally follows this condition, which is characterized by a sharply defined, hard and somewliat painful tumor, varying in size, situated in or below the mastoido-humeralis.

7. Inflammatory Changes in the Mammary Glands. - This induces the animal to show a stradlling gait behind at times, and the leg is quite often advanced in an ontward swinging fashion. The local examination reveals a painful state of the gland.

8. Inflammation of the Spermatic Cord and Testicles.-The straddling gait behind, with tendency to abduction of the leg next to the diseased cord or testicle, is explained by manual examination of the parts. 
9. Enlarged Inguinal Glands.--Give rise to similar symptoms as seen under 8 , and is recognized by palpation.

10. Fistulous Withers.--If of some standing, destruction or disease of elements essential to normal locomotion occurs. The continuous discharge and local examination will establish a correct diagnosis.

11. Sternal Fistula--The somewhat doughy but not very painful swelling between the fore-legs, with its fistulous openings, causes the animal to straddle in front. The local examination will leave no doubt as to the seat of the lameness.

12. Wounds and Inflammatory Conditions of the Stin and Underlying Tissues of the Organs of Locomotion.-Injuries, sufficiently severe to cut through muscles, tendons and nerves, swellings resulting from infection, are all apt to bring on more or less intense lameness. Inspection and palpation, if carefully executed, will readily decide upon the cause of the lameness.

13. Osteoporosis.-Intermittent lameness, first in one, then in the other leg, without distinct symptoms as to its origin, makes this an obscure trouble. The evolution of this disease is slow, and months may pass before marked symptoms appear. But if the epiphyses of the bones swell, especially the tibia and bones of the head, etc., the true cause of lameness can soon be located. 


\section{CHAPTER XXV.}

\section{DISEASE OF THE HEAD OF SUSPENSORY LIGAIMENT.}

The extreme courtesy of Dr. M. H. McKillip enables the writer to describe this peculiar and yet characteristic lameness. The latter was given an opportunity to study this lameness in two well-marked cases by Dr. M. H. MIcKillip, who also informed him that these cases are comparatively rare.

\section{History.-Over-exertion.}

Inspection.-When standing little or nothing unusual is seen, except in severe cases, when all four feet, especially the fore-feet, are brought toward the center of gravity. When walking the hock is flexed imperfectly; the point of the hock is abducted, while the toes are turned in more or less and the animal appears bow-legged. The toe touches. the ground first, the heel coming down rather suddenly, the fetlock shows excessive dorsal flexion as the function of the supporting leg begins. The above symptoms are marked when trotting. When the animal trots toward the observer, the femoro-tibial articulation appears abducted and prominent as the leg swings forward. The shoe shows excessive wear at the toe. In cases of long standing exostoses about the suspensory ligament, the result of a subsequent periostitis, are apparent.

Palpation.-In the earliest stages nothing, or a slight soreness, is present. Periostitis and its characteristic symptoms are manifested later on. 


\section{Paresis of the Flexor Pedis Perforans.}

This form of lameness was also shown the writer through the kindness of Dr. M. H. McKillip, who has met with twelve cases within the past twenty years.

History.-Slipping and making desperate efforts to rise when cast.

Inspection.-In backing the leg swings back as a whole, so to speak. The hock is flexed imperfectly and the heels touch the ground first; the foot is planted in a careful, searching manner. The animal flexes the hock excessively when walking on smooth and slippery ground, while all the other joints below the hock are not flexed; the hoof hangs loosely from the fetlock and in extreme cases even dangles. As the hoof is planted the heel strikes the ground first; at this moment the hoof slides backward from two to fourteen inches, according to the severity of the lesion. When the animal is moved on soft footing, there is decided improvement. 


\section{N D EX.}

$\mathbf{A}$

\section{FORELEG.}

Abduction, entire limb, 39

Abduction, sudden, of shoulder, 40

Action, faulty, 14

Anatomo-physiological laws of foreleg, 25

Anatomy, axillary glands, 36

Anatomy, flexor brachii, 40

Anatomy, phalangeal region, 62

Anatomy, postea spinatus muscle, 39

Anatomy, prescapular glands, 36

Anatomy, radial nerve, 42

Anatomy, supra-scapular nerve, 40

Antea spinatus, its function, 27

Atrophy of antea spinatus, 18

Atrophy of groups of muscles, 18

Atrophy of olecranian muscles, 18, 43

Atrophy of postea-spinatus, 18,40

Atrophy of shoulder muscles, 18, 37

\section{Hindleg AND Hoof.}

Abduction of whole leg, 84

Abnormal extension of joints, 82 , 83

Abnormal flexion of joints, 82, 83

Adduction of whole leg, 84

Anatomo-physiological review of hindleg, 78

Anatomo-physiological review of hoof, 126, 127, 128

Anatomy, femoro tibial articulation, 100

Anatomy, lumbo-sacral nerve plexus, 96

Anatomy, middle gluteus, 88
B

Foreleg.

Backing, difficulty in, 11

Bridle lameness, 10

\section{C}

FOREI EG.

Carpus, dorsal fiexion, 33

Carpus, examination, 21

Carpus, volar flexion, 33

Check apparatus, its function, 26

Cocaine, its use, 23, 24.

Coronet, swelling, 15

Crepitation in fracture, 20

Crepitation in inflammation of tendon sheath, 20, 21

Croup in lameness, 10

\section{Hindleg AND Hoof.}

Club-foot, 132

Corns, 131, 132, 133, 134, 145

Curb-lameness, 115

\section{D}

\section{FORELFG.}

Detection of the lame leg, 9, 31

Detection of the seat of lameness, 13

Differential diagnosis of fracture, sesamoid bones, 68

Differential diagnosis of inflammation, posterior ligament coronet joint, 66

Differential diagnosis of knee lameness, 50

Differential diagnosis of navicular lameness, 76,77 
Differential diagnosis of radial nerve paralysis, 44

Differential diagnosis of ringbone lameness, 73

Disease of shoulder muscles, 37

Diseased conditions of shoulder joint and neighborhood, 36

Distention of carpal sheath, 53

Distention of sheath, extensor metacarpus magnus, 54

Distention of sheath, extensor metacarpus obliquus, 54

Distention of sheath, extensor pedis, 54

Distention of sheath, extensor suffraginis, 54

Distortion, how to locate, 65

\section{HiNdieg AND HoOF.}

Diagnosis, hoof lameness, 130, 131

Differential diagnosis, acute inflammation, hock joint, 113

Differential diagnosis, crural nerve paralysis, 98

Differential diagnosis, curb lameness, 116

Differential diagnosis, fracture, astragulus, 114

Differential diagnosis, fracture, hock bones, 114

Differential diagnosis, fracture of vertebræ, 95, 121

Differential diagnosis, inflammation of podophyll ous $m \in m$ ane, 138,139

Differential diagnosis, laminitis, 141

Differential diagnosis, outward luxation, patella, 105

Differential diagnosis, rupture, flexor metatarsi, 108

Differential diagnosis, spavin lameness, 109

Differential diagnosis, stringhalt, 112,118

Disease of the head of suspensory ligament, 157
E

FORELEG.

Elbow, abnormal extension, 33

Elbow, abnormal flexion, 33

Examination for fructure, pelvis, 22

Examination for splint lameness, 61

Examination for thrombosis aorta and branches, 22

Examination, general, 19

Examination of hoof, 14

Examination of lame animal, 14

Examination of shoulder, 18

Examination per rectum, 21

Exostoses, as causes of lameness, 23

Extensor of forearm, function, 26

Extention, abnormal elbow, 33

External angle of ilium,inspection of, 19

\section{F}

Forelea.

Femur, luxation, 22

Fetlock, excessive dorsal flexion, 64,68 .

Fetlock gall, 53

Fetlock, swelling, 15

Flexion, abnormal, elbow, 33

Flexior brachii, its function, 25, 27

Flexor tendons, their function, 25 Flexor tendons, palpation, 19.

Fracture, how to locate, 20

Fracture, pelvis, 20.

\section{HindeEg AND Hoof.}

Femur, backward luxation, 92

Femur, forward luxation, 91

Femur, inward luxation, 92

Femur, outward luxation, 92

Flexor metatarsi, its function, 78, 79 
Flexor metatarsi, rupture, 83

Fracture, femur, 83, 93

Fracture, tibia, 83

Founder, 134

\section{G}

\section{ForeleG}

Gluteal region, inspection of, 19

Hindleg and Hoof.

Gastrocnemii, rupture, 83,86

Gastrocnemii, their function, 78,79

\section{H}

\section{ForeLEG.}

Hand, proper temperature when palpating, 20

Hindleg, examination of, 18

History, lameness due to chronic inflammation of knee, 50

History, lameness due to contusions, scapul-humeral articulation, 38.

History, lameness due to diseased shoulder muscles, 37

History, lameness due to distention, articular and tendinous synovial sacs, 53

History, lamenessdue to distortion, phalangeal articulation, 64

History, lameness due to fracture, bones of knee, 49 .

History, lameness due to fracture, forearm, 45

History, lameness due to fracture, metacarpal bone, 58

History, lameness due to fracture, navicular bone, 73

History, lameness due to fracture, os pedis, 70

History, lameness due to fracture, os suffraginis, 69

History, lameness due to fracture, radius, 48
History, lameness due to fracture, scapula, 45

History, lameness due to fracture, sesamoids, 68

History, lameness due to fracture, ulna, 48

History, lameness due to inflammation, bursa flexor brachii, 42

History, lameness due to inflammation, carpal bursa flexor pedis tendon, 50

History, lameness due to inflammation, elbow joint, 47

History, lameness due to inflammation, flexor tendons, 57

History, lameness due to inflammation, posterior ligaments, coronet joint, 65

History, lameness due to inflammation, tendon postea spinatus, 39

History, lameness due to injuries, anterior surface, knee, 49

History, lameness due to luxation, phalanges, 64

History, lameness due to luxation, scapul-humeral articulation, 39

History, lameness due to paralysis, brachial nerve plexus, 44

History, lameness due to paralysis, radial nerve, 43

History, lameness due to paralysis, supra-scapular nerve, 40

History, lameness due to rupture, flexor tendons, 56

History, lameness due to splints, 59

History, lameness due to thrombosis, brachial artery, 36

History, lameness due to wounds and bruises, forearm, 48

History, navicular lameness, 74

History of patient, 13

History, ringbone lameness, 70

History, sesamoid lameness, 66

High-strung animals, how to examine, 9 
Hock, examination of, 18

Hock, sickle-shaped, examination of, 18.

Hoof, how to palpate, 16

Hoof lameness of long standing, 15

Hoof lameness, pulsation of arteries, 17

Hoof, left, 15

Hoof, temperature, 16

Horny box, acute inflammatory process, 15

Horse with upright shoulders, 9

Horse with wide chest, 9

Horse with wide hips, 9

\section{HINDLEG ANDHOOF.}

Hindleg, its function, 78

Hip-joint, excessive flexion, 82, 85

Hip-lameness, 87

History, acute inflammation, hockjoint, 112

History, acute inflammation, stiflejoint, 101

History, chronic inflammation, stifle joint, 101

History, curb lameness, 115

History, disease head of suspensory ligament, 157

History, fracture, astragulus, 114

History, fracture, bones of hock, 113

History, fracture, femur, 93

History, fracture, patella, 105

History, fracture, tibia, 106

History, fracture, vertebræ, 120

History, hip lameness, 87

History, incomplete nerve paralysis, hindleg, 98

History, inflammation, podophyllous membrane, 138

History, luxation, femur, 91

History, luxation, flexor pedis perforatus, 116

History, luxation, patella, 108

History, middle gluteus lameness, 88
History, paresis, flexor pedis perforans, 157

History, rupture, flexor metatarsi, 107

History, rupture, straight ligaments, patella, 105

History, rupture, tendo achilles, 108

History, spavin lameness, 109

History, thrombosis, posterior aorta and branches, 95

Hock-joint, excessive extension, 83,85

Hoof, brittle, 132

Hoof, contracted, 150

Hoof, contracted, in coronary region, 153

Hoof, contracted, in region of quarters, 151

Hoof, crooked, 131

Hoof, narrow, 131

Hoof-lameness, 126, 130

Hoof-lameness, diagnosis, 130, 131

Hoof-lameness in colts, 133

Hoof, soft, 133

Hoof, upright, 131

Hoof with ridges, 134, 133

\section{I}

\section{Foreleg.}

Inflammation, flexor tendons, 17

Inflammatory swellings and new growths, 36

Inspection, bruises forearm, 48

Inspection, chronic inflammation, knee, 50

Inspection, complete paralysis, radial nerve, 43

Inspection, contusions, scapulhumeral articulation, 38

Inspection, diseased shoulder muscles, 37

Inspection, distended articular and tendinous synovial sacs, 53 
Inspection, distortion, phalangeal articulation, 64

Inspection, fracture, forearm, 45

Inspection, fracture, knee bones, 49

Inspection, fracture, metacarpal bones, 59

Inspection, fracture, navicular bone, 73

Inspection, fracture, os pedis, 70

Inspection, fracture of suffraginis, 69

Inspection, fracture, radius, 48

Inspection, fracture, scapula, 45

Inspection, fracture, sesamoid bones, 68

Inspection, fracture, ulna, 47

Inspection, gluteal region, 19

Inspection, incomplete paralysis, radial nerve, 43,44

Inspection, inflammation, bursa flexor brachii, 42

Inspection, inflammation, carpal bursa flexor pedis tendons, 51

Inspection, inflammation, elbow joint, 47

Inspection, inflammation, flexor tendons, 57

Inspection, inflammation, posterior ligaments coronet joint, 65

Inspection, inflammation, tendon postea spinatus, 39

Inspection,inflammatory swellings and new growths, 36

Inspection, injuries, anterior surface knee, 49

Inspection, ischium postero-external angle, 19

Inspection, luxation, phalanges, 64

Inspection, navicular lameness, 74

Inspection of coronary region, 15

Inspection of shoe, 15

Inspection of shoulder joint, 36

Inspection of wall of hoof, 15

Inspection, paralysis brachial nerve plexus, 44
Inspection, paralysis supra scapular nerve, 40

Inspection, ringbone lameness, 70

Inspection, rupture, flexor tendons and sesamoid ligaments, 56

Inspection, sesamoid lameness, 66

Inspection, splint lameness, 59

Inspection, thrombosis, brachial artery, 37

Ischium, postero-external angle, inspection, 19

\section{Hindleg AND HoOF.}

Ilio-psoas, its function, 80

Inspection, acute inflammation, hock-joint, 112

Inspection, acute inflammation, stifle-joint, 101

Inspection, chronic inflammation, stifle-joint, 101

Inspection, crural nerve paralysis, 98

Inspection, curb lameness, 115

Inspection, disease, head of suspensory ligament, 157

Inspection, fissure, tibia, 106 .

Inspection, flat hoof, 131

Inspection, fracture, astragulus, 114

Inspection, fracture, cotyloid cavity, 124

Inspection, fracture, femur, 91

Inspection, fracture, hock bones, 113

Inspection, fracture of vertebræ, 120

Inspection, fracture, os pubis, 124

Inspection, fiacture, patella, 105

Inspection, fracture, pelvis, 122

Inspection, fracture, shaft of ilium, 122

Inspection, fracture through obturator foramen, 123

Inspection, fracture, tibia, 106

Inspection, fracture, tuberosity ischium, 124 
Inspection, hip lameness, 87

Inspection, hoof lameness, 131,132, 133,134

Inspection, incomplete nerve paralysis, hindleg, 98

Inspection, inflammation, podophyllous membrane, 136

Inspection, interfering, 119

Inspection, ischiatic nerve paralysis, 96

Inspection, laminitis, 140

Inspection, loosening of sole from wall, 148

Inspection, Iuxation, femur, 91

Inspection, luxation, flexor pedis perforatus, 116

Inspection, luxation, patella, 103

Inspection, middle gluteus lameness, 88

Inspection, narrow hoof, 131

Inspection, outward luxation, patella, 104

Inspection, paresis, flexor pedis perforans, 157

Inspection, pricking in shoeing, 145

Inspection, punctured wounds, sole and frog, 144

Inspection, quittor, 143

Inspection, rupture, flexor metatarsi, 107

Inspection, rupture, straight ligaments, patella, 105

Inspection, rupture, tendo Achilles, 108

Inspection, sand cracks, 148

Inspection, seedy toe, 150

Inspection, septic inflammation, flexor tendon sheaths, 117

Inspection, sidebones, 146

Inspection, spavin, 109

Inspection, stringhalt, 118

Inspection, thickening, sesamoidal sheath, 117

Inspection, thrombosis, posterior aorta and branches, 95
Inspection, tibial nerve paralysis, 96

Inspection, upright hoof, 131

Inspection, wounds of the coronet, 142

I

FORELEG.

Knee gall, 53

L

FORELEG.

Lame, both fore and behind, 11

Lame, diagonally, 11

Lame leg, detection, 9, 10

Lameness, behind, 10

Lameness, complicated, 12

Lameness due to chronic inflammation of knee, 50

Lameness due to contusions, scapul-humeral articulation, 38

Lameness due to corns, 32

Lameness due to disease of anteaspinatus, 30

Lameness due to disease of bones, 30

Lameness due to disease of coracohumeralis, 30

Lameness due to disease of flexor pedis perforans, 31

Lameness due to disease of flexor pedis perforatus, 31

Lameness due to disease of inhibi. tory apparatus, 31

Lameness due to disease of joints, 12

Lameness due to disease of ligaments, tendons and their sheaths, 31

Lameness due to disease of mastoido-humeralis, 30

Lameness due to disease of pectoral muscles, 37

Lameness due to disease of postea spinatus muscle, 32 
Lameness due to disease of prescapular and axillary glands, 30

Lameness due to disease of subscapularis, 32

Lameness due to disease of superior and inferior sesamoidal ligaments, 31

Lameness due to disease of teres major, 32

Lameness due to distortions, 32

Lameness due to distortion, articular synovial sacs, 51

Lameness due to distortion, phalangeal articulations, 64

Lameness due to fissured metacarpal bone, 59

Lameness due to fracture, forearm, 45

Lameness due to fracture, knee bones, 49

Lameness due to fracture, navicular bone, 73

Lameness due to fracture, metacarpal bone, 58

Lameness due to fracture, os corona, 69

Lameness due to fracture, os pedis, 70

Lameness due to fracture, os suffraginis, 69

Lameness due to fracture, radius, 48

Lameness due to fracture, scapula, 45)

Lameness due to fracture, sesamoid bones, 68

Lameness due to fracture, ulna, 47

Lameness due to hoof diseases, 31 , 32

Lameness due to inflammation, bursa flexor brachii, 40

Lameness due to inflammation, carpal bursa flexor pedis tendons, 50

Lameness due to inflammation, elbow joint, 47
Lameness due to inflammation, flexor tendons, 57

Lameness due to inflammation, posterior ligaments, coronet joint, 65

Lameness due to inflammation, shoulder and elbow joint, 30

Lameness due to inflammation, skin of phalanges, 30

Lameness due to inflammation, tendon postea spinatus, 39

Lameness due to injuries, anterior surface of knee, 49

Lameness due to lacerations, olecranian muscles, 30

Lameness due to luxation, phalanges, 64

Lameness due to luxation, scapulhumeral articulation, 39

Lameness due to nail prick, 32

Lameness due to navicular disease, 31

Lameness due to painful affections, breast, 32

Lameness due to painful states about shoulder, 30

Lameness due to paralysis, axillary plexus, 30

Lameness due to paralysis, brachial nerve plexus, 44

Lameness due to paralysis, olecranian muscles, 30

Lameness due to paralysis, radial nerve, 42

Lameness due to paralysis, supra scapular nerve, 40

Lameness due to periarthritis, phalangeal articlulations, 31

Lameness due to periostitis, 30,32

Lameness due to quarter-crack, 32

Lameness due to rupture, extensors, metacarpus and foot, 30

Lameness due to rupture, perforans tendon, 56

Lameness due to rupture, perforatus tendon, 56 
Lameness due to rupture, superior and inferior sesamoidal ligaments, 56

Lameness due to splints, 32

Lameness due to transverse fracture, ulna, 30

Lameness due to wounds and bruises, forearm, 48

Lameness in both forelegs, 10

Lameness in both hind legs, 10

Lameness in lumbar region, 11

Lameness in metacarpal region, 56

Lameness in phalangeal region, 62

Lameness in region of elbow and forearm, 47

Lameness in region of knee, 49

Lameness in region of shoulder, 35

Lameness in the foreleg, 25

Lameness in two legs of same side, 11

Lameness, how to detect, 11

Lameness, mixed, 29

Lameness, slight, 11

Levators of forearm, 35

\section{HindeEg AND Hoof.}

Lameness due to acute inflammation of hock joint, 112

Lameness due to acute inflammation of stifle joint, 101

Lameness due to chronic inflammation of stifle joint, 101

Lameness due to contraction of muscular elements, 81

Lameness due to corns, 145

Lameness due to crural nerve paralysis, 97

Lameness due to disease, head of suspensory ligament, 157

Lameness due to diseases of hoof, 84

Lameness due to diseases of joints, 81,84

Lameness due to disease of perforans, 84
Lameness due to disease of the tensor fasciae lata, 81

Lameness due to fracture and fissure of tibia, 106

Lameness due to fracture, astragulus, 114

Lameness due to fracture, cotyloid cavity, 124

Lameness due to fracture, external branch ischium, 125

Lameness due to fractures of femur, 93

Lameness due to fracture, hock bones, 113

Lameness due to fracture of vertebræ, 120

Lameness due to fracture, os pubis, 124

Lameness due to fracture, patella, 105

Lameness due to fracture, pelvis, 84,122

Lameness due to fracture, shaft of ilium, 122

Lameness due to fracture, through obturator foramen, 123

Lameness due to fracture, tuberosity ischium, 124

Lameness due to incomplete paralysis of hindleg, 98

Lameness due to individual hoof diseases, 140

Lameness due to inflammation and rupture, ilio-psoas, 81

Lameness due to inflammation, gluteal muscles, 81

Lameness due to inflammation, hip-joint, 93

Lameness due to inflammation of the tendon and tendon sheath of middle gluteus muscle, 88

Lameness due to inflammation, podophyllous membrane, 136

Lameness due to inflammation, stifle joint, 82

Lameness due to interfering, 119 
Lameness due to laminitis, 140

Lameness due to loosening of sole from wall, 148

Lameness due to luxation, flexor pedis perforatus, 116

Lameness due to luxation of femur, 91

Lameness due to luxation of patella, 82, 83, 103

Lameness due to old fractures of pelvis, 90

Lameness due to painful states of bones, 82

Lameness due to painful states of tendon sheaths, 82

Lameness due to paralysis, crural nerve, 83,86

Lameness due to paralysis, ischiatic nerve, 96

Lameness due to paralysis, sciatic nerve and branches, 81

Lameness due to paralysis, tibial nerve, 83,96

Lameness due to paralysis, triceps femoris, 83

Lameness due to paresis, flexor pedis perforans, 157

Lameness due to peripheral nerve paralysis, 96

Lameness due to pricking in shoeing, 145

Lameness due to punctured wounds, sole and frog, 144

Lameness due to quittor, 143

Lameness due to rupture, extensor pedis, 83

Lameness due to rupture, flexor metatarsi, 107

Lameness due to rupture, gastrocnemii, 83,86

Lameness due to rupture, straight ligaments, patella, 105

Lameness due to rupture, tendo Achilles, 108

Lameness due to sandcracks, 148

Lameness due to seedy toe, 149
Lameness due to septic inflammation, flexor tendon sheath, 117

Lameness due to side-bones, 146

Lameness due to thickening of the sesamoidal sheath, 117

Lameness due to thrombosis, femoral artery, 95

Lameness due to thrombosis, iliac artery, $83,84,95$

Lameness due to thrombosis, posterior aorta and branches, $9 \overline{5}$

Lameness due to wounds of coronet, 142

Lameness following enlarged inguinal glands, 156

Lameness following fistulous withers, 156

Lameness following inflammation, mammary gland, 155

Lameness following inflammation, spermatic cord and testicles, 15.5

Lameness following osteo porosis, 156

Lameness following shoulder abscess, 155

Lameness following sternal fistula, 156

Lameness following wounds and inflammatory conditions of skin and underlying tissues, 156

Lameness in the gluteal region, 87

Lameness in the hindleg, 78

Lameness in the region of the femoro-tibial articulation, 100

Lameness in the region of the hock. 109

Lameness in the region of the hipjoint, 91

Lameness in the region of the metatarsus, 117

Lameness in the region of the tibia, 106

Lameness of flat hoof, 131

Lameness of glanders and farcy, 154

Lameness of inflarnmatory conditions of skin, 155 
Lameness of influenza, 154

Lameness of maladie du coit, 154

Lameness of purpura haemorrhagica, 155

\section{II}

\section{ForeLEG.}

Mastoido-humeralis, its function, 26,27

Mucous bursa of extensor pedis, 55

\section{$\mathbf{N}$}

\section{FORELEG.}

Nail-holes, examination of, 17

Navicular lameness, 74

Nervous horses, how to examine, 14

\section{O}

\section{Foreleg.}

Olecranian muscles, their function, 26

\section{$\mathbf{P}$}

\section{FORELEG.}

Pain, how to interpret, 19

Pain in region of shoulder, 21

Pain when rotating a joint, 21

Palpation, 19, 20

Palpation, chronic inflammation of knee, 50

Palpation, contusions, scapulhumeral articulation, 38

Palpation, diseased shoulder muscles, 37

Palpation, distended articular and tendinous synovial sacs, 53

Palpation, distortion, phalangeal articulations, 65

Palpation, fracture, forearm, 46

Palpation, fracture, knee bones, 49

Palpation, fracture, metacarpal bones, 59
Palpation, fracture, navicular bones, 73

Palpation, fracture, os pedis, 70

Palpation, fracture, os suffraginis, 69

Palpation, fracture, scapula, 45

Palpation, fracture, sesamoid bones, 68

Palpation, fracture, radius, 48

Palpation, fracture, ulna, 47

Palpation, inflammation, bursa flexor brachii, 42

Palpation, inflammation, elbow joint, 47

Palpation, inflammation, flexor tendons, 58

Palpation, inflammation, posterior ligaments, coronet joint, 65

Palpation, inflammation, tendon postea spinatus, 39

Palpation, inflammatory swellings and new growths, 36

Palpation, injuries, anterior surface of knee, 49

Palpation, luxation, phalanges, 64

Palpation, luxation, scapul-humeral articulation, 39

Palpation, metacarpal bones, 19

Palpation, navicular lameness, 75

Palpation of shoulder, 19

Palpation, paralysis, supra-scapular nerve, 40

Palpation, pelvis, 22

Palpation, ringbone lameness, $r 0$

Palpation, sesamoid lameness, 66, $6 \tau$

Palpation, shoulder joint, 36

Palpation, splint lameness, 59

Palpation superior and inferior sesamoidal ligaments, 56

Palpation, thrombosis brachial artery, 37

Palpation, to detect pain in hoof, 16

Passive flexion in sesamoid lameness, $6 \%$ 
Passive flexion, knee-joint, 50

Passive movements, scapul-humeral articulation, 39

Phalangeal articulations, how to rotate, 21

Phalanges, dorsal flexion, 33, 34

Phalanges, excessive volar flexion, $46,47,58,66,73$

Phalanges, prominent, 58

Pelvic cavity, examination of, 21

Periostitis, cause of lameness, 23

Podophyllous membrane, inflammation, 15

Pointing, 14, 31

Pointing, backward, 32

Pointing, forward, 32

Postea spinatus, its function, 26

Pulsations of digital arteries, 15

\section{HINDLEG。}

Palpation, acute inflammation, hock joint, 113

Palpation, a cute inflammation, stifle joint, 101

Palpation, chronic inflammation, stifle joint, 102

Palpation, crural nerve paralysis, 97

Palpation, disease head of suspensory ligament, 157

Palpation, fissure tibia, 106

Palpation, fracture, astragulus, 114

Palpation, fracture, cotyloid cavity, 124

Palpation, fracture, femur, 94

Palpation, fracture, hock bones, 114

Palpation, fracture, patella, 105

Palpation, fracture, pelvis, 122

Palpation, fracture, os pubis, 124

Palpation, fracture, shaft of ilium, 122

Palpation, fracture, through obturator foramen, 123

Palpation, fracture, tibia, 106

Palpation, fracture, tuberosity ischium, 125
Palpation, fracture, vertebræ, 120

Palpation, hip-lameness, 88

Palpation, hoof-lameness, 134, 135

Palpation, inflammation, podophyllous membrane, 137

Palpation, interfering, 119

Palpation, ischiatic nerve paralysis, 97

Palpation, laminitis, 141

Palpation, loosening of sole from wall, 148

Palpation, luxation of femur. 91

Palpation, luxation, flexor pedis perforatus, 116

Palpation, middle gluteus lameness, 90

Palpation, outward luxation, patella, 105

Palpation, pricking in shoeing, 145

Palpation, punctured wounds of sole and frog, 144

Palpation, quittor, 144

Palpation,rupture flexor metatarsi, 108

Palpation, rupture straight ligaments patella, 105

Palpation, rupture, tendo Achilles, 108

Palpation, sanderacks, 148

Palpation, seedy toe, 150

Palpation, septic inflammation, flexor tendon sheath, 117

Palpation, side-bones, 146

Palpation, spavin, 111

Palpation, thickening, sesamoidal sheath, 117

Palpation, thrombosis, posterior Aorta and branches, 95

Palpation, tibial nerve paralysis, 96

Palpation, wounds of coronet, 143

Paralysis, crural nerve, 83

Paralysis, triceps femoris, 83

Patella, straight ligaments, rupture, 83

Patella muscles, rupture, 83 
Phalanges, volar flexion, 83, 85

Pointing, 130

Podophyllous membrane, 128

Podophyllous membrane, parenchymatous inflammation, 129, 136

Podophyllous membrane, superficial inflammation, 129, 136

\section{$\mathbf{R}$}

\section{FORELEG.}

Rheumatic shoulder lameness, 38 Ringbone lameness, 70

\section{$\mathbf{S}$}

\section{ForeleG.}

Searching knife, when to use, 17

See-sawing of head and haunch, 11

Servatus magnus, its function, 25

Sesamoid lameness, 66

Shifting weight, 14, 31

Shoe, when to remove, 17

Short abductor of arm, its function, 26

Shoulder, abduction, 33

Shoulder, abnormal flexion, 33

Shoulder lameness, 35, 38

Sole, examination of, 17

Sore shins, 61

Spavin, 14

Spavin, lame, 11

Spavin test, 12

Splint, cause of lameness, 23,59

Step of quadruped, 29

Stringhalt, 14

Stringhalt lameness, 11

Stumbling, 44

Subscapularis, its function, 26

Supporting leg, 25, 29

Supporting leg, function, 27

Supporting leg lameness, 29

Swelling along flexor tendons, 17
Swinging leg, 25, 28

Swinging leg, action of, 27

Swinging leg, function, 27

Swinging leg lameness, 29

HINDLEG.

Sandcracks, 152, 148

Sartorius, its function, 80

Sole, bruised, 131

Sole, contracted, 152

Spavin, 82, 184

Stifle joint, excessive extension, 83

Stifle joint, excessive flexion, 82 , 83,85

Stifle joint, inflammation, 82

Stringhalt, 82, 118

Supporting leg, 78, 80, 81

Swinging leg, 78, 79, 80

Swinging-leg lameness, 81

$\mathbf{T}$

\section{FORELEG.}

Teres major, its function, 26

Teres minor, its function, 26

Thrombosis, brachial artery, 36

Thrombosis, posterior aorta and branches, 22

Thrush, 23

Thrush lameness, 76

HiNDLEG.

Thrombosis, iliac arteries, 83

Tibial nerve paralysis, 83

Triceps femoris, its function, 80,81

\section{W}

FORELEG.

White line, examination of, 17

Windgalls, 54

HINDLEG.

White line, examination of, 135 


\section{GLOSSARY.}

ANCHYLOSIS : Permanent union of the articulating extremities of one or more bones of a joint ; stiff joint.

ATROPHY : A wasting away.

CELLULITIS : Inflammation of loose connective tissue.

CHECK-APPARATUS : See inhibitory apparatus.

CONTUSION : A bruise.

CREPITATION : The grating sound resulting from the rubbing of the ends of a broken bone against each other.

DIAPHYSIS: The body or middle portion of a long bone.

DISTORTION : A twisting out of regular shape ; a sprain.

EPIPHYSIS : The extremities of a long bone.

EXOSTOSIS : A morbid enlargement of the whole or part of a bone.

EXTENSION, passive: Extension of a part by some artificial means, the muscles normally concerned remaining inactive.

FLEXION, dorsal, of the phalanges: That state of flexion depending upon the action of the extensor muscles.

FLEXION, passive: Flexion of a part by some artificial means, the muscles normally concerned remaining inactive.

FLEXION, volar, of the phalanges: That state of flexion depending upon the action of the flexor muscles.

INHIBITORY APPARATUS: That mechanism which fixes the various joints of the leg, without the assistance of muscular elements.

INSPECTION : The act of looking at anything closely and critically.

LAMENESS, remittent: A lameness with intervals of lessened intensity.

LAMENESS, intermittent: A lameness totally absent at more or less regular intervals.

LEVATOR: A muscle which serves to raise a part.

LUXATION: A dislocation.

MOVEMENT, passive : Movement of a part by some artificial means, the muscles normally concerned remaining inactive.

PALPATION : Examination of a part by touch.

PERIARTHRITIS: Inflammation of the tissues surrounding a joint.

PERIOSTITIS: Inflammation of the thin delicate membrane, the immediate covering of a bone.

PETECHI E: Small reddish spots in the skin, mucous or serous membranes.

SEPTIC : Causing putrefaction; containing pathogenic bacteria.

SYNOVITIS: Inflammation of the synovial membrane.

THROMBOSIS : The clogging of a blood-ressel by a clot, formed at the point of obstruction.

171 



\section{WILLIAM R. JENKINS'}

\section{Veterinary Books. 1897.}

(*) Single asterisk designates New Books.

(**) Double asterisk designates Recent Publications.

ANDERSON. "Vice in the Horse" and other papers on Horses and Riding. By F. L. Andersnn. Demy, $8 \mathrm{vo}$, cloth................................ 00

- "How to Ride and School a Horse." With a System of Horse Gymnastics. By Edward L. Anderson. Cr. 8 vo ................................. 00

$\left(^{* *}\right) \boldsymbol{B} \boldsymbol{A} \boldsymbol{C H}$. "How to Judge a Horse." A concise treatise as to its Qualities and Soundness; Including Bits and Bitting-Saddles and Saddling, Stable Drainage, Driving One Horse, a Pair, Four-in-hand, or 'Tandem, etc. By Captain F. W. Bach. 12mo, cloth, fully illustrated $\$ 100 ;$ paper........................... 50

BANILAM. "Tables of Veterinary Posology and Therapentics," with weights, measures, ete. By George A. Banham, F.R.C.V.S. 12mo, eloth.....75

B A UCHER. "Method of Horsemanship." Including the Breaking and Training of Horses........... 00 
CURTIS. "Horses, Cattle, Sheep and Swine." The origin, history, improvement, description, characteristics, merits, objections, etc. By Geo. W. Curtis, M.S.A. Superbly illustrated. Cloth, $\$ 200$; half sheep, $\$ 2.75$; half moroceo................ 50

D ALRYMPLE. "Veterinary Obstetries." A compendium for the use of advanced students and Practitioners. By W. H. Dalrymple, M.R.C.V.S., late principal of the Department of Veterinary Science in the Louisiana State University and A. \& M. College; late Veterinarian to the Louisiana State Bureau of Agriculture, and Agricultural Experiment Stations; Member of the United States Veterinary Medical Associations, etc. (In preparation.)

DALZIEL. "Britislt Dogs." Deseribing the History, Charasteristies, Points, and Club Standards, ete., ete. With numerous colored plates and wood engravings. By Hugh Dalziel. Vol. I., \$t 00. Vol. II., 8vo.4 $\mathrm{lU}$

- "The Fox Terrier." Illustrated. (Nonographs on Eritish Dogs).......................... 100

— "Fox Terrier Stud Book." Edited by Hugh Dalziel.

Vol. I. Containing Pedigrees of over 1,400 of the bestknown Dogs, traced to their most remote known ancestors.............................. 00

Vol. II. Pedigrees of 1,544 Dogs, Show Record, de.1 00

Vol. III. Pedigrees of 1,214 Dog£, Show Record,se.1 00

Vol. IV. Pedigrees of 1,168 Doys, Show Record,dc.1 00

Vol. V. Pedigrees of 1,662 Dogs, Show Record, de.1 00

— "The St. Bernard," Illustrated......... 100 
"St. Bernard Stul Book." Edited by Hugh Dalziel.

Vol. I. Pedigrees of 1,278 of the best-known Dogs, traced to their most remote known ancestors, show

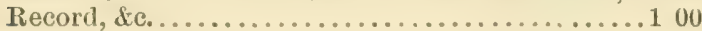

Vol. II. Pedigrees of 564 Dogs, Show Record, \&c..1 00

- "The Diseases of Dogs." Their Pathology, Diagnosis and Treatment, with a dictionary of Canine MateriaMedica. By Hugh Dalziel. 12mo, cloth..........80

- "Diseases of Horses." 12mo, cloth...........100

- "Brenking and Training Dogs." Being concise directions for the proper education of dogs, both for the field and for companions. Second edition, revised and enlarged. Part I, by Pathfinder: Part II, by \#ugh Dalziel. 12mo, cloth, illus ....2.60

- "The Collie." Its History, Points, and Breeding. By Hugh Dalziel. Illustrated, 8 vo, cloth........... 00

- "The Greyhound." 8vo, cloth, illus...........100

DANCE. "Veterinary Tablet." Folded in cloth case. The tablet of A. A. Dance is a synopsis of the diseases of horses, cattle and dogs with the causes, symptoms and cures............................... 75

$\boldsymbol{D A N A}$. "Tables in Comparative Physiology." Вy Prof. C. L.Dana, M.D.....................25

DAY. "The Race-horse in Training," By Wm. Day,

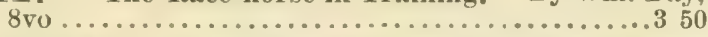

DOLLAR. "The Structure and Functions of the Horse's Foot, with especial reference to Horseshoeing, by Jno. A. W. Dollar, M.R.C.V.S. and Albert Wheatley, F.R.C.V.S. With over 300 woodcuts, about 70 large process-work plates, and 2 double-page colored plates. (In preparation.) 
${ }^{(* *)} \boldsymbol{D} \boldsymbol{U} \boldsymbol{N}$. "Veterinary Medicines, Their Actions and Uses." By Finlay Dun, V.S. Revised edition (almost entirely re-written) 8 vo, cloth............. 350

DWYER. "Seats and Saddles." Bits and Bitting, Draught and Harness and the Prevention and Cure of Restiveness in Horses. By Francis Dwyer. Illustrated. 1 vol., $12 \mathrm{mo}$, cloth, gilt.............. 50

(")FLEMIING. "Veterinary Obstetrics." Including the Accidents and Diseases incident tu Pregnancy, Parturition, and the early Age in Domesticated Animals. By Geo. Fleming, F.R.C.V.S. With 212 illustrations. New edition revised, 226 illustrations, 758 pages...6 25 773 pages, 8 vo, cloth (old edition) ............. 50

- "Rabies and Hydrophobia." History. Natural Causes, Symptoms and Prevention. By Geo. Fleming, Mr. R.C.V.S. 8vo, eloth..............375

- "Propagation of Tuberculosis." Stating Injurious Effects from the consumption of the Flesh and Milk of Tuberculous Animals. By Geo. Fleming, M.D., M.R.C.V.S., and others. 8vo, eloth......1 50

- "A Treatise on Practical Horseshoeing." By George Fleming, M.R.C.V.S. Cloth.................75

- "Tuberculosis." From a Sanitary and Pathological Point of View...........................25

- "The Contagious Diseases of Animals." Their influence on the wealth and health of nations.

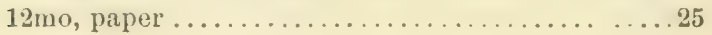


851-853 Sixth Avenue (cor. 4sth St.), New York. 7

- "Operative Veterinary Surgery." Part I, by Dr. Geo. Fleming, M.R.C.V.S. This valuable work, the most practical treatise yet issued on the subject in the English language, is devoted to the common operations of Veterinary Surgery; and the concise descriptions and directions of the textareillustrated with numerous wood engravings. 8vo, cloth.2 75 Orders will now be received for the second volume.

- "Human and Animal Variola." A Study in Comparative Pathology. Paper..............25

- "Animal Plagues." Their History, Nature, and Prevention. By George Fleming, F. R. C. V. S., etc. First Series. $8 v 0$, cloth, $\$ 6.00$; - Second Series.

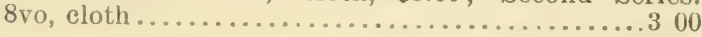

— "Roaring in Horses." By Dr. George Fleming, F.R C.V.S. A treatise on this peculiar disorder of the Horse, indieating its method of treatment and curability. 8vo, eloth, with col. plates ..... 150

(**) FLEMING-NEUMANN. "Parasites and Parasitic Diseases of the Domesticatel Animals." A work which the students of human or veterinary medi. cine, the sanitarian, agriculturist or breeder or rearer of animals, may refer for full information regarding the external and internal Parasites-vegetable and animal-which attack various species of Domestic Animals. A Treatise by L. G. Neumann, Professor at the National Veterinary School of Toulouse. Translated and edited by George Fleming, C. B., L.L. D.,F.R.C.V.S. 873 pages, 365 illustrations, cloth.7 50

FRIEDBERGER - FROINNER. "Pathology and 'Therapenties of the Domesticated Animals." Translated by Prof. L. Zuill, M. D., D. V. S. 2 vol..................................... 00 
GRESSWELL. "The Diseases and Disorders of the 0x." By George Gresswell, B.A. With Notes by James B. Gresswell. Crown, 8vo, choth, illus....3 50

- "Diseases and Disorders of the Horse." By Albert, James B., and George Gresswell. Crown, 8vo, illus-

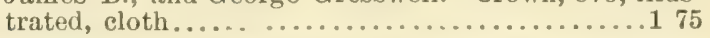

GRESS WELL. Manual of "The Theory and Practice of Equine Melicine." By J. B. Gresswell, F.R.C.V.S., and Albert Gresswell, M.R.C.V.S., second edition, enlarged, 8vo, cloth......................2 75

- "Veterinary Pharmacology and Therapentics." By James B. Gresswell, F.R.C.V.S. 16mo, cloth ...1 50

- "The Bovine Preseriber:" For the use of Veterinarians and Veterinary Students. By James B, and Albert Gresswell, M.R.C.V.S Cloth...........75

- "The Equine Hospital Preseriber." Drawn up for the use of Veterinary Practitioners and Students. By Drs. James B. and Albert Gresswell, M.R.C.V.S. Cloth................................ 75

- "Veterinary Pharmacopaia, Materia Medica and Therapentics." By George and Charles Gresswell, with descriptions and physiological actions of medicines. By Albert Gresswell. Crown,8vo,cl.......2 75

(**)GOTTHELL. "A Manual of General Histology." By Wm. S. Gottheil, M.D., Professor of Pathology in the American Veterinary College, New York; ete., ete.

Histology is the basis of the physician's art, as Anatomy is the foundation of the surgeon's science. Only by knowing the processes of life can we understand the changes of disease and the action of remedies; as the architect must know his building materials, so must the practitioner of medicine know the intimate structure of the body. To present this knowledge in an accessible and simple form has been the author's task. 8vo., cloth, 148 pages, fully illustrated... 100 
851-853 Sixth Avenue (cor. 48th St.), New York.

(") HASSLOCH. "A Compend of Veterinary Materia Mediea and Therapentics." By Dr. A. C. Hassloch, V.S., Lecturer on Materia Medica and Therapeutics, and Professor of Veterinary Dentistry at the New York College of Veterinary Surgeons and Sehool of Comparative Medicine, N. Y. $12 \mathrm{mo}$, cloth, 225 pages ..1 50

HAIES. "Veterinary Notes for Horse-0wners." An every day Hor'se Book. Jllustrated. By M. H. Hayes. $12 \mathrm{mo}$, cloth...........................50 00

- "Riding." On the Flat and Across Country. A Guide to Practical Horsemanship. By Captain M. H. Hayes. second edition, $16 \mathrm{mo}$, eloth.............4 25

- "Mllustrated Horse Breaking." By Captain M. H. Hayes. $12 \mathrm{mo}$, cloth, illustrated............8 40

- "The Horsewoman." By Captain M. H. Hayes and Mrs. Hayes. 12mo, cloth, illustrated........4 25

("*) HEATLEY. "The Stock 0wner's Guide." A handy Medical Treatise for every man who owns an ox or cow. By George S. Heatley, M.R.C.V. 12mo,

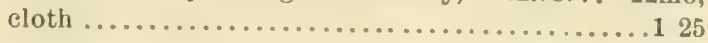

- "The Horse Owner's Safeguard." A handy Medical Guide for every Horse Owner. 12mo, cloth..... 150

- "Practical Veterinary Remedies." 12 mo, cloth...1 00

HILL. "The Principles and Practice of Bovine Med" icine and Surgery." By J. Woodroffe Hill, F.R.C.V.S. Cloth. (Temporarily out of print). 
HILL. "The Management and Diseases of the Dog." Containing full instructions for Breeding, Rearing and Kenneling Dogs. Their Different Diseases. How to detect and how to cure them. Their Medicines, and the doses in which they can be safely administered. By J. Woodroffe Hill, F.R.C.V.S. $12 \mathrm{mo}$, cloth, extra fully illustrated....................2 00

HINEBAUCH. "Veterinary Dental Surgery." For the use of Students, Practitioners and Stockmen. $12 \mathrm{mo}$, cloth, illustrated..................200 sheep.......................... 275

$\left({ }^{* *}\right)$ HOARE. "A Mannal of Veterinary Therapentics and Pharmacology." By E. Wallis Hoare, F.R.C.V.S. $12 \mathrm{mo}$, cloth, 560 pages.....................2 75

"Deserves a good place in the libraries of all veterinarians. *** Cannot help but be of the greatest assistance to the young veterinarian and the every day busy practitioner."-American Veterinary lieview.

HUNTING. The Art of Horse-shoeing. A manual for Farriers. By William Hunting, F.R.C.V.S., editor of the Veterinary Record, ex-president of the Royal College of Veterinary Surgeons. (Ready in January.)

(*)KOBERT. "Practical Toxicology for Physicians and Students" By Prof. Dr. Rudolph Kobert, Director of the Pharmacological Institute, Dorpat, Russia. Translated and edited by L. H. Friedburg, Ph.D., of Dept. of Chemistry, College of City of New York, Prof. of Chemistry and Toxicology at the American Veterinary College, New York, and New York Homœpathic Medical College and Hospital. Authorized edition. $8 v_{0}$, cloth.................... 50

KОСН. "Etiology of Tubereulosis." By Dr. R. Koch. Translated by 'T. Saure. 8vo, cloth .....100 
85ั1-853 Sixth Avenue (cor. 48th St.), New Tork. 11

KEATING. "A New Unabridged Pronouncing Dictionary of Medicine." By John M. Keating, M.D., LL.D., Henry Hamilton and others. A voluminous and exhaustive hand-book of Medical and scientific terminology with Phonetic Pronunciation, Accentuation, Ftymology, etc. With an appendix containing important tables of Bacilli, Mierocei Leucomaines, Ptomaines; Drugs and Materials used in Antiseptic Surgery; Poisons and their antidotes; Weights and Measures; Themometer Scales; Nerv Officinal and Unofficinal Drugs, etc., etc. 8 vo, 818 pages ....5 00

LAMBERT. "The Germ Theory of Disease." Bearing upon the health and welfare of man and the domesticated animals. By James Lambert, F.R.C.V.S. 8 vo. paper.............................25

$\boldsymbol{L} \boldsymbol{A} \boldsymbol{W}$. "Farmers' Veterinary Adviser." A Guide to the Prevention and Treatment of Disease in Domestic Animals. By Professor James Law.Illustrated. 8vo, cloth.................................... 00

KI U U ARD. "Median Nemrotomy in the Treatment Chronic 'Tendinitis and Periostosis of the Fetlock." By C. Pellerin, late Repetitor of Clinic and Surgery to the Alfort Veterinary School. Translated with additional facts relating to it, by Prof. A. Liautard, M.D., V.M.

Hàving rendered good results when performed by himself, the author believes the operation, which consists in dividing the cubito-plantar nerve and in excising a portion of the peripherical end, the means of improving the conditions, and consequently the values of many apparently doomed animals. Agricul. ture in particular will be benefited.

The work is divided into two parts. The first covers the study of Median Neurotomy itself; the second, the exact relations of the facts as observed by the author. 8 vo., boards.......................1 00 
${ }^{(* *)} \boldsymbol{L I} d U T A R D . \quad$ "Manual of Operative Veterinary Suruery" By A. Liautard, M.D., V.M., Principal and Professor of Anatomy, Surgery, Sanitary Medicine and $J$ urisprudence in the American Veterinary College; Chevalier du Merite Agricole de France, Honorary Fellow of the Royal College of Veterinary Surgeons (London), etc., etc. $8 \mathrm{vo}$, cloth, 786 pages and nearly 600 illustrations. . . . . . . . . . . . . . . . . . 6 60

_ "Animal Castration." A concise and practical Treatise on the Castration of the Domestic Animals. The only work on the subject in the English language. Illustrated with forty-four euts. $12 \mathrm{mo}$, cloth...200

(") "Vade Mecum of Equine Anatomy." By A. Liautard, M.D.V.S. Dean of the American Veterinary College. $12 \mathrm{mo}$, cloth. New edition, with illustrations....2 00

- "Translation of Zundel on the Horse's Foot." Cloth................................200

- "How to Tell the Age of the Domestic Animal." By Dr. A. Liautard, M.D., V.S. Profusely illustrated.

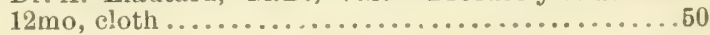

— "On the Lameness of Ilorses." By A. Liautard,

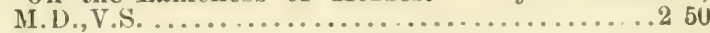
See also "Cadiot's Surgery."

LONG. "Book of the Pig." Its selection, Breeding, Feeding and Management. 8vo, cloth .........4 25

$\left(^{*}\right)$ LOWE. " Breeding Racehorses by the Figure Sys= tem." Compiled by the late C. Bruce Lowe. Editerl by William Allison. With numerous fine illustrations of celebrated horses. Ready Dec. 15 . $\$ 7.50$.

(*) LUPTON. "Horses : Sound and Unsound," with Law relating to Sales and Warranty. By J. Irvine Lupton, F.R.C.V.S. 8vo, cloth, illustrated......1 25

- "The Horse." As he Was, as he Is, and as he Ought to Be. By J. I. Lupton, F.R.C.V.S. Illustrated. Crown, 8 vo ......................... 40 
851.853 Sixth Avenue (cor. 48th St.), New York. 13

MAGNER. "Facts for Horse Owners." By D. Magner. Upivards of 1,000 pages, illustrated with 900 engravings, $8 \mathrm{vo}$, eloth, $\$ 5.00$; sheep, $\$ 6.00$; full moroce......................... ...750

MA $\boldsymbol{Y}$ NER. "Veterinary Diagrams." (1) The Structure of Horses Feet (in colors). The Structure of Horses Feet (Effects of Bad Treatment of the Feet). Mounted and Varnished...................2 00

(2) The Shoeing of the Horse. The Education of the Horse. MIounted and Varnished............200

$M A Y H E W . \quad$ "The Illustrated Horse Doctor." An accurate and detailed account of the Various Diseases to which the Equine Race is subject; together with the latest mode of Treatment, and all the Requisite Prescriptions written in plain English. By E. Edward Maynew, M.R.C.V.S. Illustrated. Entirely new edition, 8 vo, cloth........................275

MCBRIDE. "Anatomical Outlines of the Horse." $12 m 0$, eloth............................. 50

Me COMIBIE. "Cattle and Cattle Breeders." Cloth.1 00

M'FADYEAN, "Anatomy of the Horse" A Dissection Guide. By J. M. M'Fadyean, M.R.C.V.S. This book is intended for Veterinary students, and offers to them in its 48 full-page colored plates numerous other engravings and excellent text, the most valuable and practical aid in the study of Veterinary Anatomy, especially in the dissecting room. 8vo, cloth ................................... 50

"Comparative Anatomy of the Domesticated Aninials." By J. M'Fadyean. Profusejy illustrated, and to be issued in two parts. Purt I-Osteology, ready. Paper, $\$ 250$; cloth................. 75

(Part II. in preparation.) 
MILLS. "How to Keep a Dog in the City." By Wesley Mills, M.D., V.S. It tells how to choose manage, house, feed, educhte the pup, how to keep him clean and teach him cleanliness. Paper........25

(**)MOLLER. "Operative Veterinary Surgery." By Professor Dr. H. Moller, Berlin. Translated and edited from the $2 d$ edition, enlarged and improved, by John A. W. Dollar. M.R C.S.

Prof. Moller's work presents the most recent and complete exposition of the Principles and Practice of Veterinary Surgery, and is the standard text-book on the subject throughout Germany.

Many subjects ignored in previous treatises on Veterinary Surgery here receive full consideration, while the better known are presented under new and suggestive aspects.

As Prof. Moller's work represents not only his own opinions and practice, but those of the best Veterinary Surgeons of various countries, the translation cannot fail to be of signal service to American and British Veterinarians and to Students of Veterinary and Comparative Surgery.

1 vol., 8vo. 722 pages, 142 illustrations......5 25

MORETON, "0n Horse-breaking," 12mo, cl...50

MOSSELMA N-LIENAUX, "Veterinary Microbiology." By Professors Mosselman and Liénaux, Nationai Veterinary College, Cureghem, Belgium. Translated and edited by R. R. Dinwiddie, Professor of Veterinary Science, College of Agriculture, Arkansas State University. $12 \mathrm{mo}$, eloth, 342 pages......2 00 
851-853 Sixth Avenue (cor. 48th St.), New York. 15

$\left.{ }^{* *}\right)$ NOCARD. "The Animal Tubereuloses, and their" Relation to Human Tuberculosis." By Ed. Nocard, Professor of the Alfurt Veterinary College. Translated by H. Scurfield, M.D. Ed., Ph. Camb.

Perhaps the chief interest to doctors of human medicine in Professor Nocard's book lies in the demonstration of the small part played by heredity, and the great part played by contagion in the propagation of bovine tuberculosis. It seems not unreasonable to suppose that the same is the case for human tuberculosis, and that, if the children of tuberculosis parents were protected from infection by cohabitation or ingestion, the importance of heredity as a cause of the disease, or even of the predisposition to it, would dwindle away into insignificance. 12mo, cloth 143

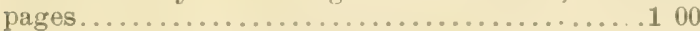

PEGLER. "The Book of the Goat." 12mo, cloth.1 75

PELLERIN. "Median Neurotomy in the Treatment of Chromic Tendinitis and Periostosis of the Fetlock." By C. Pellerin, late repetitor of Clinic and Surgery to the Alfort Veterinary School. Translated, with Additional Facts Relaing to It, by Prof. A. Liautard, M.D., V.M. $8 \mathrm{vo}$, boards, illustruted.............100 See also under Liautard.

PROCTOR. "The Management and Treatment of the Horse" in the Stable, Field and on the Road. By William Proctor. 8vo................ 240

PETERS. "A Tubereulous Herd-Test with Tuber" culin." By Austin Peters, M. R. C. V.S., Chief Inspector of Cattle for the New York State Board of Health during the winter of 1892-93. Pamphlet....25 


\section{REYNOLD. "Breeding and Management of Draught}

Horses." \&vo, cloth..................... 40

\section{ROBERTSON. "The Practice of Equine Medicine."}

A text-book especially adapted for the use of Veterinary students and Veterinarians. By W. Robertson, Principal and Professor of Hippopathology in the Royal Veterinary College, London. 8vo. cloth, 806 pages, revised edition...................6 25

${ }^{(* *)}$ ROBERGE. "The Foot of the Iorse," or Lameness and all Diseases of the Feet traced to an Unbalanced Foot Bone, prevented or cured by balancing the foot. By David Roberge. 8vo, cloth ........5 00

(**)SMITH. "A Manual of Veterinary Physiology." By Veterinary Captain F. Smith, M.R.C.V.S. Author of "A Manual of Veterinary Hygiene."

Throughout this manual the object has been to condense the information as much as possible. The broad facts of the sciences are stated so as to render them of use to the student and practitioner. In this second edition-rewritten-the whole of the Nervous System has been revised, a new chapter dealing with the Development of the Ovum has been added together with many additional facts and illustrations. About one hundred additional pages are given. Second edition, revised and enlarged, with additional illustrations ................................ 75

(**) SMITH, "Manual of Veterinary Hygiene." 2nd edition, revised. Crown, 8vo, cloth ..........3 25 
851-853 Sixth Avenue (cor. 48th St.), New York. 17

STORNMOUTH. "Manual of Scientific Terms." Especially referring to those in Botany, Natural History, Medical and Veterinary Science. By Rev. James Stornmouth........................3 00

(**)STRANGEWAY. "Veterinary Anatomy." New edition, revised and edited by I. Vaughn, F.L.S., M.R.C.V.S., with several hundred illustrations. 8vo, cloth ............................. 00

(*)SUSSDORF. Colored Plates specially for Lectures. Size 40x27. By Professor Sussdorf, M.D. Translated by Prof. W. Owen Williams, of the New Veterinary College, Edinburgh.

Plate 1.- "Diagram of the Horse." Left or near side view.

Plate 2.-" Diagram of the Mare." Right side view.

Plate 3. "Anatomy of the Cow," showing the position of the viscera in the large cavities of the body.

Plate 4. "The 0x." Showing right side view of the position of the viscera in the large cavities of the body.

Plate 5. "The Boar." Left side view of the position of the viscera in the great cavities (thoracic and abdominal). "6rhe Sow." Tight side view.

Plate 6. "The Dog." Left side view of the position of the viscera in the great cavities (thoracic and abdominal). "The Bitclı." Right side view.

Price, unmounted..................1 75 each

" mounted on linen, with roller...1 75 extra " 
VAN MATER. "A Text Book of Veterinary 0phthalmology." By George G. Van Mater, M.D., D.V.S., Professor of Ophthalmology in the Americas Veterinary College; Oculist and Aurist to St. Martha's Sanitarium and Dispensary; Consulting Eye and Ear Surgeon to the Twenty-sixth Ward Dispensary; Eye and Ear Surgeon, Brooklyn Eastern District Dispensary, etc. Illustrated by one chromo lithograph plate and seventy-one engravings, 8 vo cloth.........3 00

TETERINARY DIAGRAMS in Tabular Form. Size, $28 \frac{1}{2}$ in. $x 22$ inches. Price per set of five...4 75

No. 1. "The Extermal Form and Elementary Anatomy of the Horse." Eight coloured illustrations1. External regions; 2. Skeleton; 3. Muscles (Superior Layer); 4. Muscles (Deep Layer); 5. Respiratory Apparatus; 6. Digestive Apparatus; 7. Circulatory Apparatus ; 8. Nerve Apparatus ; with letter-press descrip-

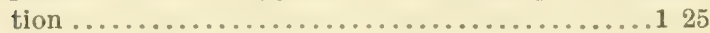

No. 2. "The Age of Domestic Animals." Forty-two figures illustrating tho structure of the teeth, indicating the Age of the Horse, $\mathrm{Ox}$, Sheep, and Dog, with full description .......................... 75

No. 3. "The Unsoundness and Defects of the Horse." Fifty figures illustrating-1. The Defects of Conformation; 2. Defects of Position; 3. Infirmities or Signs of Disease; 4 . Unsoundnesses; 5 . Defects of the Foot; with full description..................... 75

No.4. "The Shoeing of the Horse, Mule and 0x." Fifty figures descriptive of the Anatomy and Physio$\operatorname{logy}$ of the Foot and of Horse-shoeing............75 
851-853 Sixth Avenue (cor. 48th St.), New I ork. 19

No. 5. "The Elementary Anatomy, Points, and Butcher's Joints of the Ox." Ten coloured illustrations -1. Skeleton; 2. Nervous System: 3. Digestive System (Right Side); 4. Respiratory System ; 5 . Points of a Fat $\mathrm{Ox}$; 6. Muscular System; 7. Vascular System; 8. Digestive System (Left Side); 9. Butcher's Sections of a Calf: 1U. Butcher's Sections of an Ox; with full description .......................... 25

WALLEY. "Hints on the Breeding and Rearing of Farm Animals." $12 \mathrm{mo}$, eloth..............80

- "Fonr Bovine Seourges." (Pleuro-Pneumonia, Foot and Mouth Disease, Cattle Plague and Tubercle.) With an Appendix on the Inspection of Live Animals and Meat. Illustrated, 4to, cloth..6 40

- "The Horse, Cow and Dog." By Dr. Thomas Walley. A poetical account of the "Troub]ous Life of the Horse"; "The Life of a Dairy Cow," and "The Life of a Dog"; with an article on Animal Characteristics. $12 \mathrm{mo}$, cloth. .............. 80 ,

" WAL LEY. "A Practical Guide to Meat Inspection." By Thomas Walley, M.R.C.V.S., formerly principa] of the Edinburgh Royil (Dick) Veterinary College; Professor of Veterinary Medicine and Surgery, etc. Third Edition, thoroughly revised, with forty-five coloured illustrations, $12 \mathrm{mo}$, cloth............3 00

An experience of over 30 years in his profession and a long official connection (some sixteen years) with Edinburgh Abattoirs have enabled the author to gather a large store of information on the subject, which he has embodied in his book. Dr. Walley's opinions are regarded as the highest authority on Meat Inspection. 
("*) WILLIAMS. "Principles and Practice of Veter" inary Medicine." New author's edition, entirely revised and illustrated with numerous plain and colored plates. By W. Williams, M.R.C.V.S.8vo., cl..6 00

- (**) "Principles and Practice of Veterinary Surgery." New author's edition, entirely revised and illustrated with numerous plain ánd colored plates. By W. Williams, M.R.C.V.S. 8vo, cloth..........6 00

WYMAN. "The Clinical Diagnosis of Lameness in the Horse." By W. E. A. Wyman, V.s., Prof. of Veterinary Science, Clemson A. \& M. College, and Veterinarian to the South Carolina Experiment Station. (In preparation.)

ZUNDEL. "The Horse's Foot and Its Diseases." By A. Zundel, Principal Veterinarian of Alsace Lorraine. Translated by Dr. A. Liautard, V.S. 12mo, cloth

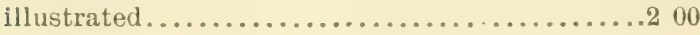

ZUILL. "Typhoid Ferer; or Contagious Influenza in the Horse." By Prof. W. L. Zuill, M.D.,D.V.S.

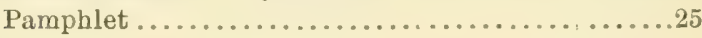

Our Boolis are for sale by all booksellers, or will be sent prepaid for prices quoted.

WILLIAT R. JENKINS,

851 and 853 Sixth Avenue, NEW YORK. 





LIBRARY OF CONGRESS

||||||||||||||||||||

00028637809 